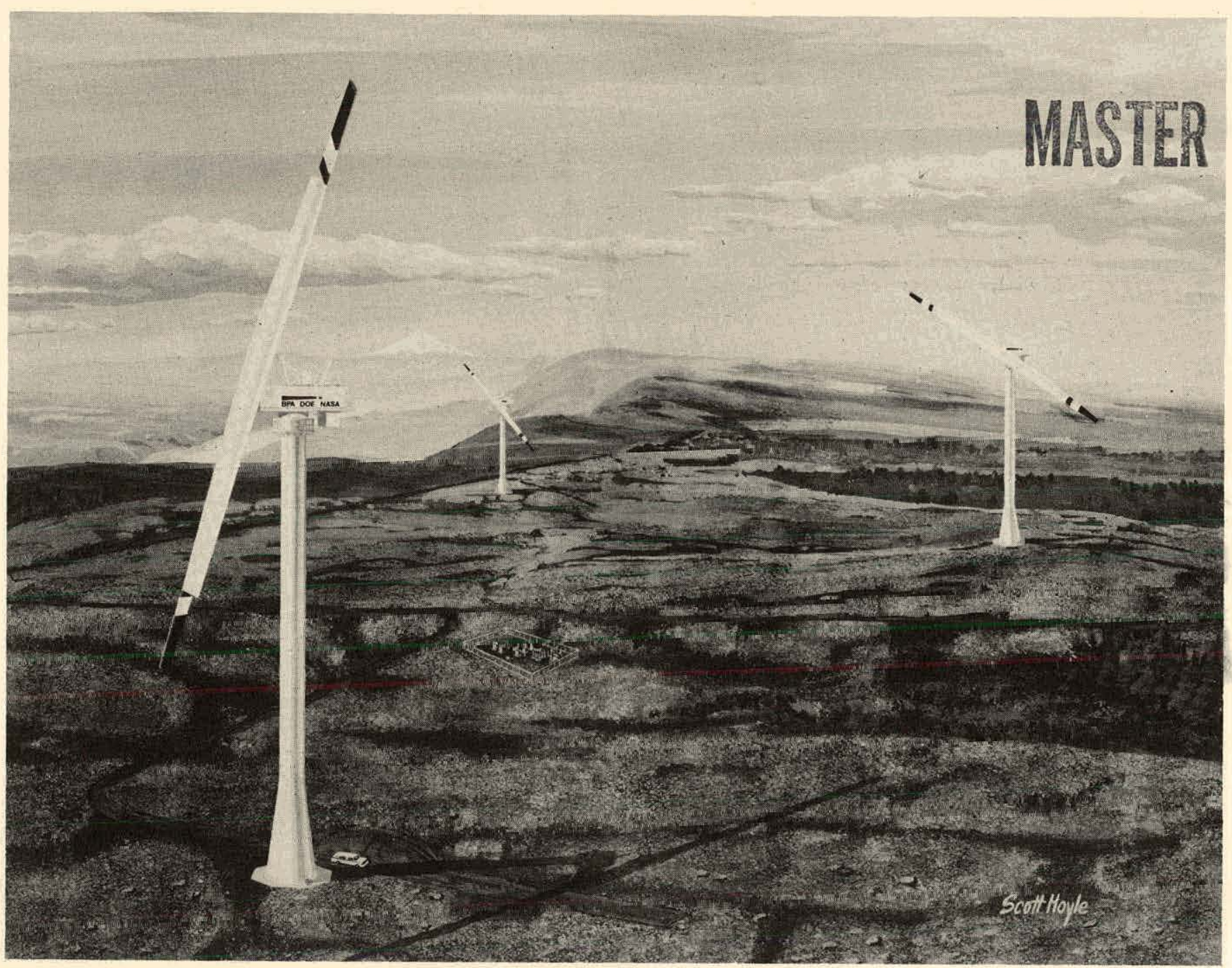

\title{
WIND FIELD PREDICTIONS FOR THE COLUMBIA GORGE AND THE GOODNOE HILLS WIND TURBINE SITE
}

\author{
Submitted to
}

Bonneville Power Administration

by

Scott D. Veenhuizen and Jung-Tai Lin United Industries Corporation 


\section{DISCLAIMER}

This report was prepared as an account of work sponsored by an agency of the United States Government. Neither the United States Government nor any agency Thereof, nor any of their employees, makes any warranty, express or implied, or assumes any legal liability or responsibility for the accuracy, completeness, or usefulness of any information, apparatus, product, or process disclosed, or represents that its use would not infringe privately owned rights. Reference herein to any specific commercial product, process, or service by trade name, trademark, manufacturer, or otherwise does not necessarily constitute or imply its endorsement, recommendation, or favoring by the United States Government or any agency thereof. The views and opinions of authors expressed herein do not necessarily state or reflect those of the United States Government or any agency thereof. 


\section{DISCLAIMER}

Portions of this document may be illegible in electronic image products. Images are produced from the best available original document. 


\title{
WIND FIELD PREDICTIONS FOR THE COLUMBIA GORGE AND THE GOODNOE HILLS WIND TURBINE SITE
}

by

Scott D. Veenhuizen

Jung-Tai Lin

August 1980

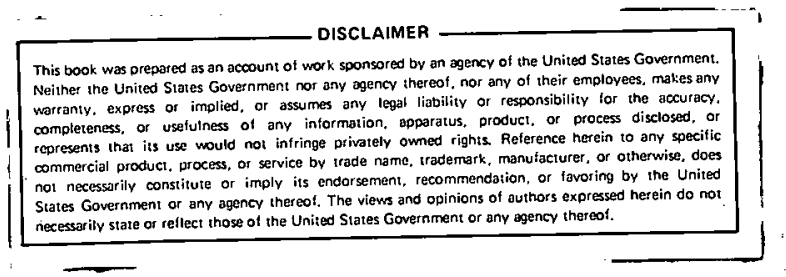

Submitted to

\author{
Bonneville Power Administration \\ Portland, Oregon
}

\section{UNITED INDUSTRIES CORPORATION 12835 Bell-Red Rd. Bellevue, Washington 98005 \\ Tel: (206) 453-8995}

\begin{abstract}
THIS PUBLICATION WAS PREPARED AS AN ACCOUNT OF WORK SPONSORED BY THE UNITED STATES GOVERMMENT, DEPARTMENT OF ENERGY, BONNEVILLE POWER ADMINISTRATION. NEITHER THE UNITED STATES NOR THE UNITED STATES DEPARTMENT OF ENERGY, NOR ANY OF THEIR EMPLOYEES, NOR ANY OF THEIR CONTRACTOB.S, SUBCONTRACTONE, ON TIEIR EMPLOYTES, MAKR ANY WARRANTY, EXPKESS OR IMPLIED, OR ASSUME ANY LEGAL LLABILITY OR RESPONSIBILITY FOR THE ACCURACY, COMPLETENESS, USEFULNESS, OR RELLABILITY OF THE RESEARCH, DATA, AND CONCLUSIONS REPORTED HEREIN, OR OF ANY INFORMATION, APPARATUS, PRODUCT, OR PROCESS DISCLOSED, OR REPRESENTS THAT ITS USF, WDIJIR NOT INFR INGE PRETVATELY OWNED RIGHTS. FOR THESE REASONS AND FOR THE REASON THAT THE VIEWS, OP INIONS, AND CONCLUSIONS CONTAINED IN THIS MATERIAL ARE THOSE OF THE CONTRACTOR AND DO NOT NECESSARILY REPRESENT THOSE OF THE UNITED STATES GOVERNMENT OR THE BONNEVILLE POWER ADMINISTRATION, INQUIRIES CONCERNING THE MATERLAL CONTAINED IN THE REPORT MAY IN ALL INSTANCES BE BETTER DIRECTED TO THE AUTHORS THAN TO THE BONNEVILLE POWER ADMINISTRATION.
\end{abstract}




\section{EXECUTIVE SUMMARY}

Numerical estimates of the long term seasonal mean wind speeds, wind directions, and available wind power density were conducted for comparison with the results of field wind measurements obtained by the Bonneville Power Administration for the Columbia Gorge region along the Oregon-Washington border. The authors had previously used the numerical method of estimating wind flows in complex terrain to identify high wind energy areas within the Olympic Peninsula and Northern Cascade regions of the State of Washington. The numerical technique was used as a generalized wind prospecting tool to provide the link between regional assessments and on-site biological or geomorphological indicators of mean wind speeds and available wind energy.

The wind flow model used is a two dimensional model based upon simplified hydrodynamical equations describing the fluid and thermodynamic motion of the atmosphere. Although the equations do not describe all flow characteristics, the resulting solution does describe the wind speeds and wind directions over the specified terrain. The model requires much less data than traditional approaches and it can therefore be used as an estimator of wind. patterns and speeds in areas where dense observational networks are not economically feasible, or where observations do not currently exist.

Because of the quantity and quality of the measured wind data obtained by the Bonneville Power Administration, the Columbia Gorge region was selected as a test case to establish the validity of the numerical technique, to establish the quantitative accuracy of the numerical wind speed and wind power density estimates, and to demonstrate the range of applicability of the numerical technique between large scale regional assessments and small scale site evaluations. The two primary objectives were (i) to compare the results of numerical predictions of long term mean wind speeds, wind directions, and available wind power with the observed wind measurements, thereby establishing the validity of the numerical approach as a viable tool in an overall wind prospecting methodology, and (ii) to perform preliminary numerical estimates of the wind field for the Goodnoe Hills wind turbine site area to illustrate the application of the numerical technique as an 
aid to understanding the free airflow to be experienced by the cluster of three Boefng MOD-2 wind turbines being constructed at Goodnoe Hills.

Numerical calculations of the seasonal mean wind field were conducted for five computational grids ranging in size from 10,900 square miles to 10 square miles. In each case the computational grids were arranged to include the location of existing wind measuring stations such that results of the numerical estimates could be compared with existing wind measurements. The smallest computational grid was focussed on the Goodnoe Hills area because of its selection as a test site for a cluster of three Boeing MOD-2 wind turbines. Measured wind data for 21 anemometer stations in the region of the Columbia Gorge were obtained and used as the standard against which to compare the results of the numerical estimates of wind speeds, wind directions, and available power densities.

Quantitative comparisons were made between numerically calculated mean wind speeds, wind directions, and available wind power densities and available wind data. The numerically calculated mean wind speeds were shown to agree with the observed mean wind speeds within a mean error of plus or minus 14 , $13,10,7$, and 7 percent for the five computational grids ranging from the largest to the smallest. In each case the numerically calculated wind directions were within the reported one compass point resolution of the observed data. It was estimated that the measured wind data accurately reflects the true long term mean wind speeds within a mean error of plus or minus nine percent, and therefore; it may be expected that the numerically predicted mean wind speeds represent the true long term mean wind speeds with a mean error of plus or minus $17,16,13,11$, and 11 percent for the five computational grids ranging from the largest to the smallest. As anticipated, the agreement between numerically calculated available wind power density and observed power density, because of the wind speed cubed nature of power density, was poorer at 34 percent than the agreement shown between the numerically calculated and observed mean speeds. The accuracy of the observed wind power density derived from hourly averaged wind data from six BPA data stations was estimated to be plus or minus 19 percent, resulting in an estimated mean error of plus or minus 39 percent between the numerically predicted mean wind power density and the true long term mean wind power density. 
The significant conclusions and recommendations derived from the work may be summarized as follows:

\section{Conclusions}

(i) Numerical estimation of seasonal mean wind speeds and seasonal mean power densities is a valid and useful tool for performing the initial phases of searching for wind power generating sites. The best application of the numerical technique is as a guide for locating potential high wind speed areas, and in optimizing locations for on-site anemometer stations to assess and characterize the on-site wind resource.

(ii) The demonstrated accuracy between the numerically predicted and observed seasonal mean wind speeds varies between a mean error of plus or minus 14 percent and plus or minus seven percent, depending upon the complexity of the terrain and spacing between adjacent computational grid points. The numerically calculated seasonal mean wind speeds, when an estimate of the error in the observed data of plus or minus nine percent is included, represents the true long term seasonal mean wind speeds within a corresponding mean error between plus or minus 17 percent and plus or minus 11 percent.

(iii) The demonstrated accuracy between the numerically estimated and observed available wind power density is plus or minus 34 percent. It was estimated that the observed wind power density derived from hourly averaged data is within plus or minus 19 percent of the true long term seasonal wind power density, therefore the numerical estimates of power density are within approximately plus or minus 39 percent of the true long term seasonal mean power density. Power density estimates from numerical calculations should, therefore, only be used if no other information is available and if they are properly qualified.

(iv) The technique of numerically calculating estimates of the wind field at reduced grid spacings is an effective technique that leads to improved accuracy in the predicted wind field results and a more detailed identification of high speed wind areas.

(v) The techniques of using the predicted wind field results from the large scale computations to extend the wind field computations into smaller 
areas without any available wind data is an effective and useful technique.

(vi) Although only preliminary, the applicability of the numerical method as an aid to understanding the free air flow variation at a specific wind turbine site was illustrated. Detailed mapping of the probable wind field at very small scales, in conjunction with on-site anemometer tower measurements, can be a valuable aid in understanding the mean wind field for the placement of wind instrumentation and wind turbines.

\section{Recomendations}

(i) During the performance of the numerical estimates of wind speeds, several high speed areas were identified, but were not investigated further. These areas were Identified as being much more extensive in size than the Goodnoe Hills site and in locations where favorable terrain for the placement of a large number of wind turbines may be found. It is recommended that the following two areas be considered in more detail in any future siting activities: (a) the area south and west across the Columbia Gorge from the Goodnoe Hills site, and (b) the area east and south of Goldendale, Washington.

(ii) The applicability of the numerical method as a viable technique in a generalized wind prospecting and siting methodology was quantified and demonstrated in previous sections of this report. It is therefore recommended that the numerical technique be included as an integral part of any future wind prospecting, or siting efforts.

(iii) The potential for using the numerical method as an aid to understanding the subtle variations in the wind field at potential wind turbine sites was demonstrated using the Goodnoe Hills wind turbine site as an example. The developemnt of the numerical technique for this application is not complete. Because of the potential value of this application, it is recommended that the development of the numerical technique for understanding the free air flow field at specific wind turbine sites be continued in conjunction with wind turbine experiments being conducted at Goodnoe Hills. 


\section{ACKNOWLEDGEMENT}

We are grateful for the support of this effort, "Wind Field Predictions for the Columbia Gorge and the Goodnoe Hills Wind Turbine Site", sponsored by the Bonneville Power Administration, General Equipment, Services and Construction Unit - EMRF, under contract number DE-AC79-80BP18979. We are especially indebted to Mr. Nick Butler of BPA for his support and encouragement in the performance of this work. We would also like to thank Mr. Ed Warchol and Mr. Ron Holeman of BPA for their cooperation, and Mr. Robert W. Baker of Oregon State University for providing the observed wind dati. Finally, we would like to acknowledge Mrs. Karla Dvorak for her patience, understanding, and hard work when preparing the manuscript. The artists concept of the Goodnoe Hills MOD-2 wind turbine site by Mr. Scott Hoyle was supplied through the courtesy of Mr. Ron Holeman of BPA. 


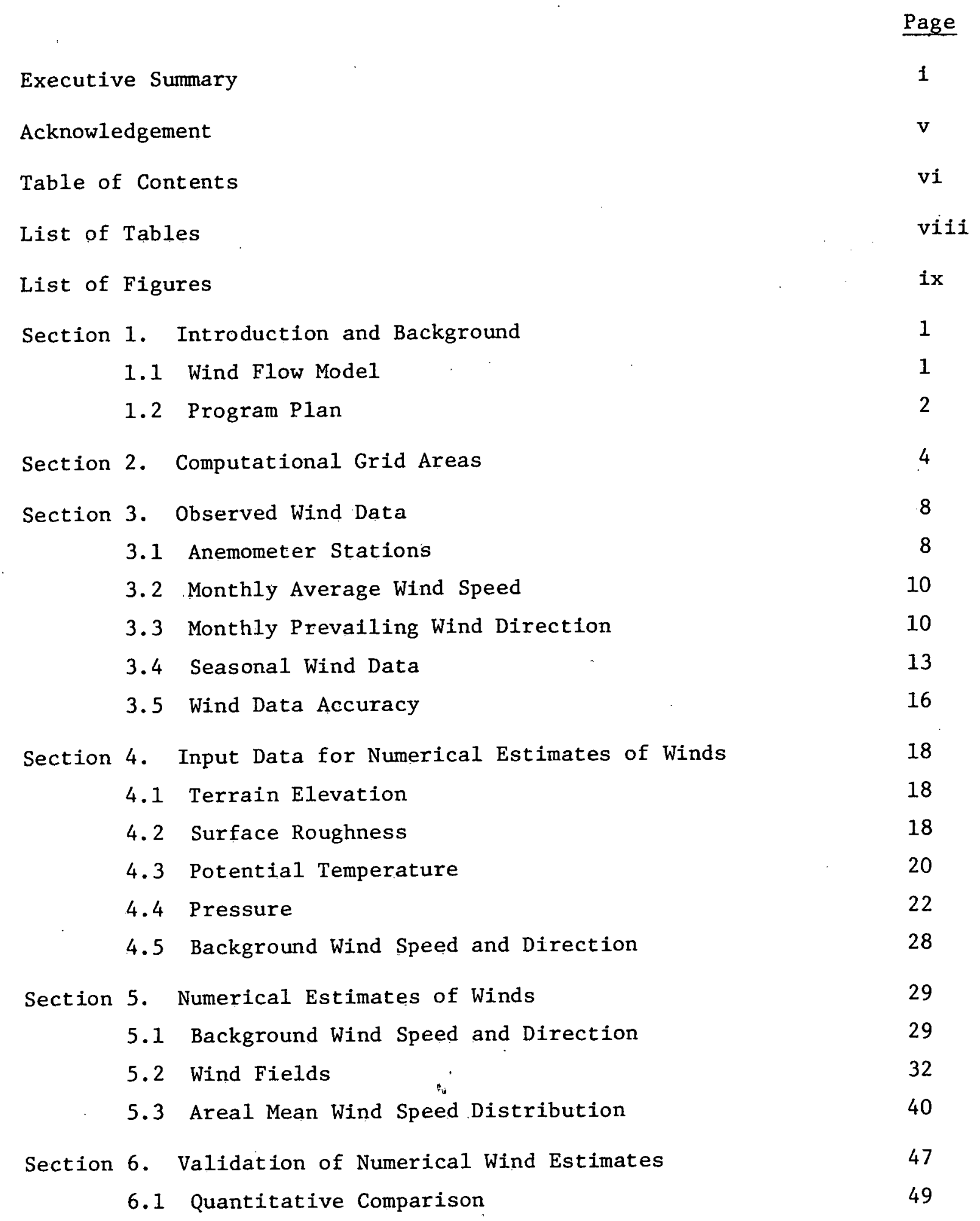




$$
\text { -vii- }
$$

6.2 Error Sources $\quad 52$

6.3 Seasonal Temperature and Pressure Effect 58

6.4 Available Wind Power Density 60

Section 7. The Goodnoe Hills Wind Turbine Site 64

Section 8. Conclusions and Recommendations 69

8.1 Conclusions $\quad 69$

8.2 . Recommendations 70

$\begin{array}{ll}\text { References } & 71\end{array}$

$\begin{array}{ll}\text { Appendix A } & 72\end{array}$ 


\section{LIST OF TABLES}

\begin{tabular}{|c|c|c|}
\hline No. & Title & Page \\
\hline 1 & Computation Grid Characteristics & 6 \\
\hline 2 & Wind Data: Station Characteristics. & 9 \\
\hline 3 & $\begin{array}{l}\text { Station Monthly Average Wind Speed Data: } \\
\text { (MPH) }\end{array}$ & 11 \\
\hline 4 & Monthly Mean Observed Power Density Data. & 12 \\
\hline 5. & Seasonal Summary of Observed Wind Data & 15 \\
\hline 6 & $\begin{array}{l}\text { Summary' of Monthly Average Temperature } \\
\text { Data. }\end{array}$ & $21:$ \\
\hline 7 & Seasonal Mean Temperature Data & $23^{\circ}$ \\
\hline 8 & $\begin{array}{l}\text { Summary: of Calculated Monthly Average } \\
\text { MSL Pressure Data }\end{array}$ & 26 \\
\hline 9 & Sèasonal. MSL Pressure Data: & 27 \\
\hline
\end{tabular}




\section{LIST OF FIGURES}

\begin{tabular}{|c|c|c|c|}
\hline $\begin{array}{c}\text { Figure } \\
\text { No. }\end{array}$ & & & Page \\
\hline 1 & & Computation Grid Areas of the Columbia Gorge & 5 \\
\hline 2 & & Prevailing Wind Directions & 14 \\
\hline 3 & & $\begin{array}{l}\text { Surface Characteristics Codes for Grid } 1 \text { - } \\
\text { GORGE }\end{array}$ & 19 \\
\hline 4 & & $\begin{array}{l}\text { Summer Station Mean Temperature Variation with } \\
\text { Elevation }\end{array}$ & 24. \\
\hline 5 & & $\begin{array}{l}\text { Mean Sea Level Temperature Distribution for } \\
\text { Grid 1, GORGE }\end{array}$ & 25 \\
\hline 6 & & $\begin{array}{l}\text { Flow Chart for Numerically Estimating Wind } \\
\text { Fields }\end{array}$ & 30 \\
\hline 7 & & Velocity Vector-plot for Grid 1, GORGE & 33 \\
\hline 8 & & Velocity Vector-plot for Grid 1, GORGE & 34 \\
\hline 9 & & Velocity Vector-plot for Grid 2, DALLES & 36 \\
\hline 10 & & Velocity Vector-plot for Grid 3, ROOSEVELT & 37 \\
\hline 11 & & Velocity Vector-plot for Grid 4, JUNIPER & 38 \\
\hline 12 & & Velocity Vector-plot for Grid 5, GOODNOE & 39 \\
\hline 13 & & Areal Distribution of $20 \mathrm{mph}$, Isotach, GORGE Grid & 42 \\
\hline 14 & & $\begin{array}{l}\text { Areal Distribution of } 20 \mathrm{mph} \text {, Isotach, DALLES } \\
\text { Grid }\end{array}$ & 43 \\
\hline 15 & & $\begin{array}{l}\text { Areal Distribution of } 20 \mathrm{mph} \text { Isotach; ROOSEVELT } \\
\text { Grid and JUNIPER Grid }\end{array}$ & 45 \\
\hline 16 & & $\begin{array}{l}\text { (a) GOODNOE Grid Area. (b) Areal Distribution of } \\
20 \mathrm{mph} \text { Isotach }\end{array}$ & 46 \\
\hline 17 & & $\begin{array}{l}\text { Comparison between Calculated and Observed Wind } \\
\text { Directions, GORGE Giid }\end{array}$ & 49 \\
\hline
\end{tabular}


Tablulated Comparison between Calculated and Observed Wind Speed and Direction Data, GORGE Grid Observed Wind Speed and Direction Data, Grids 2 - 5 the Vicinity of Wind Mountain Anemometer Station Goodnoe Hills

Comparison between Computed. Power Density and Observed Power Density Based on Observed Wind Speed

26 Comparison between Computed and Observed Power Density Based on Numerically Calculated Wind Speed Site Hills Wind Turbine Site 


\section{Introduction and Background}

This report sumnarizes the results of a research program conducted to demonstrate the applicability of numerical estimates of wind fields as a useful and economic tool for wind energy prospecting and wind energy site evaluation. The two primary objectives to be achieved in the program were (i) to compare the results of the numerical predictions of long term average wind speeds, wind directions, and available wind power with the results of wind measurements obtained by the Bonneville Power Administration (BPA) in the Columbia Gorge region, thereby establishing

the validity of the numerical approach for wind power prospecting, and (ii) to perform preliminary numerical estimates of the wind field for the Goodnoe Hills wind turbine site area as a possible aid to understanding the free airflow experienced at the Goodnoe Hills site where a cluster of three Boeing MOD-2 wind turbines are being installed.

\subsection{Wind Flow Model}

Veenhuizen and Lin (1979) used the numerical technique as part of a general siting methodology to identify high wind energy areas within the 0lympic Peninsula and Northern Cascade regions of the state of Washington. The numerical technique of estimating wind speeds in regions of complex terrain was used to provide the link between the regional assessments of wind energy in the Pacific Northwest by Hewson and Baker (1978), and more recently by E1liott and Barchet (1980), and the on-site technique of examining the effects of wind on the localized vegetation developed by Hewson et. al. (1979). The numerical technique was further refined by Veenhuizen et. al. (1980) to provide specific site wind field estimates for areas without any existing wind anemometer data by using the numerical results of a large scale area as the background input for numerical wind estimates for a small scale area. The numerical technique may then be used as a general application tool for wind prospecting, even when other local biological and geomorphological indicators are absent.

The wind flow model used by Veenhuizen and Lin for numerically estimating wind fields is a two dimensional model based upon simplified hydro- 
dynamical equations describing the fluid and thermodynamic motion of the atmosphere, that was developed by Fosberg et. a1. (1976). The mathematical simplifications in the model impose several limitations on the flow. field solutions. Moving flow systems characterized by intermittency, flow discontinuities, and flow separation are explicitly excluded since the model was intended to depict quasi-steady state processes and non-linear advection was ignored. Although the equations do not describe all flow characteristics, the resulting solution does describe the wind speeds and wind directions over the specified terrain.

The paper by Fosberg et. al. (1976) describing the mathemat1cal formulation of the wind flow model is included in Appendix A. The intended uses for this model were in providing wind fields for fire behavior prediction and in the evaluation of air pollution transport patterns. The model was used by Fosberg et. al. (1976) to estimate the wind field for part of the Cascade Mountains of Oregon, and it was used by Wood et. al. (1979) to estimate pollution transport for the Northern Puget Sound Region. Veenhuizen and Lin modified the higher order terms in the coordinate transformation of the thermodynamic terms in the model, thereby improving the accuracy of the numerical estimates in areas with complex terrain.

The model requires much less data than traditional approaches and it can therefore be used as an estimator of wind patterns and speeds in areas where dense observational networks are not economically feasible, or where observations do not currently exist. Because of the model's two dimensionality, it is well suited to wind prospecting applications where large areas may be examined with sufficient resolution to provide realistic estimates of the wind field.

\subsection{Program Plan}

The numerical technique was subsequently proposed to BPA as a valuable tool in a general siting methodology for prospecting for future wind turbine sites. Although previous results shown by Veenhuizen and Lin had included a comparison between the numerically estimated wind speeds and observed wind speed data, these comparisons were not considered to be sufficient 
to determine the validity, or the limitations of the numerical technique. Because of the quantity and quality of the measured wind information obtained by the BPA for the Columbia Gorge, it was decided to use the Columbia Gorge region as a test case to establish the validity of the numerical technique, establish the quantitative accuracy of the wind speed and wind power density estimates, and to demonstrate the range of applicability of the numerical technique between large scale regional assessments and small scale site evaluation.

The program plan called for numerical estimates of the long term seasonal mean wind speeds and wind directions for each of five different computational areas. The first computational area was a large scale grid that spanned the Cascades and included the major topographical features of this region of the Cascades. Each succeeding grid was smaller in scale encompassing a smaller area. The final computation grid was a small scale grid focussed on the Goodnoe Hills area of the Columbia Gorge. Goodnoe Hills was selected. from the several BPA wind monitoring sites as the focal point for this grid because of its selection as a test site for a cluster of three Boeing MOD-2 wind turbines. In each case the computational grids were arranged to include the location of at least some of the existing wind measuring stations such that observed wind data was available for comparison with the numerical estimates within each scale grid. 


\section{Computational Grid Areas}

The numerical computations were carried out on rectangular multipoint computation grids. Numerical estimates of the wind speeds were calculated for five different computation grids located in the region of the Columbia Gorge along the Oregon-Washington border. The largest grid area (Grid 1) is the entire map given in figure 1. The areas included in the other four grids are also shown in figure 1 . Some characteristics of the computation grids are given in table 1 .

For a11 five grids the east-west direction was divided into 98 evenly spaced increments $(\Delta x)$ and the north-south direction was divided into 64 even1y spaced increments $(\Delta y)$. The southwest corner of each grid was designated point $(1,1)$, the northwest corner as $(1,65)$, the northeast corner as $(99,65)$, and the southeast corner as $(99,1)$. The outside boundaries of each grid are reserved for specifying boundary conditions, resulting in numerical estimates of the wind speed and direction at each of the 6111 interior grid points.

The largest scale grid, GORGE, is 129 miles in the east-west (E-W) direction by 84.5 miles in the north-south (N-S) direction with a nominal grid spacing of 1.32 miles. This grid encloses an area of 10,900 square miles and extends from the west side to the east side of the Cascades between longitudes 122.70 degrees and 120 degrees and between latitudes 45.005 degrees and 46.2750 degrees and was selected to include the entire Columbia Gorge, Mt. St. Helens, Mt. Adams, and Mt. Hood as the dominating topographical features in this region of the Cascades.

The DALLES grid area, Grid 2, is 64.4 miles $E-W$ by 42.3 miles $N-S$ with a nominal grid spacing of 3500 feet that includes the BPA wind monitoring sites; Sevenmile Hill, KCIV, Juniper Point, Goodnoe Hills and Rooseve1t MW. The area enclosed by the DALLES grid is 2720 square miles, or approximately one fourth the area included within the GORGE grid.

The third and fourth grid areas, ROOSEVELT and JUNIPER, each have a nominal grid spacing of 1200 feet and overlap with Goodnoe Hills as a common area. Both the ROOSEVELT and JUNIPER grids are 22.5 miles E-W by 


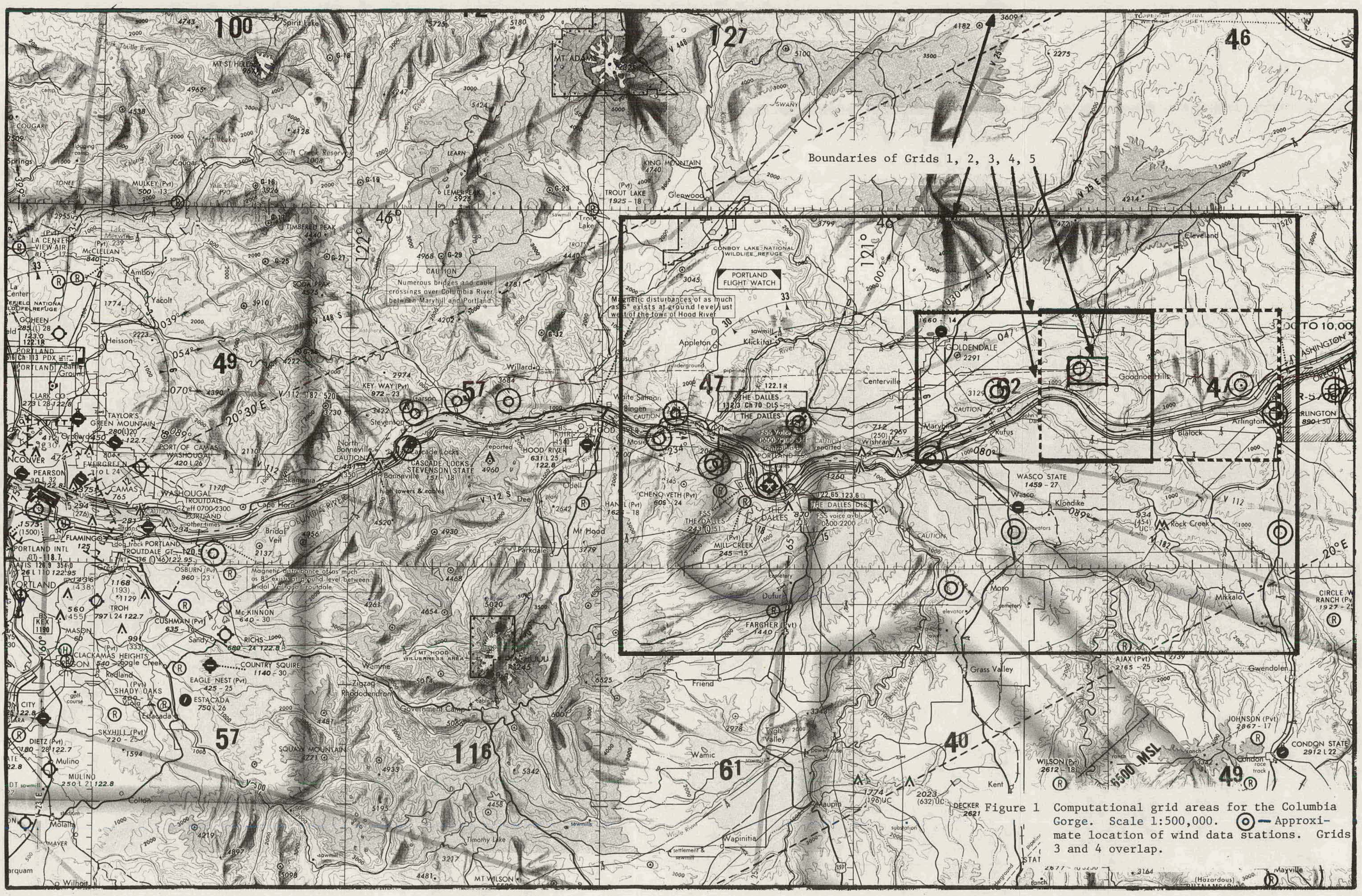


TABLE 1

COMPUTATION GRID CHARACTERISTICS

\begin{tabular}{|c|c|c|c|c|c|c|c|}
\hline \multirow[b]{2}{*}{ No. } & \multirow[b]{2}{*}{ NAME } & \multicolumn{2}{|c|}{ DIMENSIONS } & AREA & \multicolumn{2}{|l|}{ NOMINAL } & \multirow{2}{*}{$\frac{\text { LONG ITUDES }}{E / W(\mathrm{Deg})}$} \\
\hline & & $E-W(M i)$ & $\mathrm{N}-\mathrm{S}(\mathrm{Mi})$ & (Sq Mi) & $\Delta x$ or $\Delta y(f t)$ & N/S (Deg) & \\
\hline 1. & Gorge & 129.0 & 84.5 & 10900 & 7000 & $\begin{array}{l}46.2750 \mathrm{~N} \\
45.0005\end{array}$ & $\begin{array}{l}120.0000 \mathrm{~W} \\
122.7000\end{array}$ \\
\hline 2 . & Dalles & 64.4 & 42.3 & 2720 & 3500 & $\begin{array}{l}45.9917 \\
45.3943\end{array}$ & $\begin{array}{l}120.1250 \\
121.4667\end{array}$ \\
\hline 3. & Roosevelt & 22.5 & 14.8 & 330 & 1200 & $\begin{array}{l}45.8600 \\
45.6467\end{array}$ & $\begin{array}{l}120.1625 \\
120.6333\end{array}$ \\
\hline 4. & Juniper & 22.5 & 14.8 & 330 & 1200 & $\begin{array}{l}45.8593 \\
45.6450\end{array}$ & $\begin{array}{l}120.4117 \\
120.8793\end{array}$ \\
\hline 5. & Goodnoe & 3.9 & 2.5 & 10 & 200 & $\begin{array}{l}45.7956 \\
45.7583\end{array}$ & $\begin{array}{l}120.5000 \\
120.5807\end{array}$ \\
\hline
\end{tabular}


14.8 miles $\mathrm{N}-\mathrm{S}$ and enclose 330 square miles. The eastern most grid (ROOSEVELT) includes Goodnoe Hills and Roosevelt MW, while the western most grid (JUNIPER) includes Goodnoe Hills and Juniper Point.

The final computation grid, GOODNOE, is a. small scale grid, 3.9 miles E-W by 2.5 miles $\mathrm{N}-\mathrm{S}$, with a nominal grid spacing of 200 feet that includes the area surrounding the Goodnoe Hills wind turbine sites.

The locations of the grid points were specified in terms of latitude and longitude. For a rectangular, or square grid, it is only necessary to specify the common latitude through the two northern corners and the common latitude through the two southern corners of the grid, along with the longitude through the NW corner and the longitude through the NE corner of the grid to determine a rectangular area on the surface of the earth. The latitudes and longitudes that define each of the five computational grids are also given in Table 1. 
3. Observed Wind Data

The results of the numerical estimates of long term seasonal mean wind speeds and wind directions were to be compared with existing wind observation data to determine the validity of the numerical computations as a tool for wind power prospecting. The Columbia Gorge region has been investigated previously as a wind resource area and the quality and quantity of actual wind data available for this region was the primary reason for selecting this region for testing the validity of the numerical technique.

\subsection{Anemometer Stations}

At our request to $\mathrm{BPA}$, we were supplied by Oregon State University with the results of the available wind measurements within the area of the computation grids along the Columbia Gorge. The existing wind data was screened to select those data stations for which there were data for each of the 12 months of the year; and for which the location, the elevation, and the anemometer height was known. Data that satisfied these requirements were obtained for 21 stations. The wind data station characteristics for the 21 stations are summarized in Table 2 where the most westerly station is listed first and the most easterly station is listed last. The approximate location of the observed wind data stations is indicated on the map shown in Figure 1.

Data for all the stations, except stations 1 through $3,11,14$, and 19, were supplied by Oregon State University. Data for stations 1-3,, 11, and 19 were taken from the Climatological Handbook; Colubmia Basin States (1968). Data for station 14, the Moro BPA Test Facility, was supplied directly by BPA. The period of record for which data was available varied from 15 months for Mosier and Lyle to 10 years for the Portland AP. Except for stations 1 through 4,11, and 19 the data generally spanned the calendar years from 1977 through 1979 with an average record length of 27 months.

Anemometer heights varied from 16 feet for Dallesport to 155 feet for the Moro Test Facility, with six of the stations at the standard 30 foot anemometer height. The average anemometer height for all 21 stations was 49 feet. The data stations range in elevation from 26 feet at Portland AP 
TABLE 2

WIND DATA STATION CHARACTERISTICS

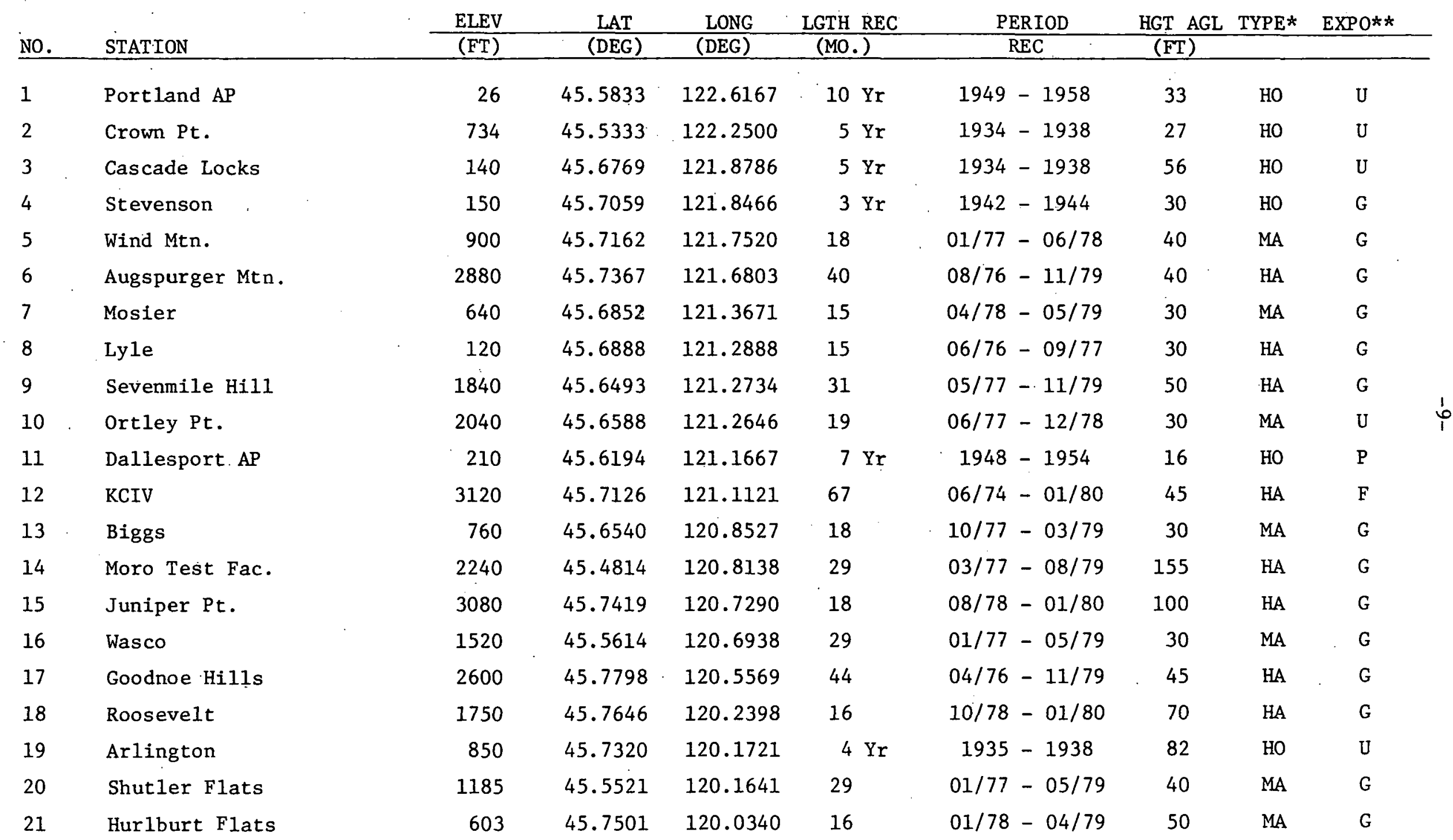

* HA - Hourly Averaged Data, HO - Five Minute Average taken Hourly, MA - Wind Run Monthly Average ** G - Good, F - Fair, P - Poor, U - Unknown 
to 3120 feet at the KCIV station with an average station elevation of 1304 feet above mean sea level (MSL). The data for eight of the 21 stations was hourly average data (HA) taken from strip charts. The data from six of the stations were hourly observations of a five minute average (HO), while the remaining seven stations were wind-run anemometers for which a monthly average (MA) was available.

An anemometer exposure rating was supplied for 15 of the wind data stations and were all rated as good (G), except for KCIV with a fair (F) rating and Dallesport with a poor (P) rating. The exposures for stations 1, 2, 3, 10, and 19 were unknown (U).

\subsection{Monthly Average Wind Speed}

The observed average monthly wind speeds in miles per hour for each of the 21 data stations are given in Table 3. The data for Stevenson and Lyle were supplied as seasonal averages for each of the four three-month seasons ( $W, S, S$, and $F$ ). The highest speed station is Juniper Point with an annual mean wind speed of $20.4 \mathrm{mph}$ at an anemometer height of 100 feet, making it the station with the highest anemometer above mean sea level.

The lowest speed station is Portland AP with, an annual mean speed of $6.5 \mathrm{mph}$. With the exception of Portland AP, Cascade Locks, and Crown Point, all of the data stations generally exhibit higher mean wind speeds during the summer months than during the winter months.

The monthly mean available power density in watts per square meter was supplied for the six data stations $6,9,12,15,17$, and 18 , as shown in Table 4. As exhibited by the monthly mean speed data, the power densities are generally higher during the summer months than during the winter months.

\subsection{Monthly Prevailing Wind Direction}

Wind direction data was available for 12 of the 21 data stations. Wind. rose information for each station for which direction data were available were examined for similarities throughout the 12 months of the year. Previously Veenhuizen and Lin (1979) had divided the year, based upon prevailing wind direction, into two six-month periods, April through September (summer) and October through March (winter), to distinguish the two major air flow patterns occurring during the year. 
TABLE 3

STATION MONTHLY AVERAGE WIND SPEED DATA (NPH)

\begin{tabular}{|c|c|c|c|c|c|c|c|c|c|c|c|c|c|c|}
\hline No. & STATION & PERIOD OF REC & JAN & FEB & MAR & $\mathrm{APR}$ & MAY & JUN & JUL & AUG & SEP & $\mathrm{OCT}$ & NOV & $\mathrm{DEC}$ \\
\hline 1 & Portland AP & $1949-1958$ & 8.7 & 7.5 & 7.1 & 5.8 & 5.4 & 5.4 & 6.1 & 5.6 & 4.9 & 5.4 & 6.8 & 8.6 \\
\hline 2 & Crown Pt. & $1934-1938$ & 17.8 & 17.9 & 10.5 & 9.1 & 8.0 & 6.6 & 6.2 & 6.7 & 8.7 & 12.2 & 16.9 & 15.0 \\
\hline 3 & Cascade Locks & $1934-1938$ & 16.8 & 17.5 & 12.8 & 14.0 & 14.7 & 14.2 & 15.6 & 14.6 & 13.5 & 14.6 & 17.1 & 18.0 \\
\hline 4 & Stevenson & $1942-1944$ & $18.4(W)$ & $* \rightarrow$ & & $11.7(\mathrm{~S})$ & & & $12.2(\mathrm{~S})$ & & & $12.9(\mathrm{~F})$ & $\longrightarrow$ & \\
\hline 5 & Wind Mtn. & $01 / 77-06 / 78$ & 9.8 & 9.9 & 12.6 & 11.2 & 13.2 & 15.4 & 17.2 & 9.1 & 11.0 & 10.3 & 11.4 & 11.2 \\
\hline 6 & Augspurger Mtn & $08 / 76-11 / 79$ & 18.1 & 11.6 & 16.8 & 15.8 & 18.4 & 21.5 & 21.6 & 18.4 & 16.1 & 16.4 & 18.0 & 17.6 \\
\hline 7 & Mosier & $04 / 78-05 / 79$ & 7.2 & 7.2 & 9.7 & 11.5 & 12.7 & 12.9 & 12.9 & 11.3 & 9.5 & 8.7 & 7.2 & 7.2 \\
\hline 8 & Lyle & $06 / 76-09 / 77$ & $5.8(\mathrm{~W})$ & $\longrightarrow$ & & $-9.3(\mathrm{~S})$ & $\longrightarrow$ & & $10.8(\mathrm{~s})$ & & & $5.6(\mathrm{~F})$ & & \\
\hline 9 & Sevenmile Hill & $05 / 77-11 / 79$ & 8.4 & 13.4 & 15.7 & 16.6 & 20.5 & 21.0 & 21.6 & 19.1 & 15.0 & 11.7 & 10.8 & 15.5 \\
\hline 10 & Ortley Pt. & $06 / 77-12 / 78$ & 12.0 & 13.0 & 12.0 & 16.8 & 15.8 & 20.2 & 20.2 & 17.2 & 13.0 & 11.6 & 11.4 & 11.8 \\
\hline 11 & Dallesport AP & $1948-1954$ & 4.9 & 5.7 & 7.9 & 9.5 & 10.8 & 11.4 & 12.0 & 11.1 & 8.0 & 5.3 & 4.5 & 5.3 \\
\hline 12 & KCIV & $06 / 74-01 / 80$ & 14.1 & 15.4 & 13.7 & 15.0 & 16.0 & 16.1 & 14.8 & 14.2 & 13.1 & 13.6 & 13.1 & 14.5 \\
\hline 13 & Bitggs & $10 / 77-03 / 79$ & 5.2 & 8.3 & 10.9 & 11.8 & 17.0 & 17.0 & 14.5 & 13.8 & 13.6 & 9.2 & 9.8 & 10.0 \\
\hline 14 & Moro Test Fac. & $03 / 77-08 / 79$ & 9.6 & 12.0 & 15.7 & 14.3 & 14.4 & 13.8 & 13.6 & 10.4 & 10.8 & 11.0 & 12.0 & 16.6 \\
\hline 15 & Juniper Pt. & $08 / 78-01 / 80$ & 14.3 & 24.6 & 20.2 & 23.9 & 21.0 & 25.2 & 23.6 & 21.2 & 21.3 & 18.0 & 16.0 & 23.0 \\
\hline 16 & Wasco & $01 / 77-05 / 79$ & 6.1 & 8.3 & 11.6 & 12.9 & 14.4 & 14.1 & 14.7 & 12.4 & 11.0 & 9.4 & 10.0 & 10.0 \\
\hline 17 & Goodnoe Hills & $04 / 76-11 / 79$ & 7.2 & 13.1 & 17.8 & 17.8 & 20.6 & 20.5 & 20.1 & 18.1 & 15.7 & 13.3 & 11.9 & 14.4 \\
\hline 18 & Roosevelt & $10 / 78-01 / 80$ & 9.3 & 12.4 & 13.7 & 15.8 & 16.7 & 18.1 & 16.9 & 13.7 & 12.1 & 11.2 & 10.7 & 14.3 \\
\hline 19 & Arlington & $1935-1938$ & 11.1 & 11.3 & 15.2 & 16.7 & 17.4 & 15.3 & 17.2 & 15.7 & 12.9 & 11.7 & 10.8 & 11.4 \\
\hline 20 & Shutler Flats & $01 / 77-05 / 79$ & 5.6 & 7.6 & 11.9 & 14.3 & 13.8 & 14.0 & 14.3 & 12.8 & 12.0 & 9.4 & 9.6 & 8.2 \\
\hline 21 & Hurlburt Flats & $01 / 78-04 / 79$ & 5.8 & 6.8 & 8.2 & 11.0 & 13.4 & 11.8 & 8.8 & 9.1 & 7.1 & 4.5 & 3.1 & 5.1 \\
\hline
\end{tabular}

* (W) - Winter, (S) - Spring or Summer, (F) - Fall 


\section{TABLE 4}

MONTHLY MEAN OBSERVED POWER DENSITY DATA (W/M $\left.{ }^{2}\right)$

\begin{tabular}{|c|c|c|c|c|c|c|c|c|c|c|c|c|c|}
\hline STATION & PERIOD OF REC & JAN & FEB & MAR & $\mathrm{APR}$ & MAY & JUN & JUL & AUG & SEP & $\mathrm{OCT}$ & NoV & $\mathrm{DEC}$ \\
\hline Augspurger Mtn. & $08 / 76-11 / 79$ & 557 & 163 & 723 & 327 & 493 & 719 & 813 & 529 & 338 & 359 & 458 & 536 \\
\hline Sevenmile Hill & $05 / 77-11 / 79$ & 97 & 309 & 437 & 518 & 823 & 835 & 841 & 586 & 427 & 241 & 317 & 486 \\
\hline KCIV & $06 / 74-01 / 80$ & 279 & 325 & 243 & 272 & 291 & 316 & 241 & 218 & 181 & 193 & 220 & 292 \\
\hline Juniper Pt. & $08 / 78-01 / 80$ & 448 & 1490 & 909 & 1313 & 876 & 1415 & 1132 & 956 & 893 & 673 & 676 & 1365 \\
\hline Goodnoe Hills & $04 / 76-11 / 79$ & 116 & 332 & 585 & 622 & 838 & 784 & 730 & 556 & 441 & 335 & 372 & 606 \\
\hline Roosevelt & $10 / 78-01 / 80$ & 158 & 241 & 314 & 387 & 415 & 560 & 467 & 286 & 257 & 206 & 232 & 395 \\
\hline
\end{tabular}


The prevalling wind direction for each of the stations for which direction data was avallable is shown in figure 2. The data stations are positioned in figure 2 with the most westerly to the left of the figure, and the most easterly data station to the right of the figure. The arrow shown for each station and each month in figure 2 shows the prevailing direction the wind was from, referenced to true north (top of the page), and the length of the arrows represent the sum of the percentage of time the wind was from the indicated direction, plus or minus one compass point (16-point compass). The length of the arrows shown is, therefore, representative of the persistence of the wind direction to lie within a 45 degree sector.

For nine of the 12 data stations, the percentage of time the wind direction is from the 45 degree sector represented by the arrow equals, or exceeds 50 percent during the March through September period indicating a very persistent and organized westerly flow through the Columbia Gorge from Portland on the west to Arlington on the east.

The prevailing wind directions for the period October through February are much less consistent than the March through September period. Portland, Crown Point, and Cascade Locks data exhibit a persistent flow in the east-to-west direction during the winter in the west end of the Columbia Gorge. Goodnoe Hills, Roosevelt, and Arlington data exhibit a westerly flow four out of five months during the winter at the east end of the Columbia Gorge.

\subsection{Seasona1 Wind Data}

Based on the persistent westerly flow direction we divided the 12 month year into a summer period, March through September ( 7 months), and a winter period, October through February ( 5 months).

From the monthly average mean wind speed data shown in Table 3, a seasonal mean wind speed was determined for each wind data station. The seasonal mean wind speed in miles per hour and associated prevailing wind directions, where available, are summarized in Table 5, and are the wind speeds and directions for comparison with the estimated wind speeds and 


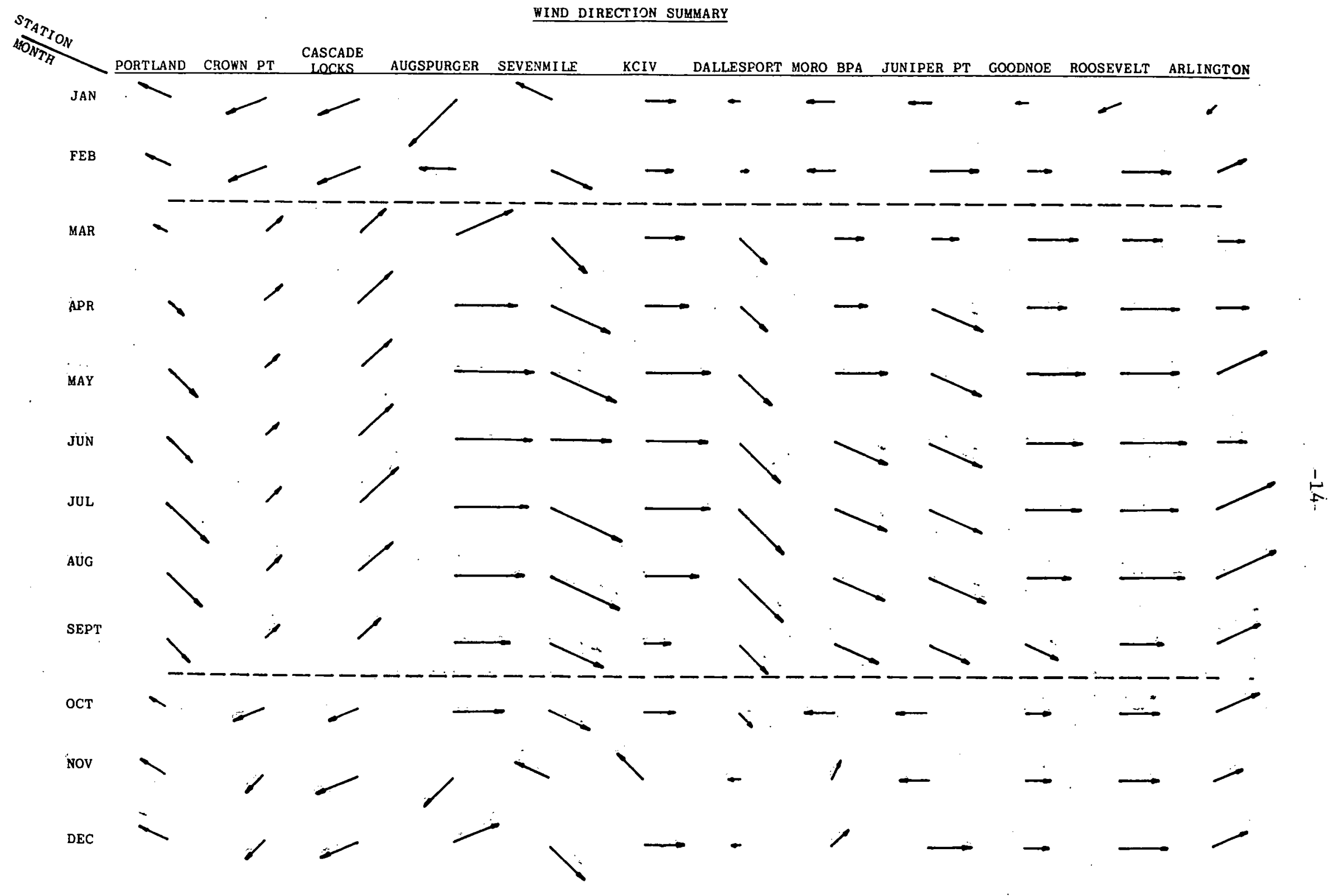

Figure $2^{\circ}$ Prevailing Wind Directions. Length of Arrow representing $100 \%$ Frequency of occurrence $\longrightarrow$ 
TABLE 5

SEASONAL SUMMARY OF OBSERVED WIND DATA

\begin{tabular}{|c|c|c|c|c|c|c|c|c|c|}
\hline & & MEAN & WIND SP & EED, (MPH) & AND DIREC & TION & MEAN POWER & RENSITY & $\left(\right.$ WATTS $\left./ M^{2}\right)$ \\
\hline STATION & $\begin{array}{c}\text { ANN } \\
\text { SPEED }\end{array}$ & DIRECT & $\begin{array}{l}\text { SUMMER } \\
\text { SPEED }\end{array}$ & DIRECT & $\begin{array}{l}\text { WINTER } \\
\text { SPEED }\end{array}$ & DIRECT & ANN & SUMMER & WINTER \\
\hline Portland AP & 6.5 & NW & 5.8 & NW & 7.4 & ESE & & & \\
\hline Crown Pt. & 11.4 & SW & 8.0 & SW & 16.0 & ENE & & & \\
\hline Cascade Locks & 15.3 & SW & 14.2 & SW & 16.8 & ENE & & & \\
\hline Stevenson & 13.8 & & 15.6 & & 12.0 & & & & \\
\hline Wind Mtn. & 11.8 & & 12.8 & & 10.5 & & & & \\
\hline Augspurger Mtn & 17.9 & $\mathrm{~W}$ & 18.4 & $W$ & 16.3 & $\mathrm{NE}(W)$ & 507 & 563 & 414 \\
\hline Mosier & 9.8 & & 11.5 & & 7.5 & & & & \\
\hline Lyle & 8.1 & & 10.0 & & 5.7 & & & & \\
\hline Sevenmile Hill & 15.9 & WNW & 18.5 & WNW & 12.0 & WNW (ESE) & 509 & 638 & 290 \\
\hline Ortley Pt. & 14.6 & & 16.5 & & 12.0 & & & & \\
\hline Dallesport AP & 8.0 & NW & 10.1 & $\mathrm{NW}$ & 5.1 & $E$ & & & \\
\hline KCIV & 14.5 & W & 14.7 & W & 14.1 & $E(S W)$ & 253 & 252 & 262 \\
\hline Biggs & 11.8 & & 14.1 & & 8.5 & & & & \\
\hline Moro Test Fac. & 12.8 & $\mathrm{~W}$ & 14.9 & $\mathrm{~W}-\mathrm{WNW}$ & 12.2 & $\mathrm{E}(\mathrm{SW})$ & & & \\
\hline Juniper Pt. & 20.4 & WNW & 22.3 & WNW & 19.2 & $E(W)$ & 975 & 1070 & 930 \\
\hline Wasco & 11.2 & & 13.0 & & 8.8 & & & & \\
\hline Goodnoe Hills & 16.2 & $\mathrm{~W}$ & 18.6 & $\mathrm{~W}$ & 12.0 & $W(E)$ & 542 & 650 & 352 \\
\hline Roosevelt & 13.2 & $\mathrm{~W}$ & 15.3 & W & 11.6 & $\mathrm{~W}(\mathrm{ENE})$ & 309 & 384 & 246 \\
\hline Arlington & 13.8 & $\mathrm{~W}$ & 15.8 & W-WSW & 11.3 & WSW(NE) & & & \\
\hline Shutler Flats & 11.1 & & 13.3 & & 8.1 & & & & \\
\hline Hurlburt Flats & 7.9 & & 9.9 & & 5.1 & & & & \\
\hline
\end{tabular}


directions produced by the numerical computations. Also included in Table 5 are the seasonal available power densities in watts per square meter as determined from the monthly power density data given in Table 4.

\subsection{Wind Data Accuracy}

Since the results of the numerical estimates of the long term seasonal mean wind speeds were to be compared with the observed wind data, it is desirable to first establish the quality of the observed wind speed data. No estimates of accuracy were supplied with the observed wind speed data. Meaningful estimates of the accuracy of field wind speed measurements are extremely difficult to obtain because of small-scale spacial resolutions defined by nearby terrain or vegetation influences, year-to-year variations in the mean wind field patterns, sensor calibration and response characteristics, and data losses due to sensor failures caused by inclement environmental conditions.

Corotis, et. al. (1977) and Corotis (1979) analyzed National Weather Service Data for 28 stations across the United States to determine the effect of the season to season variation on the reliability of measurements of wind speeds for wind power assessments, and concluded that, in general, the mean wind speed determined from a single season of data is within about ten percent of the true measured long term mean wind speed for that season of the year with a confidence of 90 percent. Corotis also concluded that a four fold increase in measurement duration leads to a doubling of accuracy (e.g. from \pm 10 percent to \pm 5 percent).

The average record length for 16 of the 21 stations was two seasons. The average data recovery rate for the six stations; $6,9,12,15,17$, and 18 was approximately 80 percent, which reduces the average record length to approximately 1.6 seasons. From Corotis' results, the observed seasonal mean wind speeds should therefore represent the long term observed seasonal mean wind speeds within eight percent with a 90 percent level of confidence.

The above estimate of the observed wind data accuracy should be furthur adjusted to include the anemometer sensor characteristics. Wind Tunnel 
and ficld calibration data of wind instruments were reported by llewson and Baker (1978) for three Aerovane anemometers and 12 wind run anemometers. In their tests, the Aerovane anemometers exhibited an accuracy of three percent, the wind run anemometers an accuracy of approximately seven percent, with a combined accuracy of approximately five percent. The observed seasonal mean wind speeds given in Table 5, when error due to season-to-season variations in the wind field, sensor calibration and response characteristics, and data losses are included, should, in general, represent the true long term seasonal mean wind speeds with an estimated accuracy of plus or minus nine percent $\left(\left((8 \%)^{2}+(5 \%)^{2}\right)^{\frac{1}{2}}\right)$.

Corotis (1979) also examined the reliability of calculating available wind power from the cube of the hourly average wind speed and concluded that to achieve the same accuracy and confidence in wind power estimates as for mean speed (e.g. \pm 10 percent with 90 percent confidence), requires a measurement duration nine times longer for mean available wind power. If the measurement period is the same for mean power as for mean speed, which is the usual case, then a nine percent accuracy in the mean wind speeds translates into a plus or minus 27 percent (factor of three) accuracy in mean wind power. The period of record for the six data stations for which available wind power density data were supplied varied from 16 months for Roosevelt to 67. months for KCIV with an average of 36 months. Including anemometer accuracy and using the results by Corotis, the seasonal mean power densities calculated from the measured wind data should be within 29 percent of the true long term mean power density for Roosevelt, 14 percent for KCIV, and within an average of 19 percent for all six stations with a 90 percent level of confidence. 
4. Input Data for Numerical Estimates of Winds

Specific data required by the numerical model at each grid point are: (I) the terrain elevation, (ii) a surface roughness characteristic, (iii) the potential temperature on the surface, and (iv) a non-dimensional pressure. Additional data that must be supplied are: (v) the latitude through the center of the computational grid, (vi) the grid.spacing in the north-south direction and in the east-west direction, (vii) the temperature lapse rate and (viii) a mean background wind speed and direction within the computational grid (geostrophic wind).

\subsection{Terrain Elevation}

The terrain elevation data was acquired from the National Cartographic Information Center (NCIC), which handles public distribution of the digital terrain tapes produced by the Defense Mapping Agency Topographic Center (DMATC) from the 1:250,000 scale series of USGS topographic maps. These digital terrain tapes were produced by a Digital Graphics Recording (DGR) system consisting of an automatic digitizing table and a computer system that recorded a grid of terrain elevations from traces of the 200 foot contour lines on the 1:250,000 topographic maps. Elevations of grid points not intersected by contour lines were then interpolated to produce a value of elevation for every 0.01 inch on each map (approximately 200 feet on the ground). The digital tapes were acquired for the regions of Oregon and Washington between longitude 120 degrees and 123 degrees and between latitudes 45 degrees and 47 degrees.

\subsection{Surface Roughness}

The surface roughness characteristics are introduced into the hydrodynamic model through an appropriate surface feature index. Four classifications of surface features were used for the Columbia Gorge region: forest (F); grass fields (G); towns (T); and-cities (C). Broad areas corresponding to these classifications were identified on the $1: 250,000$ scale topographic maps according to the map legend. Veenhuizen and.Lin (1979) had previously tried obtaining detailed identification of the surface characteristics 


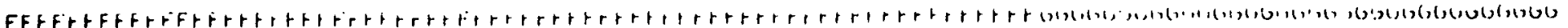

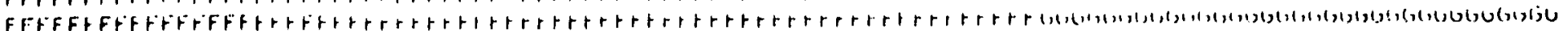

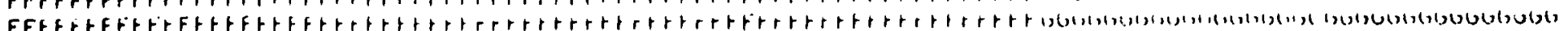

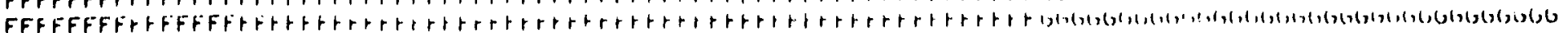

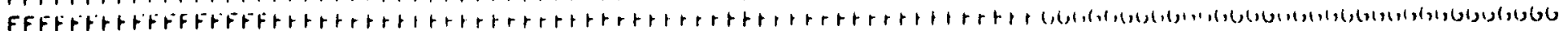

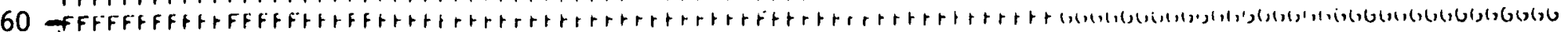

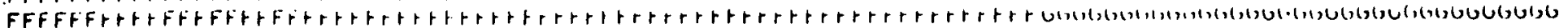

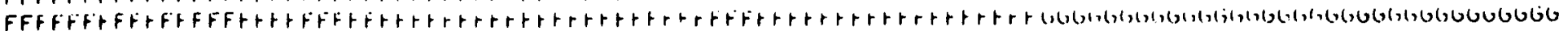

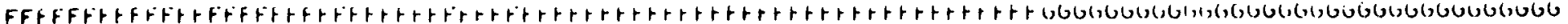

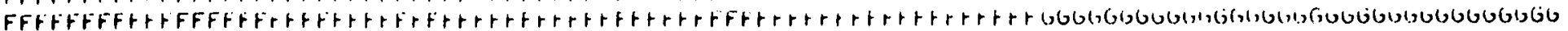

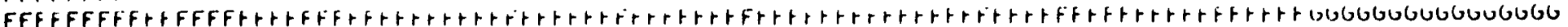

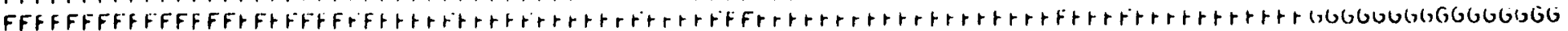

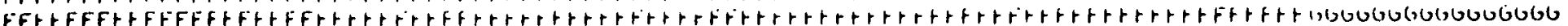

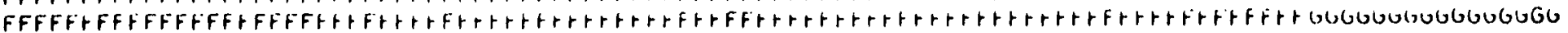

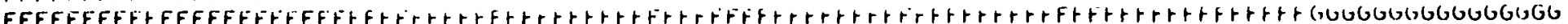

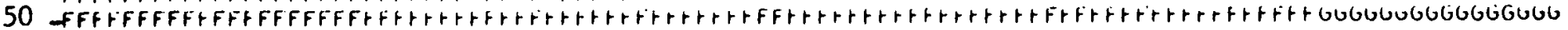

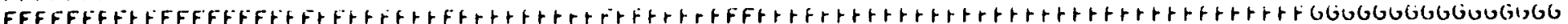

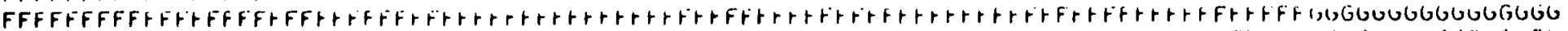

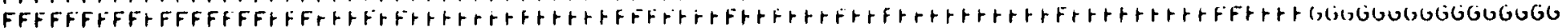

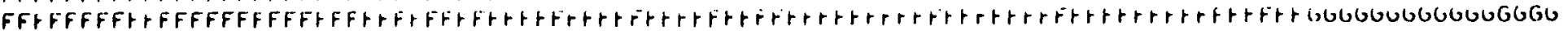

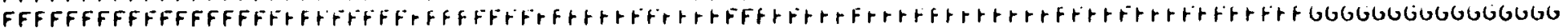

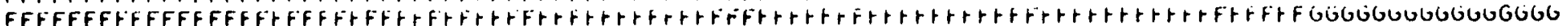

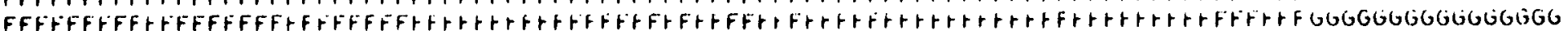

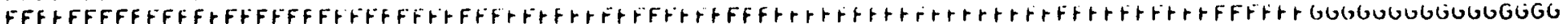

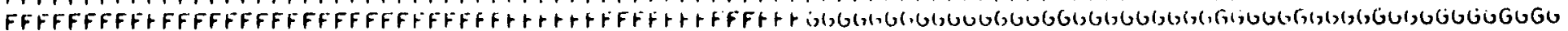

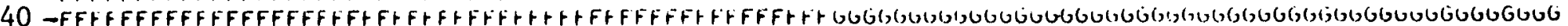

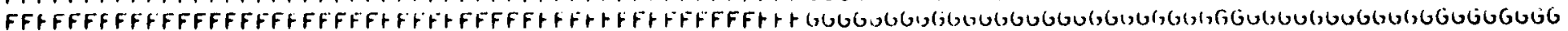

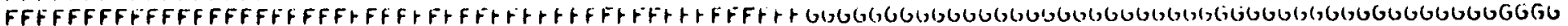

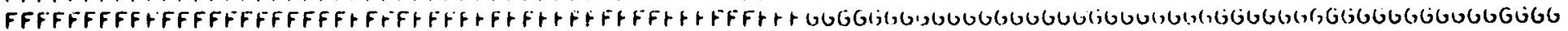

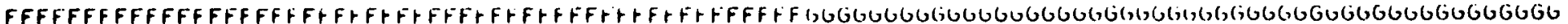

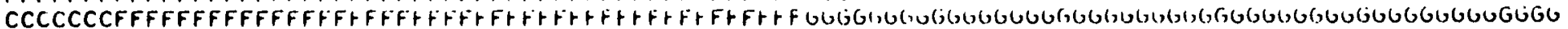

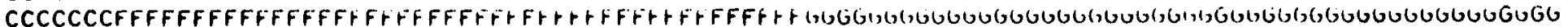

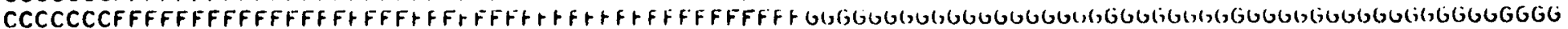

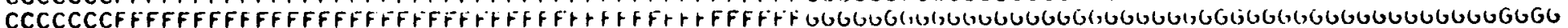

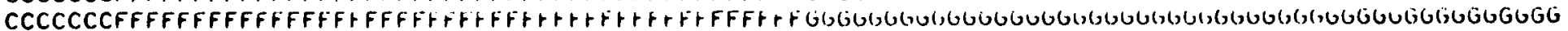

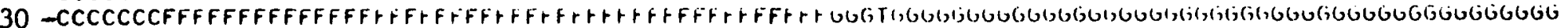

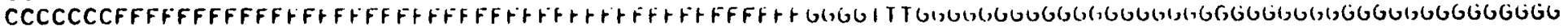

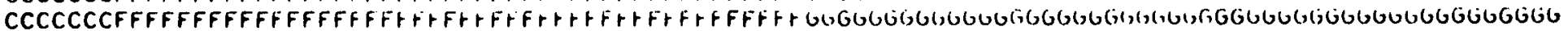

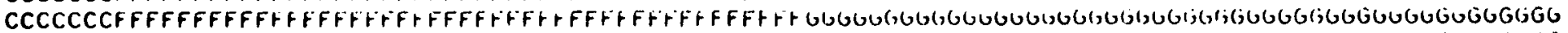

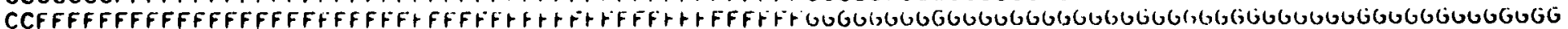

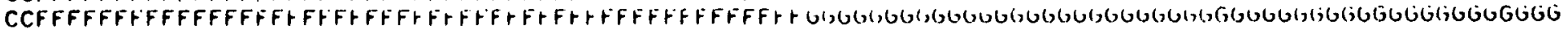

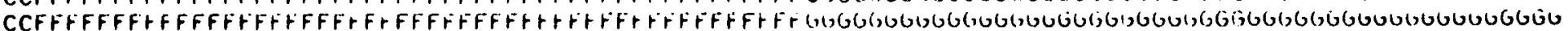

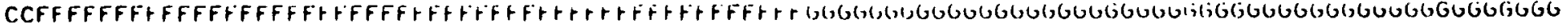

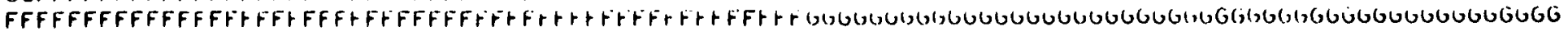

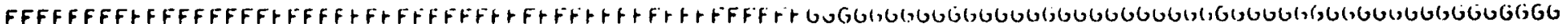

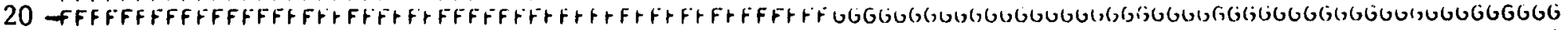

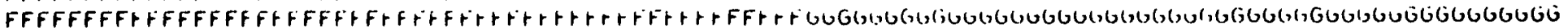

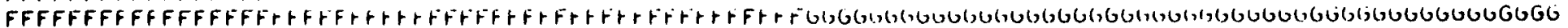

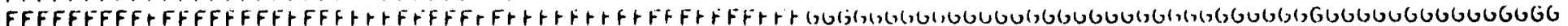

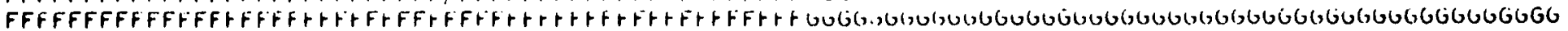

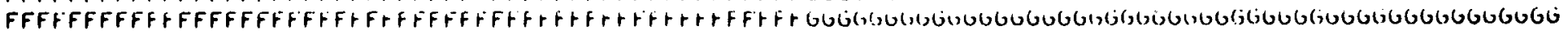

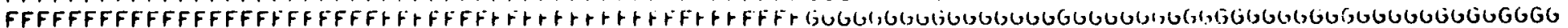

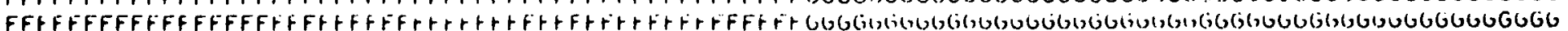

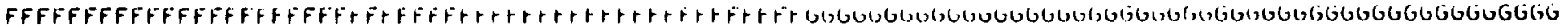

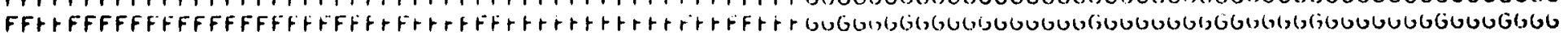

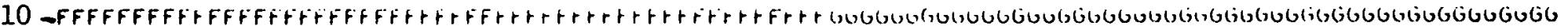

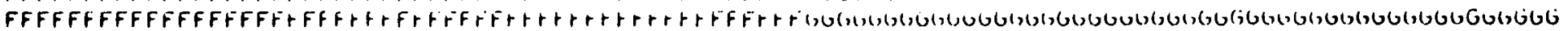

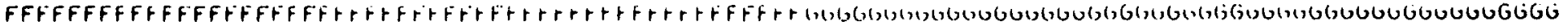

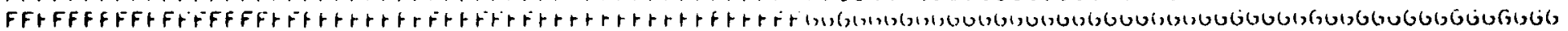

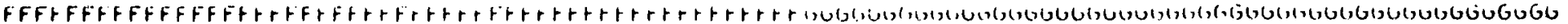

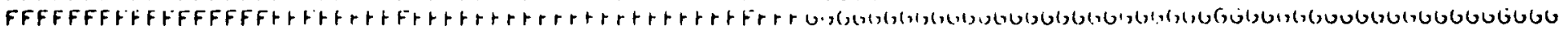

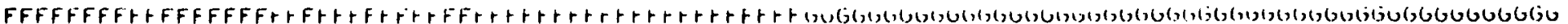

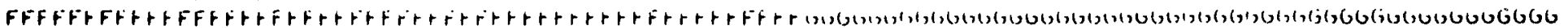

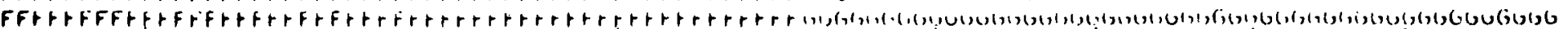
10
20
30
40 50
60
70
80
90

GRID LOCATION, WEST-EAST

Figure 3 Surface Characteristics Codes for Grid 1 - GORGE. Forest (F), Grass Fields (G), Towns (T), Cities (C) 
from the 1:250,000 scale USGS land use maps and determined that great detail in specifying the surface feature index is not warranted, and that the topographic maps are as accurate as the land use maps for defining the surface feature index. The surface roughness lengths corresponding to various surface features are: forest (F), 9.3 feet; grass fields (G), 0.16 feet; towns ( $\mathrm{T}), 5.4$ feet; and cities (C), 6.6 feet. For the largest grid, the surface feature indicies corresponding to each grid point are shown in figure 3 .

\subsection{Potential Temperature}

The potential temperature, non-dimensional pressure and background wind speed and direction are time changing parameters that determine the state of the atmospheric flow for which the resultant wind field is calculated. The numerical model may be used to estimate the wind field for atmospheric conditions that correspond to a certain time of a specific day, or it may be used to estimate the average wind field corresponding to an average atmospheric condition.

To estimate the mean wind field requires inserting values of potential temperature, non-dimensional pressure and a background wind condition that are representative of the mean atmospheric conditions for the specified averaging period. In the event of representing long term mean wind speeds, specific flow phenomena, such as diurnal variation and local valley drainage winds are submerged in the averaging process.

In previous applications of the numerical model discussed by Fosberg, et. al. (see Appendix A) it was concluded that pressure variations could be excluded, but that the topographic and temperature field must be represented in accurate detail for the model to yield realistic results with moderate to low background wind speeds. The modification to the model by Veenhuizen and Lin (1979) relaxed the requirements for detailed temperature specifications; however, it was not determined at that time if a detailed specification of the temperature field was required. Therefore, actual temperature data at 25 stations within the computational area of the largest grid, GORGE, were obtained from the National Climatic Center 
TABLE 6

SUMMARY OF MONTHL,Y AVERAGE TEMPERATURE DATA ( $\left.{ }^{\circ} \mathrm{F}\right)$

\begin{tabular}{|c|c|c|c|c|c|c|c|c|c|c|c|c|c|c|c|}
\hline STAT ION & ELEV & LAT & LONG & JAN & FEB & MAR & APR & MAY & JUN & JUL & AUG & SEP & OCT & NOV & $\mathrm{DEC}$ \\
\hline Vancouver & $210^{\prime}$ & $45^{\circ} 41^{\prime}$ & $122^{\circ} 39^{\prime}$ & 37.4 & 41.7 & 43.9 & 48.7 & 52.3 & 59.7 & 63.1 & 64.1 & 58.4 & 50.8 & 41.5 & 37.7 \\
\hline Portland & 21 & 4536 & 12236 & 40.7 & 43.8 & 46.3 & 51.2 & 55.0 & 63.1 & 67.3 & 68.3 & 62.0 & 54.4 & 43.1 & 38.9 \\
\hline Oregon C1ty & 167 & 4521 & 12236 & 41.5 & 45.4 & 47.5 & 52.0 & 56.2 & 64.0 & 68.1 & 69.0 & 62.6 & 56.1 & 45.3 & 40.3 \\
\hline Battle Ground & 295 & 4547 & 12232 & 38.9 & 44.6 & 44.4 & 49.6 & 53.1 & 60.2 & 63.6 & 65.9 & 59.3 & 52.4 & 43.0 & 39.2 \\
\hline Troutdale & 29 & 4534 & 12224 & 40.0 & 45.1 & 47.1 & 52.3 & 56.1 & 63.9 & 67.4 & 68.2 & 58.9 & 57.2 & 44.7 & 40.9 \\
\hline Estacada 2 & 410 & 4516 & 12219 & 40.2 & 43.2 & 45.0 & 50.5 & 54.0 & 61.3 & 64.9 & 65.5 & 59.1 & 52.6 & 43.0 & 38.7 \\
\hline Skamanila F.H. & 440 & 4538 & 12213 & 37.4 & 40.9 & 42.2 & 47.1 & 50.8 & 58.2 & 61.5 & 62.9 & 56.7 & 51.1 & 41.8 & 37.7 \\
\hline Cougar & 659 & 464 & 12212 & 37.8 & 40.3 & 41.5 & 47.5 & 51.7 & 59.5 & 62.9 & 64.1 & 57.8 & 52.9 & 41.6 & 36.9 \\
\hline Headwarks & 748 & 4527 & 1229 & 40.6 & 43.8 & 44.6 & 49.8 & 53.3 & 60.8 & 64.4 & 65.3 & 59.9 & 55.1 & 44.3 & 40.2 \\
\hline Three Lynx & 1120 & 457 & 1224 & 37.7 & 41.0 & 42.3 & 47.9 & 51.3 & 59.3 & 63.2 & 64.9 & 58.4 & 52.7 & 41.1 & 37.2 \\
\hline Bonneville Dam & 60 & 4538 & 12157 & 37.6 & 42.3 & 45.4 & 50.7 & 54.9 & 62.7 & 67.0 & 67.7 & 61.6 & 55.6 & 44.3 & 40.2 \\
\hline Gov't Camp & 3980 & 4518 & 12145 & 32.0 & 33.6 & 33.3 & 38.1 & 41.3 & 51.2 . & 56.3 & 57.5 & 50.2 & 45.9 & 34.5 & 30.7 \\
\hline Parkdale & 1940 & 4530 & 12135 & 31.4 & 32.6 & 39.9 & 45.8 & 49.1 & 58.3 & 62.2 & 62.9 & 55.3 & 48.4 & 36.7 & 42.9 \\
\hline Appleton & 2336 & 4549 & 12116 & 30.0 & 34.1 & 38.0 & 44.7 & 48.8 & 57.8 & 62.5 & 64.1 & 55.8 & 47.1 & 34.9 & 31.0 \\
\hline The Dalles & 102 & 4536 & 12112 & 35.1 & 42.2 & 47.5 & 54.5 & 59.3 & 68.8 & 73.6 & 73.7 & 64.5 & 55.0 & 41.5 & 38.3 \\
\hline Dallesport & 222 & 4537 & 1219 & 34.5 & 40.9 & 45.5 & 53.6 & 59.3 & 69.3 & 74.1 & 74.4 & 65.5 & 55.4 & 40.8 & 36.2 \\
\hline Dufur & 1330 & 4527 & 1218 & 31.6 & 38.0 & 41.7 & 47.9 & 51.4 & 60.5 & 65.4 & 66.6 & 59.0 & 49.7 & 37.0 & 33.2 \\
\hline Goldendale & 1800 & 4549 & 12046 & 31.2 & 36.5 & 40.9 & 47.2 & 51.4 & 61.2 & 66.1 & 67.2 & 58.4 & 49.2 & 36.5 & 32.5 \\
\hline Moro & 1870 & 4529 & 12043 & 30.4 & 36.5 & 40.9 & 47.2 & 51.4 & 61.9 & 67.5 & 68.0 & 59.0 & 49.7 & 36.3 & 32.4 \\
\hline Kent & 2720 & 4512 & 12042 & 31.2 & .35 .2 & 39.8 & 45.3 & 49.6 & 60.2 & 66.2 & 66.9 & 57.7 & 49.8 & 36.2 & 31.2 \\
\hline Satus Pass & 2610 & 4557 & 12039 & 29.3 & 33.7 & 37.3 & 44.5 & 47.7 & 57.0 & $6: 1.3$ & 62.5 & 54.2 & 46.1 & 34.2 & 28.0 \\
\hline Mikkalo & 1550 & 4528 & 12021 & 32.0 & 39.1 & 43.5 & 49.7 & 54.4 & 65.4 & 70.8 & 70.5 & 61.4 & 52.8 & 37.9 & 34.7 \\
\hline Bickleton & 3000 & 460 & 12018 & 29.1 & 33.7 & 38.2 & 45.6 & 47.8 & 59.9 & 65.8 & 66.7 & 57.6 & 49.8 & 34.9 & 30.7 \\
\hline Arlington & 285 & 2543 & 12012 & 33.9 & 40.9 & 46.0 & 55.2 & 59.6 & 69.8 & 74.7 & 75.2 & 65.0 & 53.5 & 40.3 & 36.2 \\
\hline Condon & 2830 & 4514 & 12011 & 31.4 & 36.4 & 39.9 & 46.0 & 50.0 & 59.8 & 65.8 & 65.6 & 57.4 & 49.2 & 36.4 & 32.3 \\
\hline
\end{tabular}


and used to construct a detailed temperature field for use in the wind flow model. The monthly mean temperature data in degrees Fahrenheit for these stations, averaged for the years 1976 - 1979, are shown in Table 6. These temperature data were analyzed to yield seasonal mean temperature values, given in Table 7 , corresponding to the same periods as determined by the wind direction analysis discussed in Section 3.

We assumed a linear temperature decrease with increasing height, and that the temperature gradient was constant regardless of horizontal location. The seasonal vertical temperature gradient was evaluated by obtaining a best fit between the station seasonal mean temperature and the station elevation to obtain the seasonal lapse rate. The summer case for the GORGE grid is shown in figure 4. The vertical temperature gradient was then used to calculate the values of the temperature at MSL from the seasonal station temperature at the station elevation. A numerical approximation scheme was then applied to yield interpolated values of the temperature at MSL at each of the 6,435 computational grid points. The temperature on the terrain surface at each grid point was determined by adjusting the MSL value at each grid point according to the seasonal lapse rate. The MSL temperature distributions for the GORGE grid are shown in the contour plots in figure 5. During the summer, the temperature is generally higher in the eastern part than the western part of the Columbia Gorge, corresponding to the general westerly winds experienced by the entire Gorge region. A local maximum occurs within the Gorge during the summer centered at The Dalles. During the winter period, the temperature is warmer in the western part of the GORGE. The colder area in the eastern part of the GORGE is centered near Goldendale and extends south to the Columbia river.

\subsection{Pressure}

Barometric pressure data was obtained for the National Weather Service Stations bounding the Columbia Gorge region on the west and on the east. The pressure data was first reduced to MSL values using a form of the barometer equation and the seasonal vertical temperature gradients obtained from the temperature data analysis. The monthly average pressure at MSL, 
TABLE 7

SEASONAL MEAN TEMPERATURE DATA ( $\left.{ }^{\circ} \mathrm{F}\right)$

\begin{tabular}{|c|c|c|c|c|c|}
\hline \multirow[b]{2}{*}{ STATION } & \multicolumn{3}{|c|}{ MEAN STA. TEMP } & \multicolumn{2}{|c|}{ MSL TEMP } \\
\hline & ANNUAL AVG & SUMMER & WINTER & SUMMER & WINTER \\
\hline Vancouver & 50.0 & 55.7 & 41.9 & 56.2 & 42.4 \\
\hline Portland & 52.8 & 59.0 & 44.2 & 59.1 & 44.2 \\
\hline Oregon City & 54.0 & 59.9 & 45.7 & 60.3 & 46.2 \\
\hline Battle Ground & 5.1 .2 & 56.6 & 43.6 & 57.3 & 44.4 \\
\hline Troutdale & 53.5 & 59.1 & 45.6 & 59.2 & 45.6 \\
\hline Estacada 2 & 51.5 & 57.2 & 43.5 & 58.2 & 44.7 \\
\hline Skamania F.H. & 49.0 & .54 .2 & 41.8 & 55.2 & 43.0 \\
\hline Couger & 49.5 & 55.0 & 41.9 & 56.6 & 43.7 \\
\hline Headworks & 51.8. & 56.9 & 44.8 & 58.6 & 46.8 \\
\hline Three Lynx & 49.8 & 55.3 & 41.9 & 58.0 & 45.0 \\
\hline Bonnevtlle Dam & 52.5 & 58.6 & 44.0 & 58.7 & 44.2 \\
\hline Gov't Camp & 42.1 & 46.8 & 35.4 & 56.3 & 46.3 \\
\hline Parkdale & 47.1 & 53.3 & 38.4 & 57.9 & 43.8 \\
\hline Appleton & 45.7 & 53.1 & 35.4 & 58.6 & 41.8 \\
\hline The Dalles & 54.5 & 63.1 & 42.4 & 63.4 & 42.7 \\
\hline Dallesport & 54.1 & 63.1 & 41.5 & 63.7 & 42.2 \\
\hline Dufur & 48.5 & 56.1 & 37.9 & 59.2 & 41.6 \\
\hline Goldendale & 48.2 & 56.0 & 37.2 & 60.3 & 42.1 \\
\hline Moro & 48.4 & 56.6 & 37.1 & 61.0 & 42.2 \\
\hline Kent & 47.4 & 55.1 & 36.7 & 61.5 & 44.2 \\
\hline Satus Pass & 44.7 & 52.1 & 34.3 & 58.3 & 41.4 \\
\hline Mikkalo & 51.0 & 59.4 & 39.3 & 63.1 & 43.5 \\
\hline Bickleton & 46.6 & 54.4 & 35.6 & 61.6 & 43.9 \\
\hline Arlington & 54.2 & 63.6 & 41.0 & 64.3 & 41.7 \\
\hline Condon & 47.5 & .54 .9 & 37.1 & 61.6 & 44.9 \\
\hline
\end{tabular}




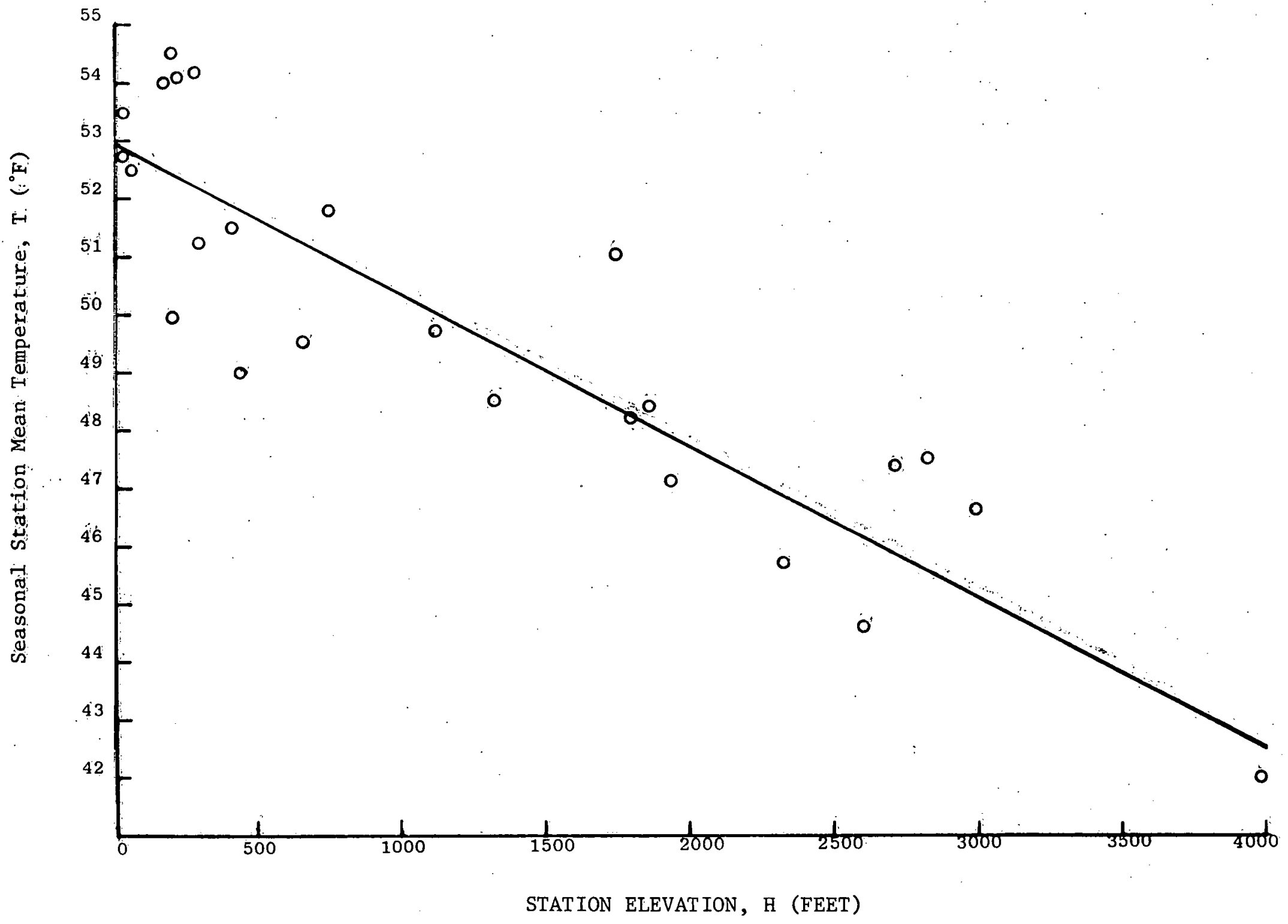

Figure 4 Summer Station Mean Temperature Variation with Elevation. Solid Line: $T=-0.0025 \mathrm{H}+52.9$ 


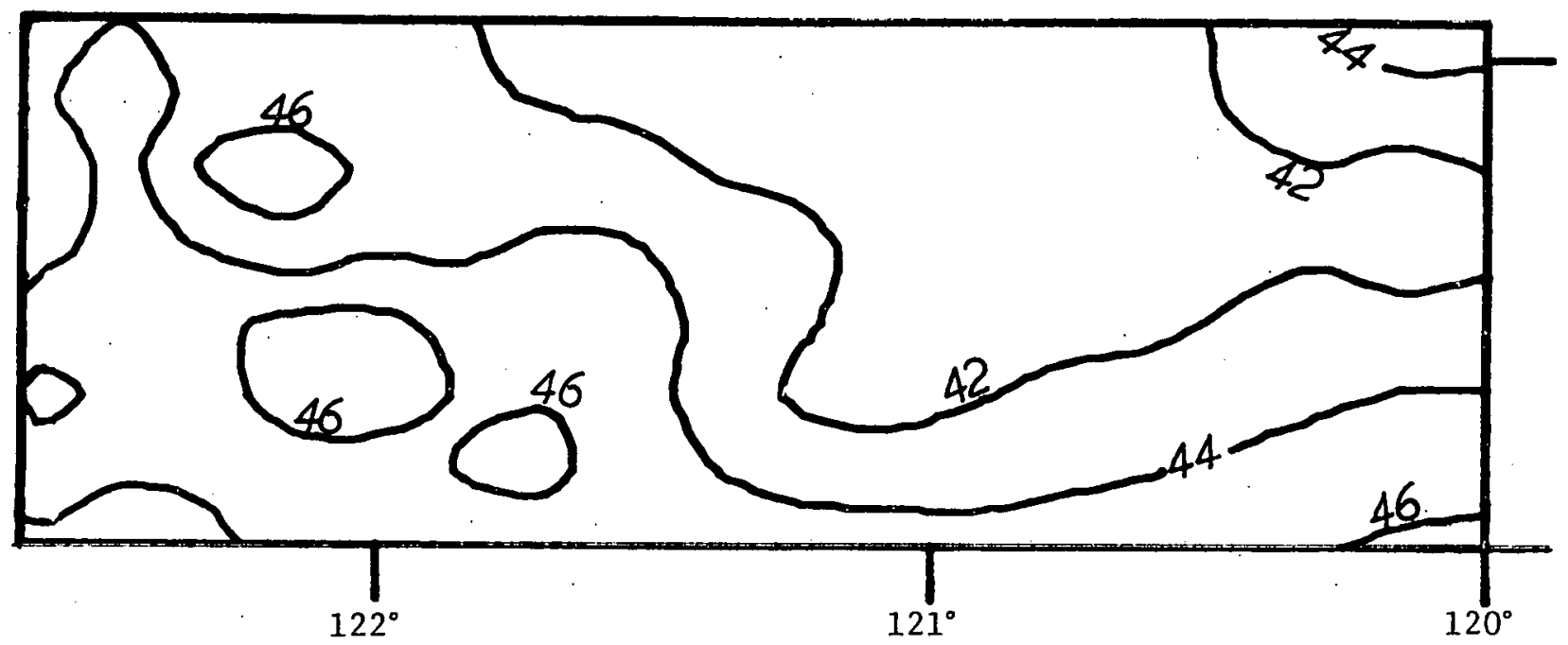

$46^{\circ}$

(a) Winter

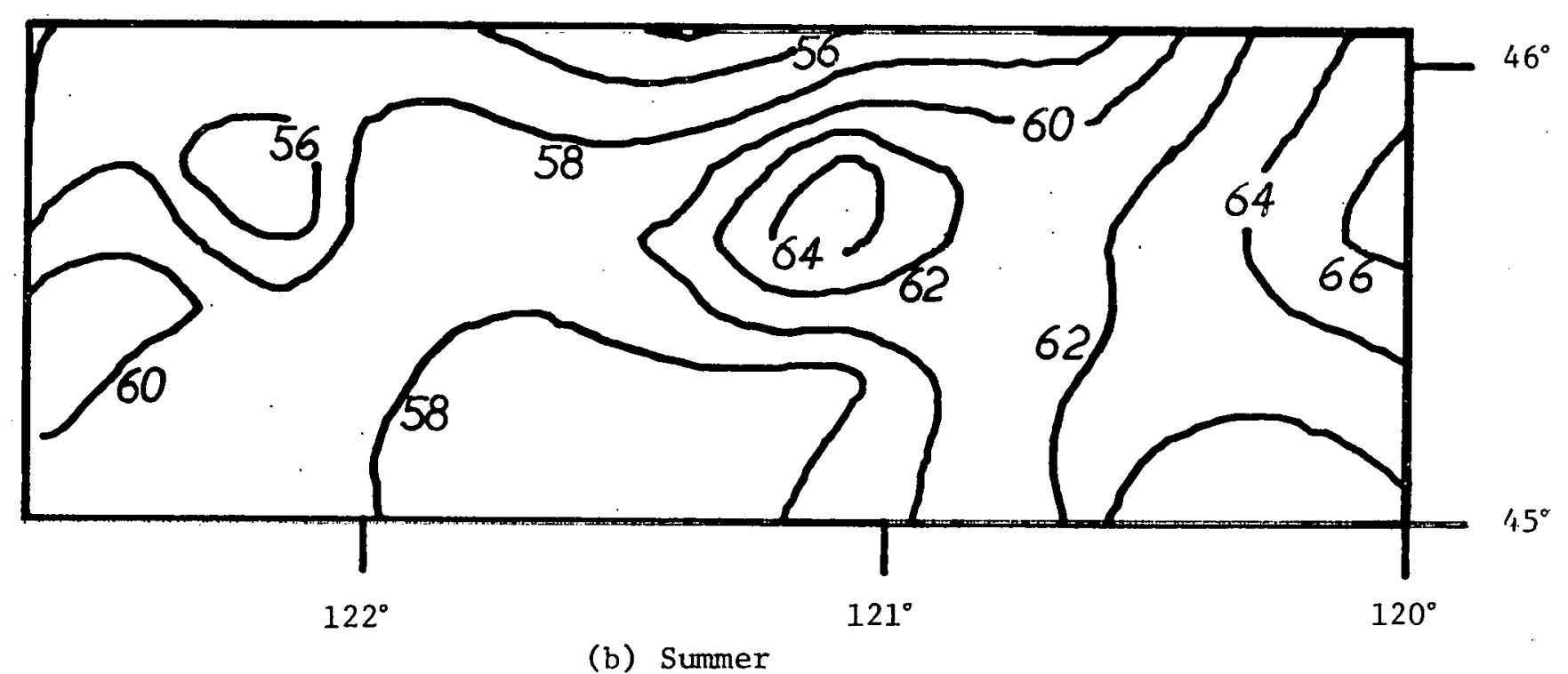

Figure 5 Mean Sea Level Temperature Distribution. Refer to Topographic Map in Figure 1 for Location of Major Features. 
TABLE 8

SUMMARY OF CALCULATED MONTHLY AVERAGE MSL PRESSURE DATA (mb)

\begin{tabular}{|c|c|c|c|c|c|c|c|c|c|c|c|c|c|c|c|}
\hline STATION & ELEV & LAT & LONG & JAN & FEB & MAR & APR & MAY & JUN & JUL & AUG & SEP. & OCT & Nov & DEC \\
\hline Portland & 22 & 4530 & 12236 & 1019.8 & 1017.5 & 1017.3 & 1017.2 & 1017.4 & 1017.6 & 1017.2 & 1015.5 & 1015.5 & 1019.2 & 1020.7 & 1019.8 \\
\hline Salem & 194 & 4457 & 1231 & 1019.9 & 1017.7 & 1017.8 & 1017.6 & 1017.9 & 1017.9 & 1017.2 & 1015.4 & 1015.5 & 1019.4 & 1020.4 & 1020.3 \\
\hline Olympla & 194 & 473 & 11724 & 1019.5 & 1016.4 & 1016.7 & 1017.2 & 1017.3 & 1017.8 & 1017.7 & 1015.8 & 1015.7 & 1019.5 & 1020.3 & 1018.8 \\
\hline Yakima & 1055 & 4635 & 10231 & 1023.8 & 1019.4 & 1016.1 & 1015.7 & 1014.4 & 1014.1 & 1013.4 & 1012.6 & 1014.2 & 1020.2 & 1023.0 & 1021.8 \\
\hline Pendleton & 1485 & 4540 & 11847 & 1023.5 & 1019.6 & 1016.8 & 1015.9 & 1015.3 & 1014.5 & 1013.4 & 1013.1 & 1014.4 & 1017.8 & 1020.5 & 1022.1 \\
\hline Spokane & 2357 & 4740 & $11724^{\circ}$ & 1021.6 & 1020.8 & 1015.6 & 1015.0 & 1013.6 & 1013.2 & 1012.6 & 1012.0 & 1013.9 & 1020.0 & 1022.7 & 1021.7 \\
\hline
\end{tabular}


TABLE 9

SEASONAL MSL PRESSURE DATA (mb)

\begin{tabular}{lccc} 
STATION & ANNUAL & SUMMER & WINTER \\
\hline Portland & 1017.9 & 1016.8 & 1019.4 \\
Salem & 1018.1 & 1017.1 & 1019.5 \\
Olympia & 1017.7 & 1016.9 & 1018.9 \\
Yakima & 1017.4 & 1014.4 & 1021.6 \\
Pendleton & 1017.2 & 1014.8 & 1020.7 \\
Spokane & 1016.9 & 1013.7 & 1021.2
\end{tabular}


averaged for the years 1976 through 1978 are given in Table 8. The seasonal average MSL pressure data for these six stations is given in Table 9. The average barometric pressure is higher during the winter reflecting the increase in air density because of lower winter temperatures. During the summer the western end of the Columbia Gorge experiences a higher pressure than the eastern end, and during the winter the eastern end experiences a higher pressure. In general, the pressure vartation exhibited by the seasonal mean values are weak pressure gradients. A simple plane surface model fitted to the six available data values was used to extrapolate the MSL pressure data to each grid point:.

\subsection{Background Wind Speed: and Direction}

The numerical model requires an input value of a background wind speed and direction with which to begin. the calculations. For computations over a large area, the background wind corresponds to the geostrophic wind. The numerical estimates of the wind field begins with a.large scale grid"covering a large area, which will generally include a number of actual wind observations. A beginning value of the background: wind may then be obtained as an average of the observed speeds and directions adjusted to the appropriate height at which estimates of. wind speed and direction are desired. 


\section{Numerical Estimates of Winds}

The hydrodynamic model is part of a numerical technique that includes preparation of the required inputs for estimating the seasonal mean wind field and analyzing the resulting numerical estimates. The numerical technique is shown schematically in the flow chart in figure 6. The process consists of five separate computer programs in addition to the hydrodynamical model. The programs GRIDPTS and GRADTP are used to provide the input values of the terrain elevations, the surface temperatures, and the surface pressure at each point of a grid over which the wind speed and wind direction are calculated. The program WINDSET establishes the invariant parameter input file for each computation grid. Once this input file is established, the program WINDS, which includes the hydrodynamic model, may be executed with a set of variable input parameters to simulate the wind field corresponding to different background conditions.

The results produced by WINDS is an estimate of the north-south wind vector, and the east-west vector components. The magnitude and direction of the resultant wind vector is printed in a tabulated format for each grid point to produce a permanent hard copy of the estimated wind field. These results are also saved internally for further analysis and computer driven plotting for visual displays of the estimate analysis and estimated wind field. The analysis consists of producing comparison plots and tables of the estimated wind field and the observed wind data within the program PREP. The plotting package includes terrain elevation contour plotting, wind vector plotting, and wind speed contour plotting. The Surface Approximation and Contour Mapping (SACM, 1979) plotting package by Applications Consultants, Inc. were supplied as systems programs through United Computing Systems, Inc..

\subsection{Background Wind Speed and Direction}

The computer program sequence shown in figure 6 was developed and tailored specifically for wind prospecting applications to produce realistic estimates of the wind field. To produce quantitatively realistic estimates of the wind field requires a calibration (validation) of the 


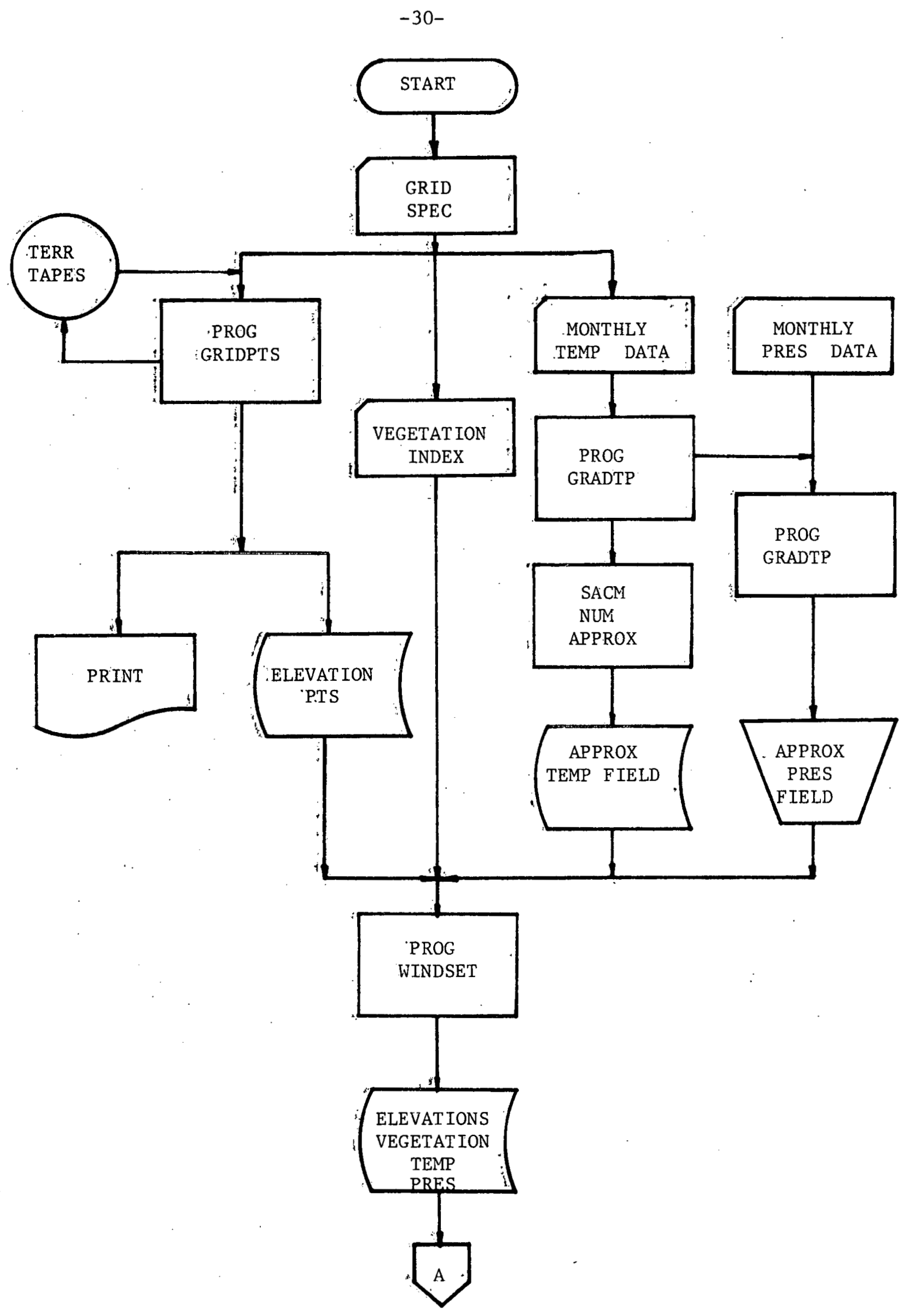

Figure 6. Flow Chart for numerically estimating wind fields. 


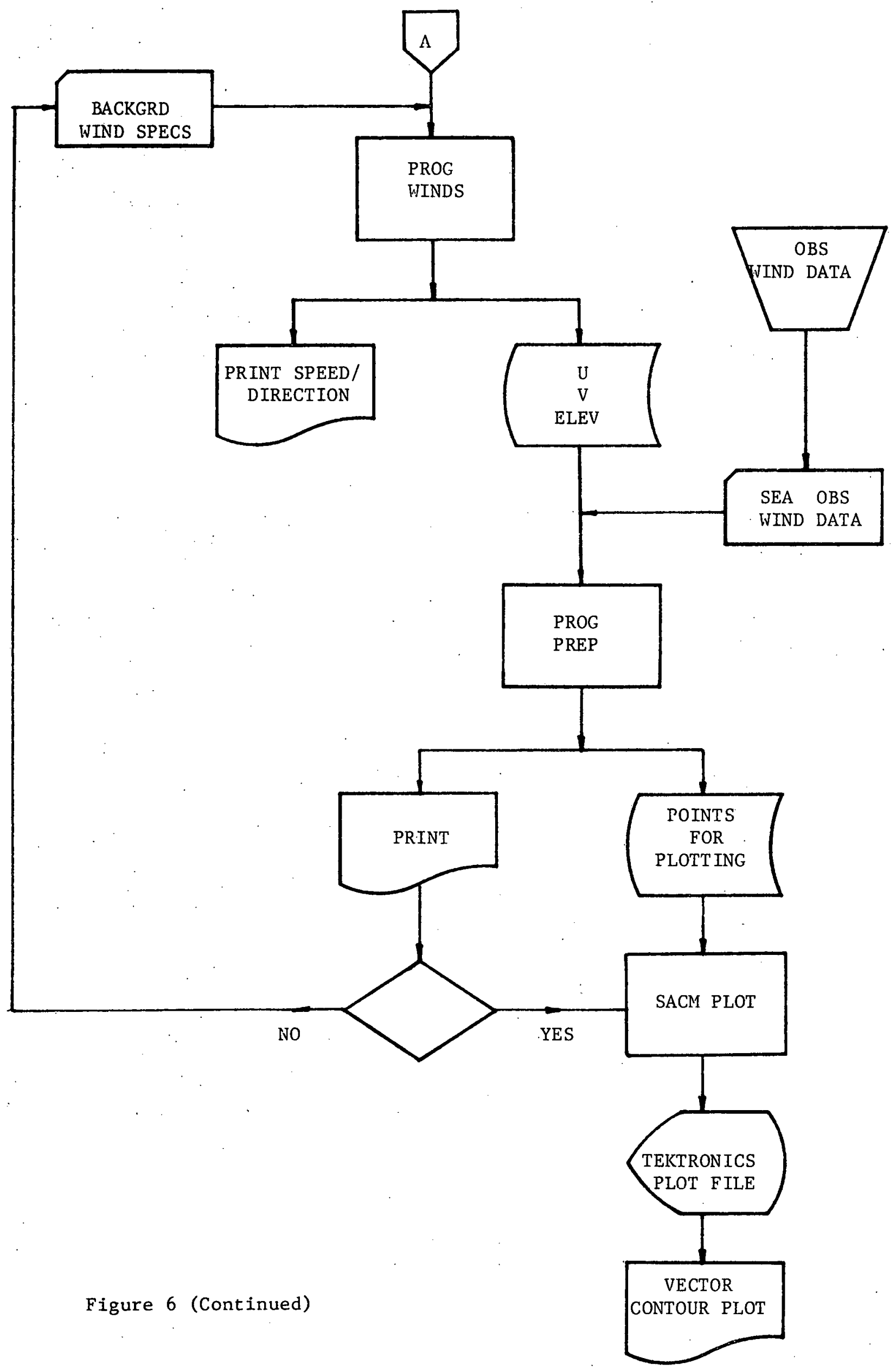


numerical results with actual wind data to define the background wind speed and background wind direction for the largest computation grid. The largest area grid computation will normally include the location of a sufficient number of existing anemometer stations to define the background wind field. Wind speed and direction data from one anemometer station is the theoretical minimum requirement to determine the appropriate background speed and direction; however, to establish a quantitative confidence interval requires a minimum of at least three data stations. Once the results of the large scale grid are considered realistic, the results may be used to determine the background wind field conditions for any smaller scale grid area within the larger grid. Wind field estimates may then be numerically calculated for smaller scale grids within the bounds of a larger grid, even if there is no existing wind data within the area of the smaller scale grid. For the present program the computation grids were selected in advance to include existing wind data for validating the cascading process of transferring the background wind specifications from the large grid to the smaller grids, and to allow a quantitative measure of the difference between numerical estimates and observed wind data at different grid resolutions.

\subsection{Wind Fields}

The numerically calculated wind fields corresponding to 200 feet above ground level, hub height of the Boeing MOD-2, for each of the five grids listed in Table 1 are shown in figures 7 through 12 . Only every third vector in each direction is shown, except.in figure 12 where every second vector is shown to improve the clarity of the figures. The vectors are plotted with the end of the tail positioned to correspond to the location in the grid. Approximate contours of the underlying terrain are also shown to provide an approximate location reference.

For the summer case for the GORGE grid in figure 7, the calculated speed ranged from 57 miles per hour at Mt. Adams to 3.5 miles per hour near Portland. Terrain elevations at the grid point locations ranged from 68 feet in the Portland area to 11,658 feet on Mt. Adams. The low level areas 


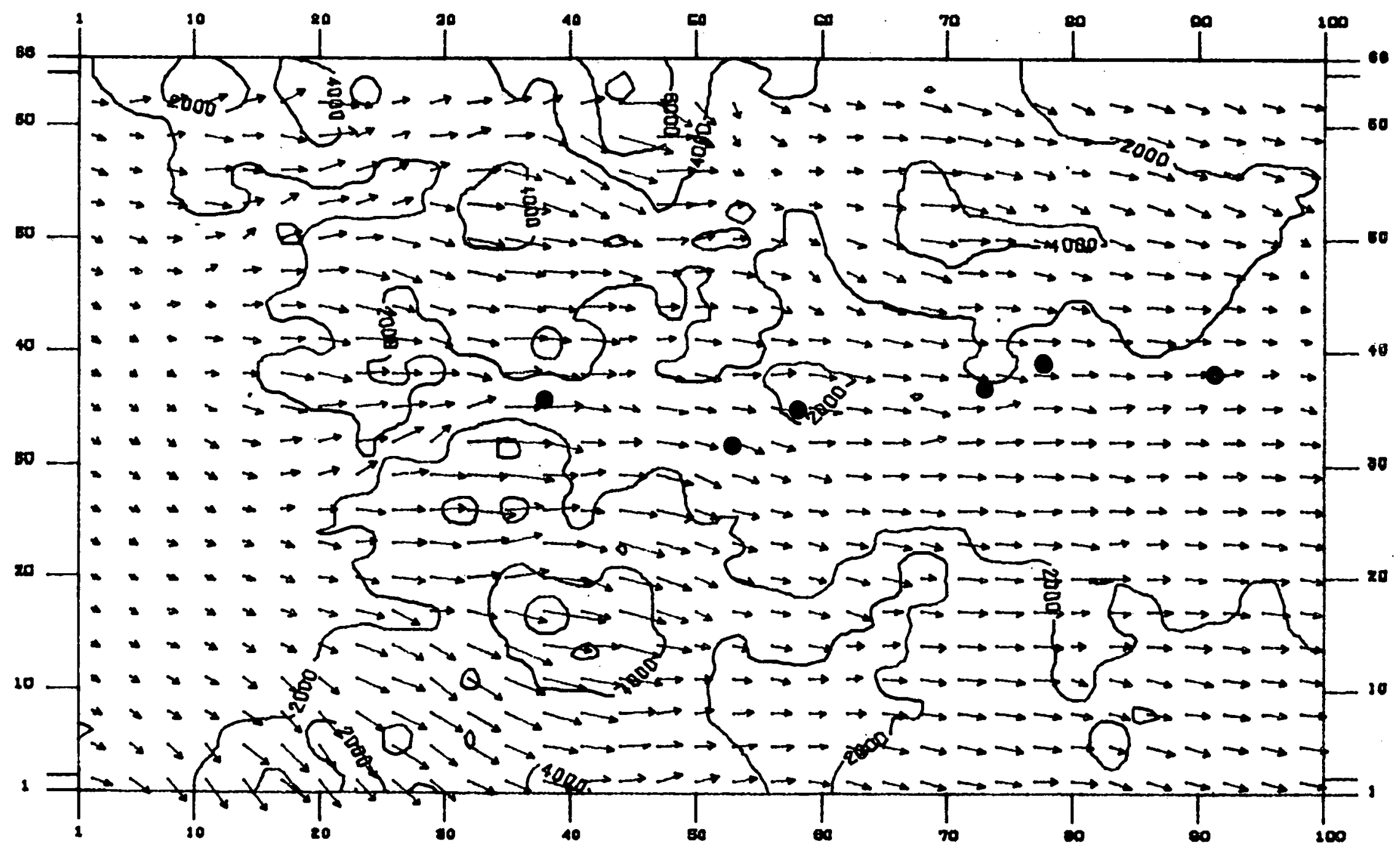

Figure 7 Velocity Vector-plot for Grid 1, GORGE, Summer; $U_{B}=17.9 \mathrm{mph}, \theta_{0}=280$. degrees. Only every third vector shown. Contour interval $=2000$ feet. $\odot$ Location of six BPA data stations with hourly averaged wind data. 


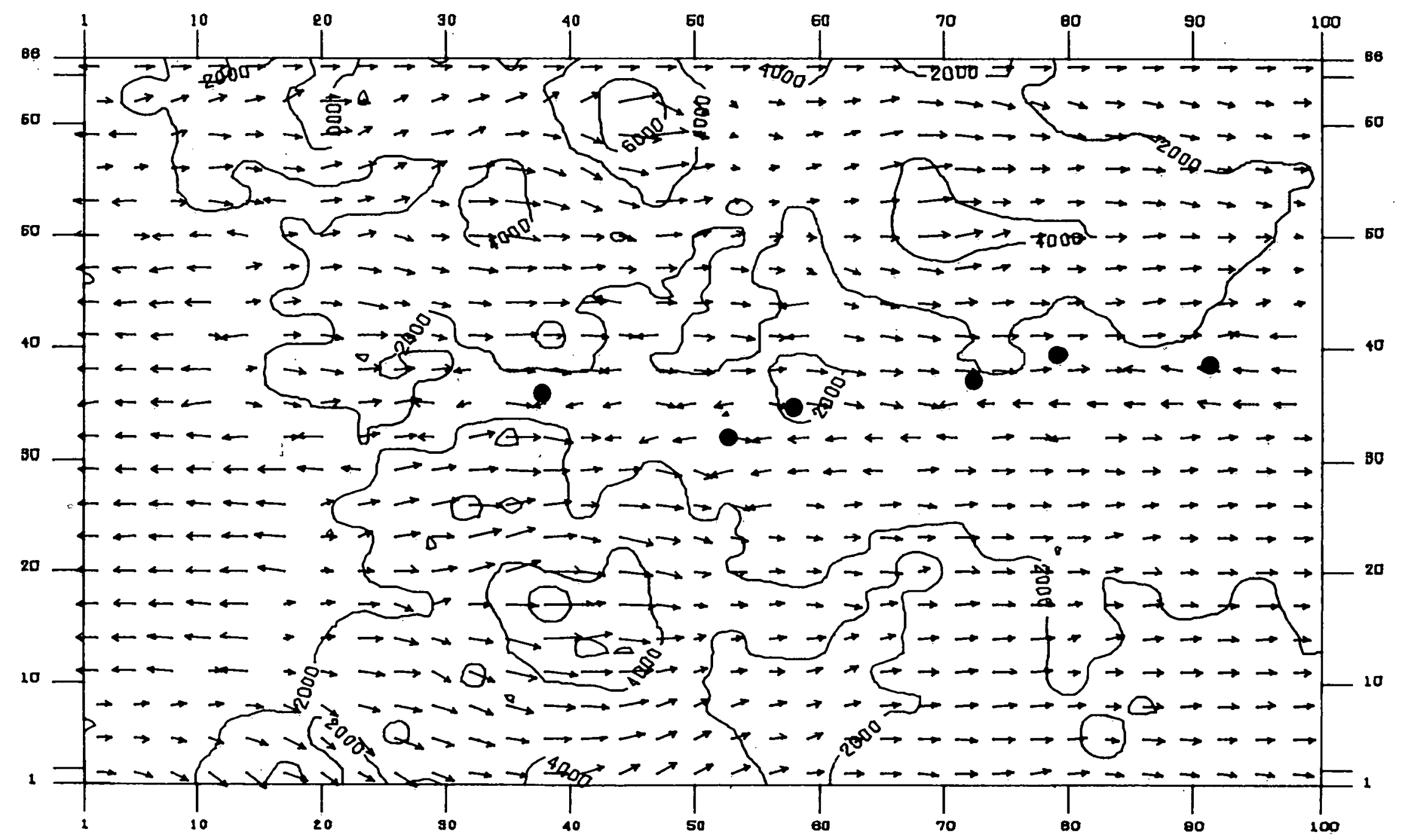

Figure 8 Velocity Vector-plot for Grid 1, GORGE, Winter; $\mathrm{L}_{B}=14.5 \mathrm{mph}, \theta_{0}=270$ degrees and $\Theta_{<1000}=90$ degrees. Only every third vector shown. Contour interval $=2000$ feet. - Location of six BPA data stations with hourly averaged wind data.

NOTE: The westerly flow direction above 1000 foct elevations and the easterly flow below 1000 foot elevations along the Columbia River.area results in 180 degree changes in direction between adjacent vectors shown. 
west of the Cascades generally exhibit lower wind speeds than the plains area east of the Cascades. The wind speeds increase dramatically over the Cascade Mountalns due to orographic lifting. Flow directions are modified from the background flow direction by the local terrain most significantly in the areas of Mt. Hood, the western end of the Columbia Gorge, south of Mt. St. Helens, and east of Mt. Adams. The channeling effect of the Columbia Gorge is most evident near Cascade Locks and remains evident near The Dalles.

The winter case for the GORGE grid is more complicated than the summer case because of the low-level cold air drainage through the Columbia Gorge from east of the Cascades to the western side of the Cascades. Although the numerical model was developed for flow regimes that are characterized by a single background wind speed and direction, we did attempt an approximation of the low-level flow through the Columbia Gorge by reversing the background wind direction 180 degrees at elevations below 1000 feet over specified areas of the terrain. The resulting wind field produced is shown in figure 8 and exhibits an easterly flow along the Columbia Gorge at elevations below 1000 feet which decreases in speed from east-to-west until the western end, where an increased speed occurs. The wind speeds for this simulation ranged from 3.3 miles per hour to 46 miles per hour. A 180 degree change in flow direction between adjacent vectors occurs along the boundary of the area with elevations below 1000 feet. Since only every third vector is shown, the horizontal distance between grid locations where the flow direction changes 180 degrees is approximately four miles.

The summer case for the DALLES grid is shown in figure 9. The calculated speeds ranged from 8.4 miles per hour just northwest of The Dalles to 30.8 miles per hour in the foothills of Mt. Hood along the western boundary near the southwest corner of the grid. The elevations ranged from 100 feet to a maximum of 5,773 feet. Because of the increased resolution with the smaller grid spacing, the channeling effect on the flow field along the Columbia River is more evident near The Dalles than it was in the GORGE grid. 


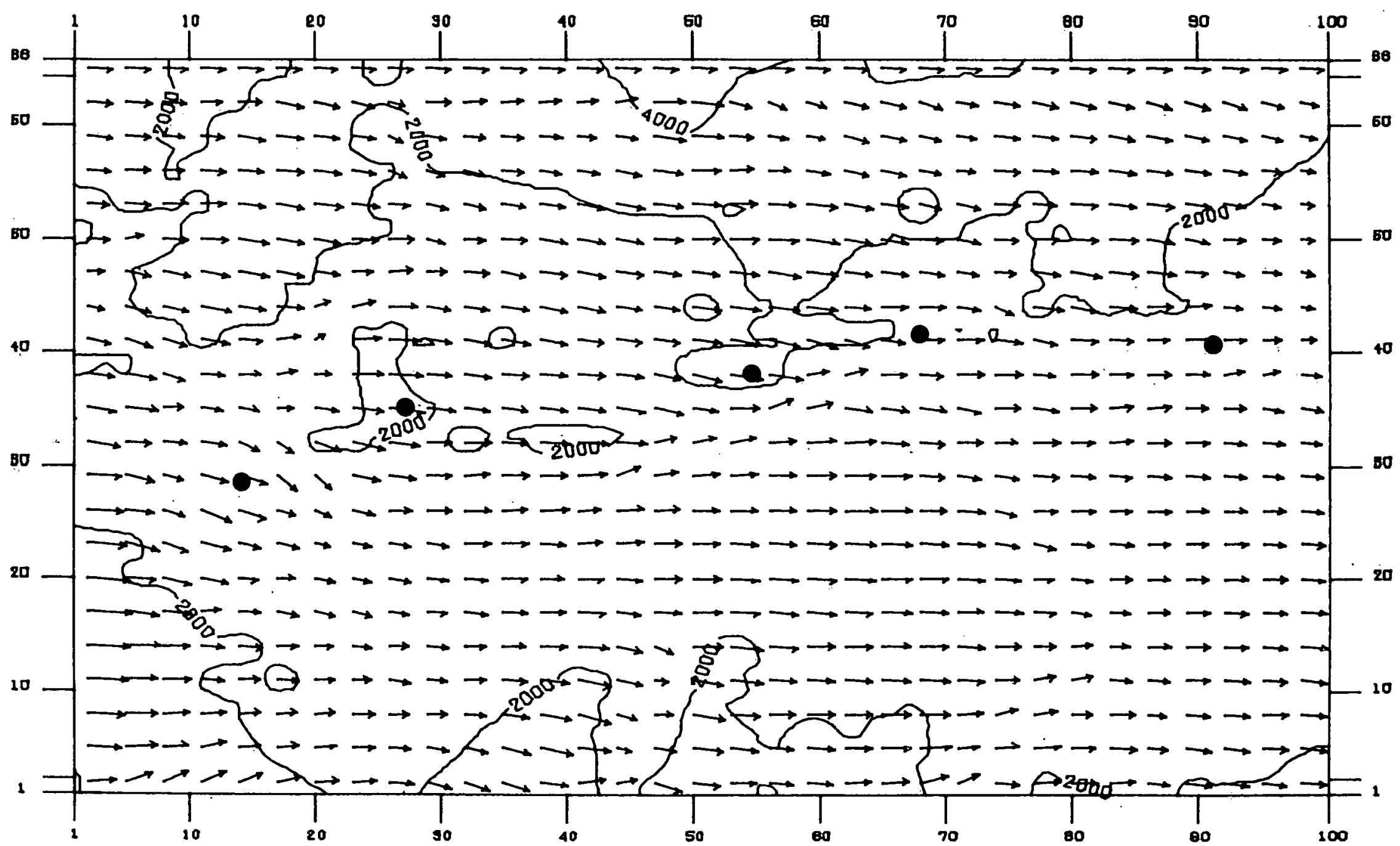

Figure 9 Velocity Vector-plot for Grid 2, DALLES, Summer; $U_{B}=18.6 \mathrm{mph}, \theta_{0}=270$ degree. Only every third vector shown. - Contour interval $=.2000 \mathrm{feet}$. Location .of BPA data stations with hourly averaged data. 


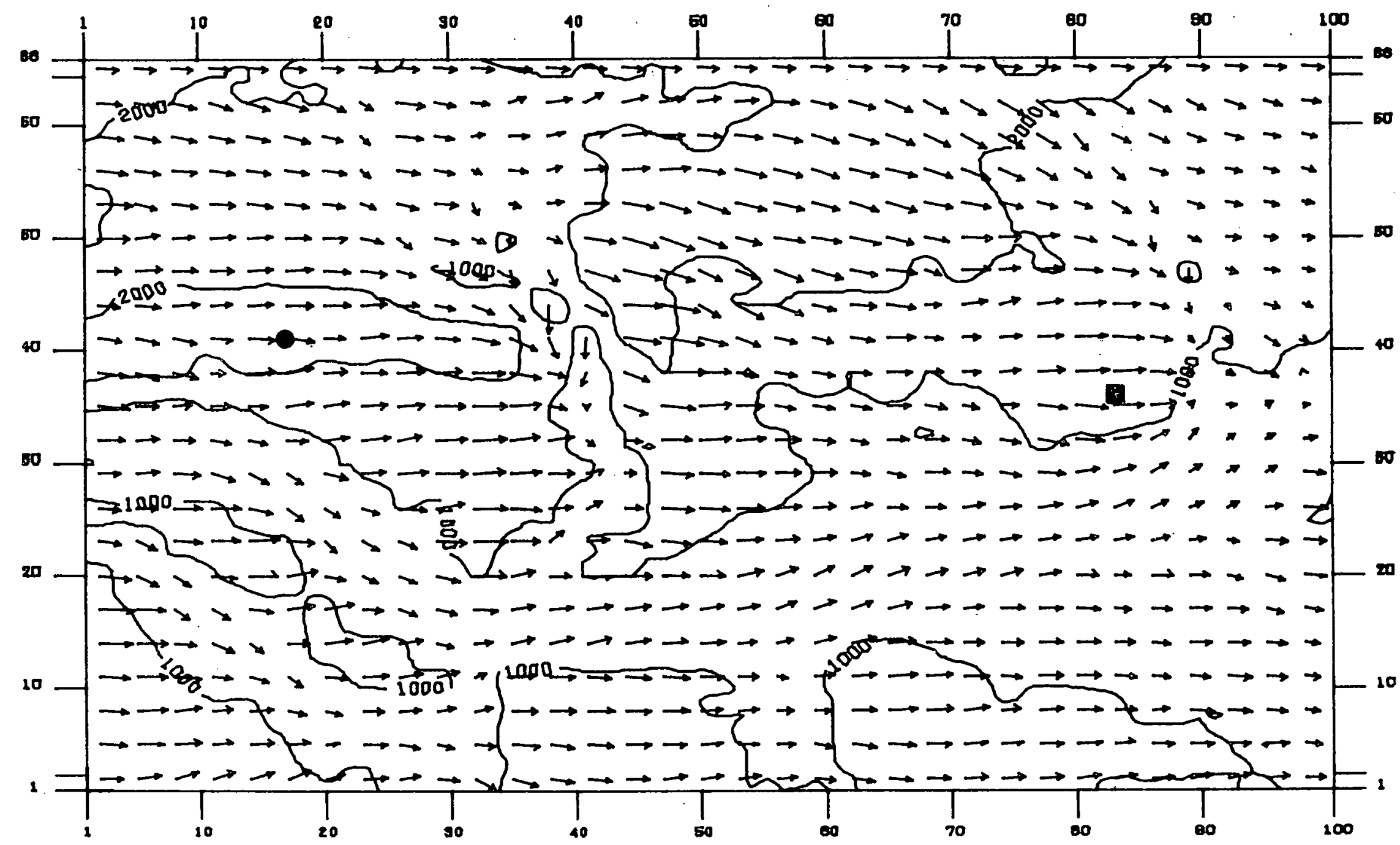

Figure 10 Velocity Vector-plot for grid 3, ROOSEVELT, Summer: $U_{B}=18.3 \mathrm{mph}, \theta_{0}=270$ degrees. Only every third vector shown. Contour interval $=1000 \mathrm{feet}$.

- Roosevelt data station. Goodnoe Hills data station. 


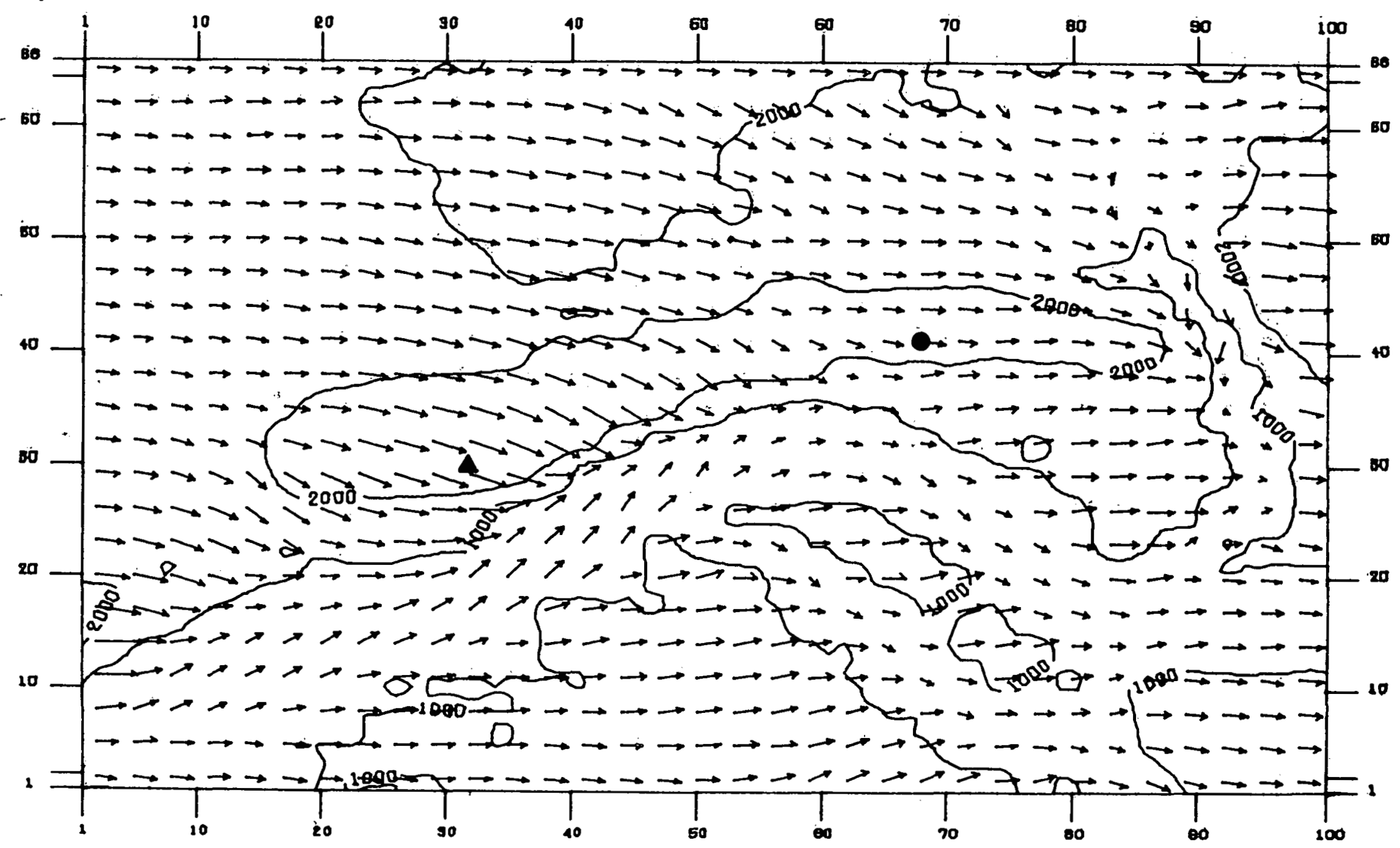

Firgure 11 Velocity Vector-plot for Grid 4, JUNIPER, Summer; $U_{B}=19.7 \mathrm{mph}, \theta_{0}=270$ degrees. Only every third vector shown. Countour interval $=1000 \mathrm{feet}$. $\Delta$ Juniper Point data station. Goodnoe Hill data station. 


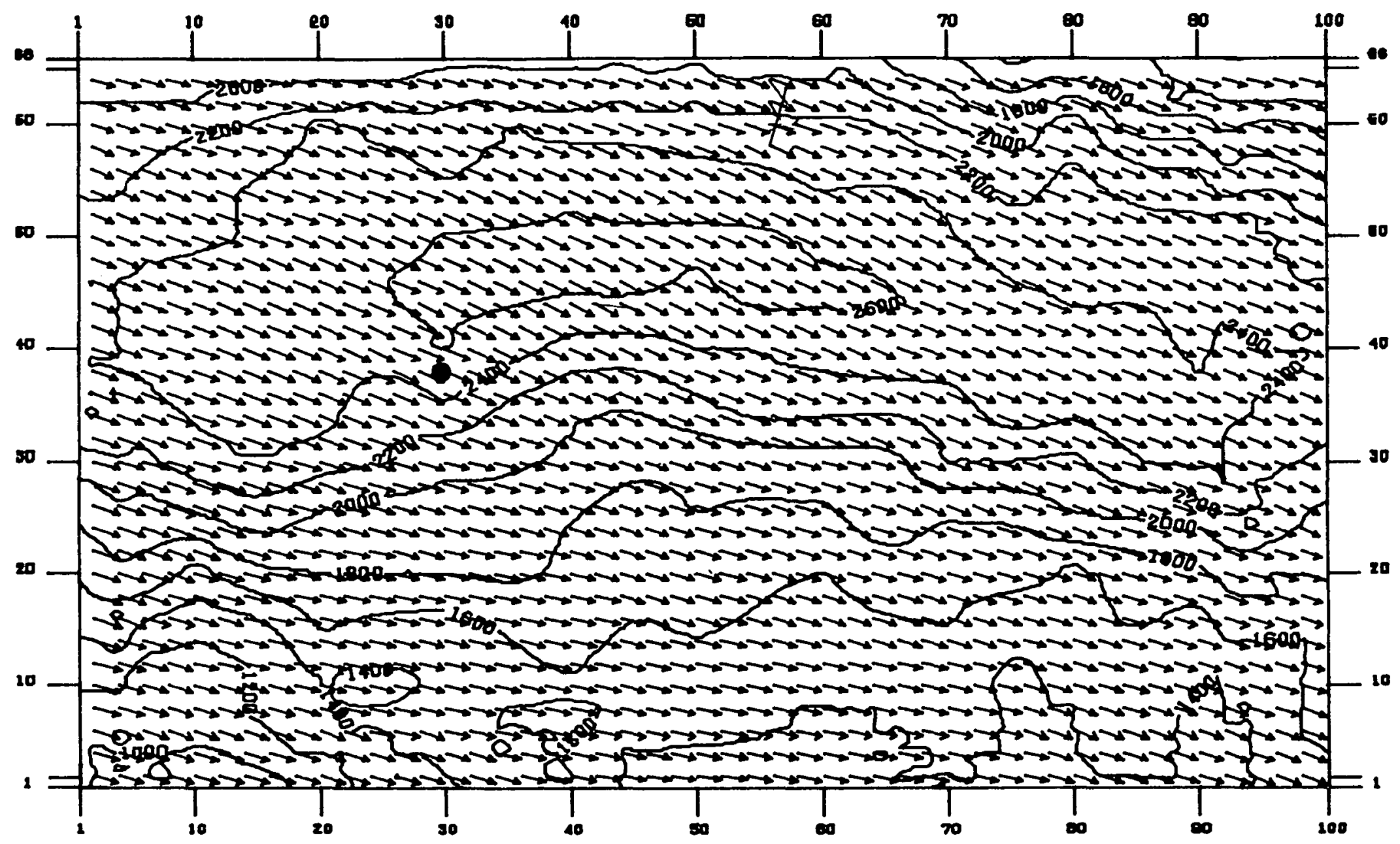

Figure 12 Velocity Vector-plot for Grid 5, GOODNOE, Summer; $U_{B}=19.7 \mathrm{mph}$, $\theta_{0}=280$ degrees. Only every second vector shown. Contour interval $=200$ feet. Goodnoe Hills data station. 
Increased detail and accuracy of the estimated wind field, because of better resolution, is the primary purpose for performing calculations with smaller grid spacings. The effect of better resolution is more evident in the wind fields for the ROOSEVELT and JUNIPER grid calculations shown in figures 10 and 11 where the terrain induced modifications of the background flow are most evident. The speeds ranged from 10.5 to 25.4 miles per hour for the ROOSEVELT grid and from 11.3 to 30.5 for the JUNIPER grid. Elevations ranged from 200 to 2,645 feet for the ROOSEVELT grid and from 200 to 3,000 feet for the JUNIPER grid.

The wind field for the GOODNOE grid is shown in figure 12 and exhibits a fairly uniform wind direction and speed over the entire area of the grid. For the case shown the speeds ranged from 17.4 miles per hour to 22 miles per hour and the terrain elevations ranged from 920 to 2,680 feet. The high speed, uniform flow depicted in figure 12 where the terrain elevations rapidly decrease as the boundary of the grid nearest the Columbia River is approached (lower third of the vector field) may not be simulated accurately because the hydrodynamic model is limited in its application to those areas where flow intermittency and separation does not occur. On the down-wind side of a sharp ridge line where the terrain is very steep is an area where flow separation would be expected to occur. This inability of the numerical model to accurately simulate the flow field where flow separation could be expected is not regarded as a serious limitation for the wind prospecting application, since the terrain in areas where separation could be expected is generally inhospitable to the placement of wind turbines.

\subsection{Areal Mean Wind Speed Distribution}

To define more precisely the distribution of seasonal mean wind speeds, contour lines representing a constant vector magnitude may be constructed for the data shown in the vector plots. Since the stated purpose of the application is prospecting for land areas where high mean wind speeds occur, it is most appropriate to superimpose these contours over topographical maps. The constant mean wind speed contour line (isotach) corresponding to 20 miles per hour at 200 feet above ground level was plotted on mylar transparencies and overlaid on topographic maps for each of the five computation grid areas. 
Twenty milcs per hour at 200 feet above ground level was selected as the most significant isotach to illustrate the utility of the numerical estimates of mean wind speed for wind power prospecting because these are the desired conditions for the MOD-2 wind turbine. Contour lines for other mean speeds may also be constructed to determine the most promising locations within the high speed areas. Areas located inside the 20 miles per hour isotach may be regarded as areas deserving further investigation as potential wind power areas.

The 20 miles per hour isotach areas for the GORGE grid is shown on the topographic map if figure 13, and the DALLES grid in figure 14. The " $\mathrm{H}$ " in figures 13 and 14 inducates a high speed area bounded by the 20 miles per hour isotachs. For both the GORGE and DALLES grid isotachs shown, the solid lines are for the summer season and the broken lines are for the winter season. The background wind parameter values correspond to those given previously for the GORGE grid and the summer condition for the DALLES grid. The winter background wind speed and direction for the DALLES grid was 14.5 miles per hour from the east.

Areas that are within the 20 miles per hour isotach for both the summer season and the winter season are considered high speed areas through the year. Areas shown that satisfy this condition occur in the Oregon and Washington Cascades and along the ridge in the eastern half of the GORGE grid near latitude 46 degrees north and longitude 120 degrees 50 minutes west directly north of Goldendale, Washington. The area north of Goldendale although reduced in size, is also indicated as a year-round highspeed area in the DALLES grid. Since this was the only area in the eastern part of the Columbia Gorge that exhibited high speeds during the winter season, wind speed estimates for the smaller scale grids was restricted to the summer case only.

The high speed areas shown for the GORGE grid may be seen to continuously cross over regions of the Columbia Gorge where it is not reasonable to expect high wind speeds to occur and reflects the effect of using a coarse grid spacing. Such a situation occurs along the Columbia Gorge in the Cascades, northwest of The Dalles and directly north of Wasco. In. 
$-42-$

THIS PAGE

WAS INTENTIONALLY

LEFT BLANK 


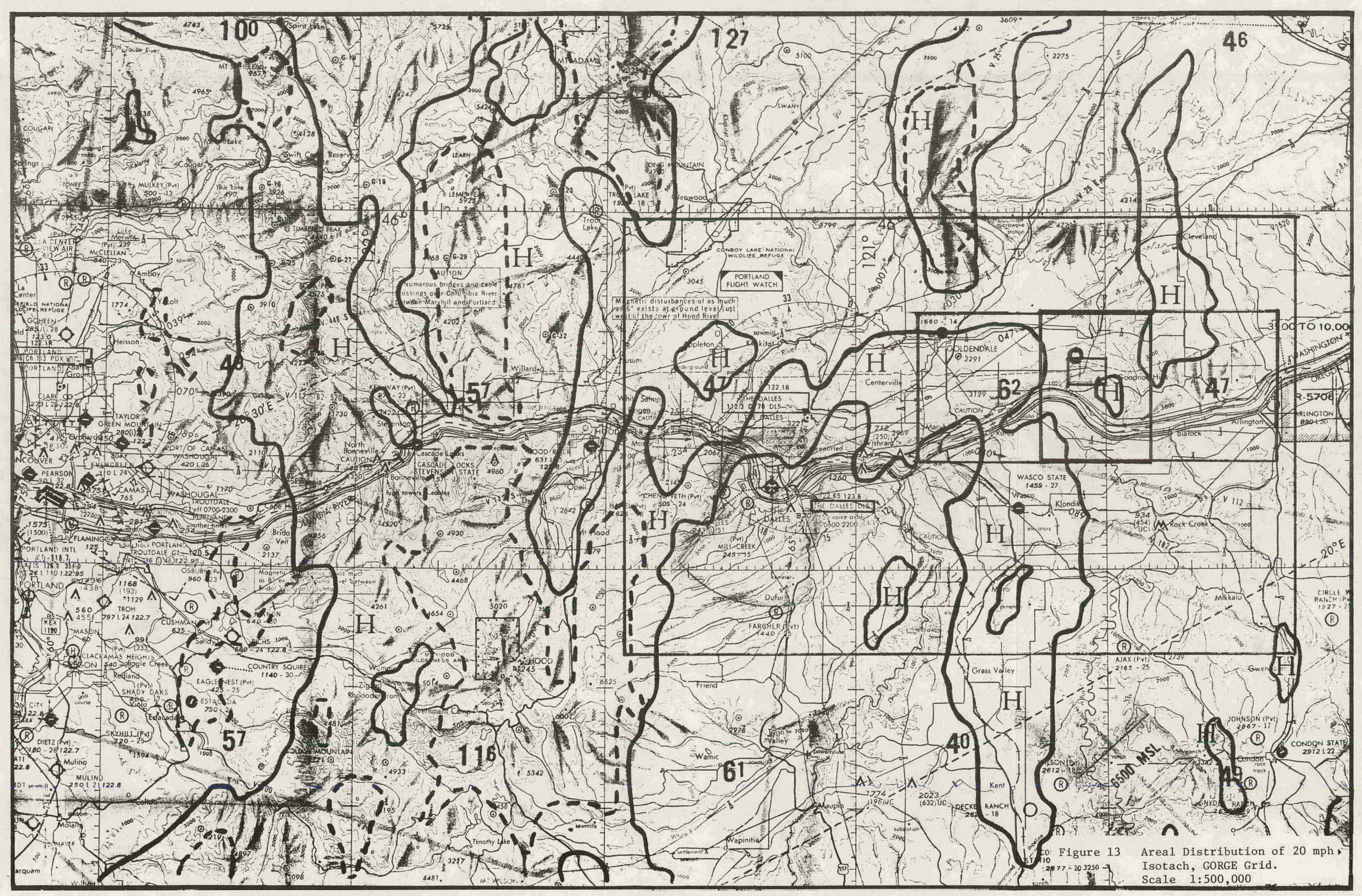




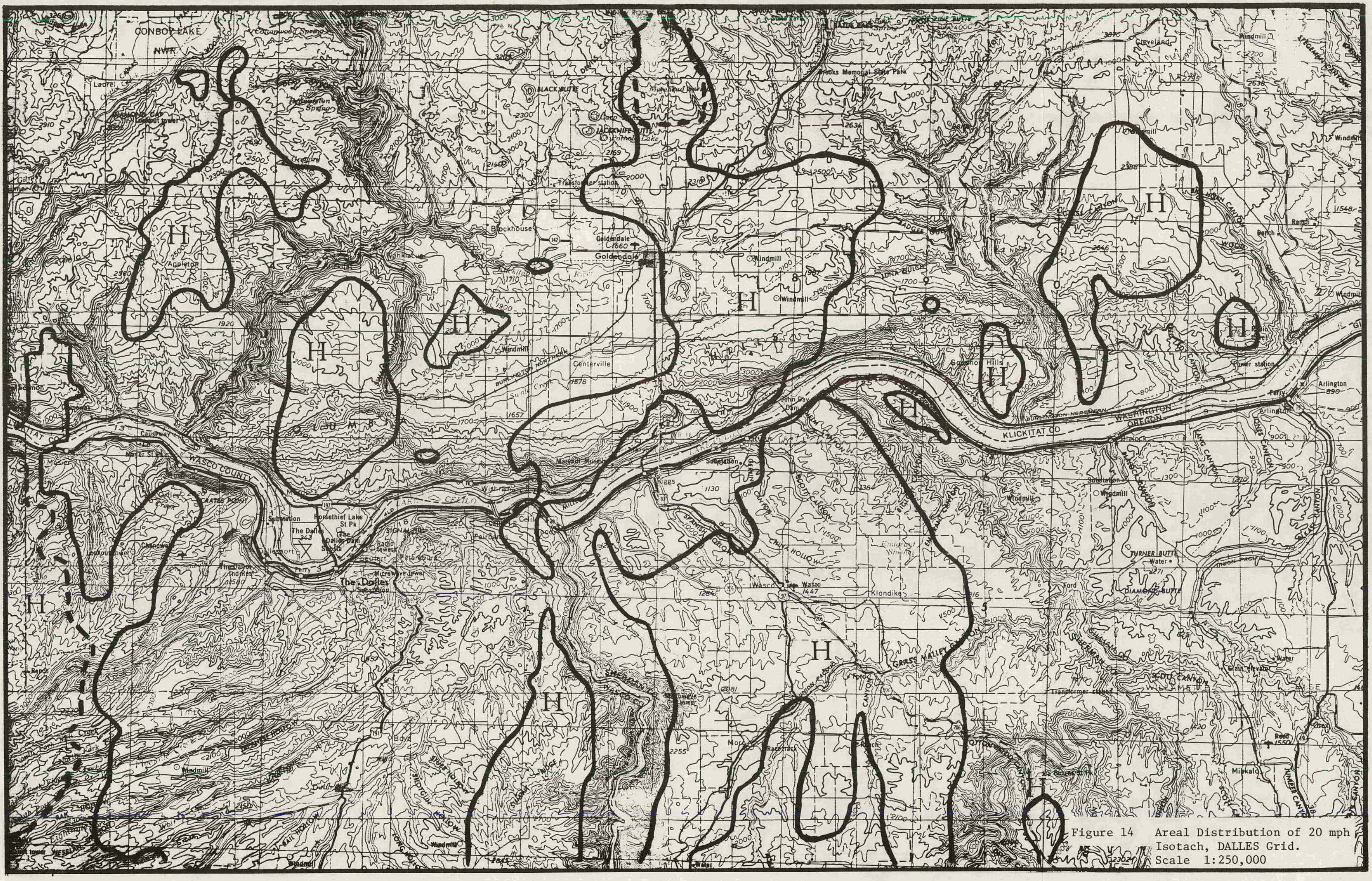




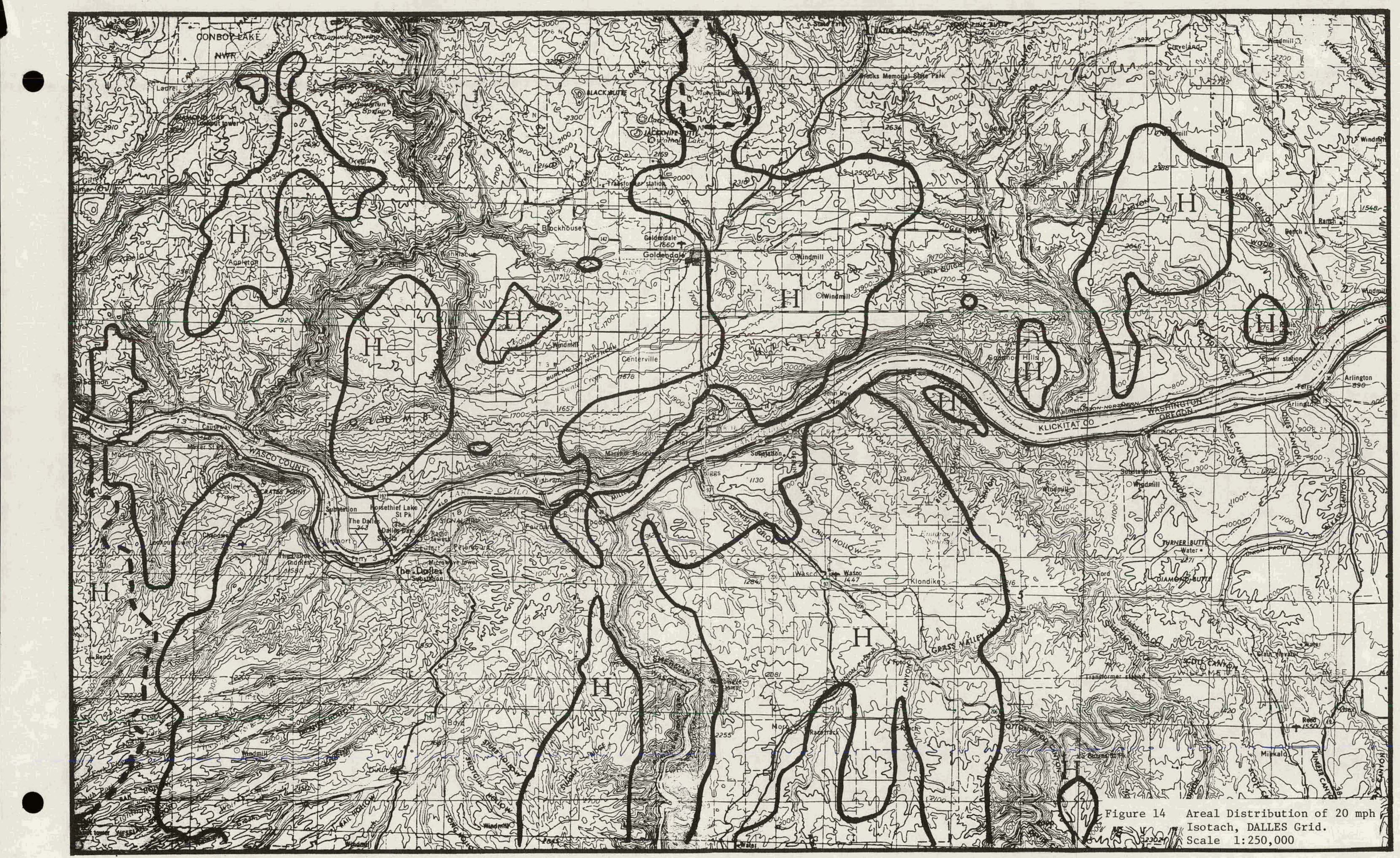


the DALLES grid, the increased resolution because of the smaller grid spacing, yields a better definition of the high speed zone north of Wasco along the Columbia River. This same area of the Columbia River also occurs in the JUNIPER grid shown in figure 15(b) where the grid spacing was reduced even further. Similar definition improvement may be seen for the ROOSEVELT grid in figure 15 (a) and the GOODNOE grid in figure 16 (b).

For several of the grid areas multiple computer runs were made where the background direction was changed to qualitatively examine the sensitivity of the areal speed distribution to the background flow direction. The areal speed distribution for a background wind direction of 270 degrees and 280 degrees is shown in figure $15(\mathrm{~b})$ for the JUNIPER grid and in figure 16 for the GOODNOE grid. In general, the identity of the large high speed zones are maintained and those areas that exhibit speeds of 20 miles per hour, or only slightly higher, were modified slightly in shape and size. Some small areas that marginally exhibit wind speeds above, or below 20 miles per hour either disappear, appear, or shift slightly in location. The same condition occurs for the GOODNOE grid. Those areas that consistently appear within the high speed zones are of primary interest for wind power. 
$-44 a$.

Blank Page 


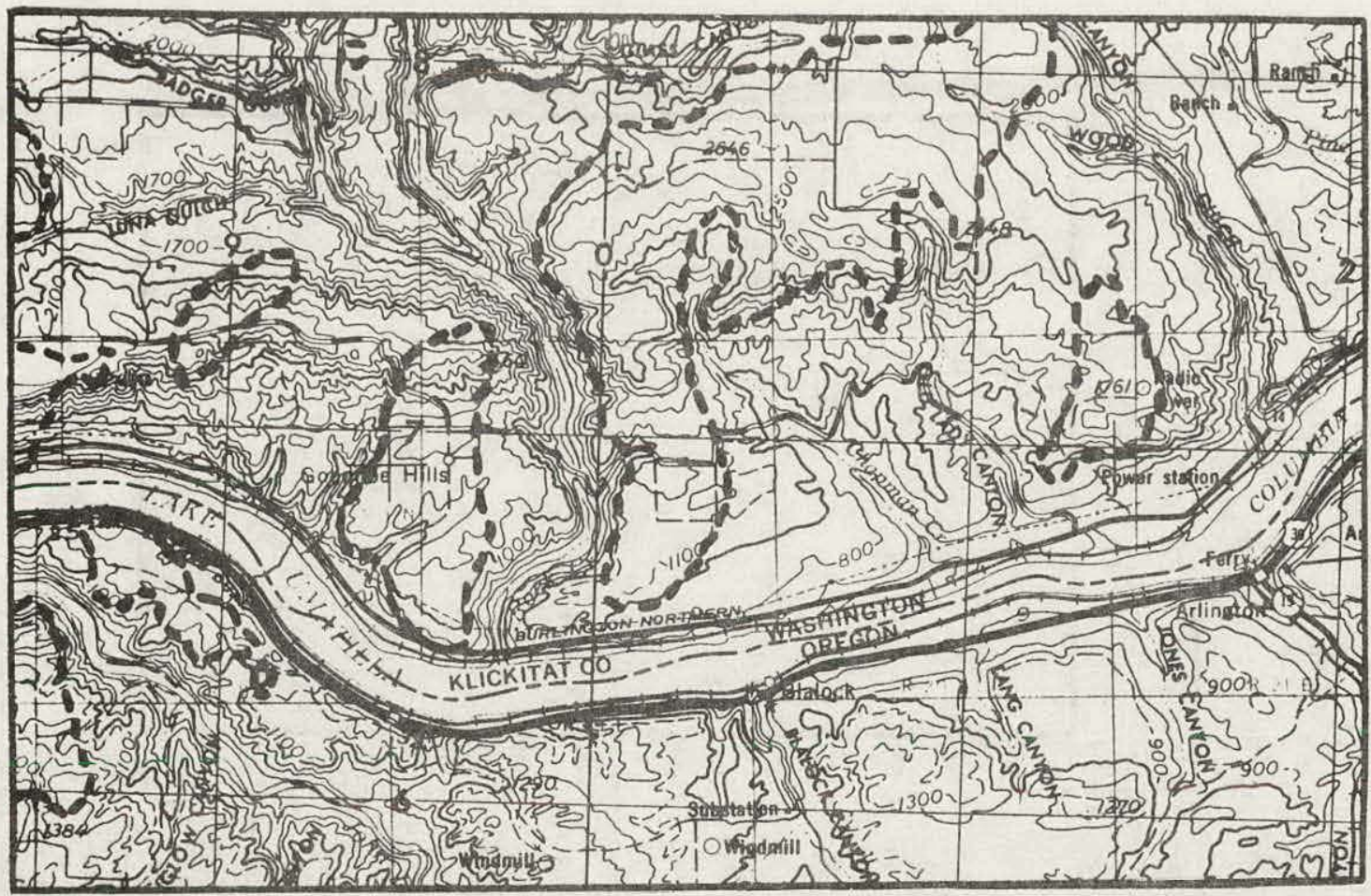

(a)

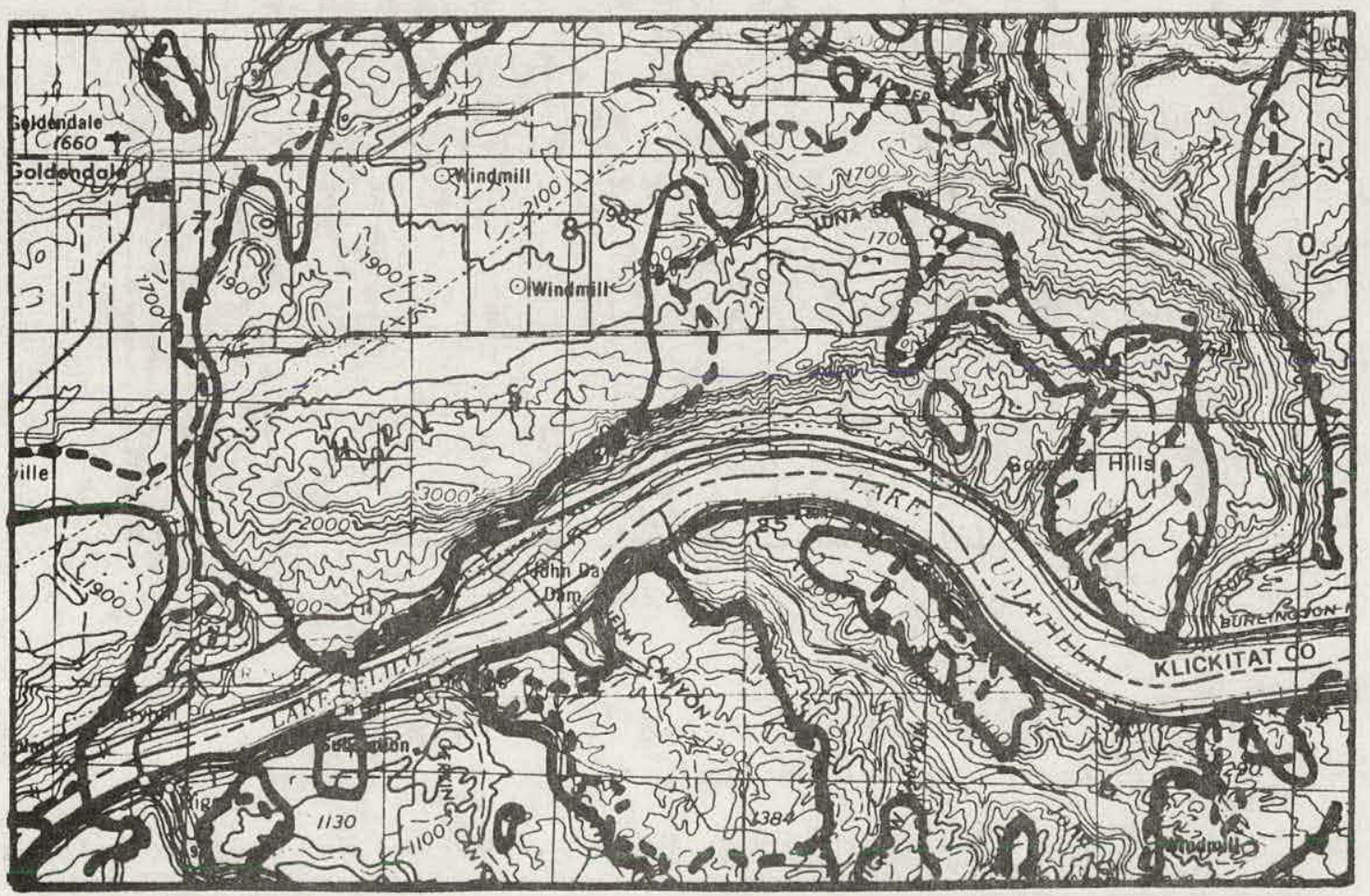

(b)

Figure 15 Areal Distribution of $20 \mathrm{mph}$ Isotach; (a) ROOSEVELT Grid $\mathrm{U}_{\mathrm{O}}=18.3 \mathrm{mph}, \theta_{0}=280^{\circ}$; (b) JUNIPER Grid U $=19.7 \mathrm{mph}$ o $\theta_{0}=270^{\circ},-\theta_{0}=280^{\circ}$. Scale $1: 250^{\circ}, 000$ 

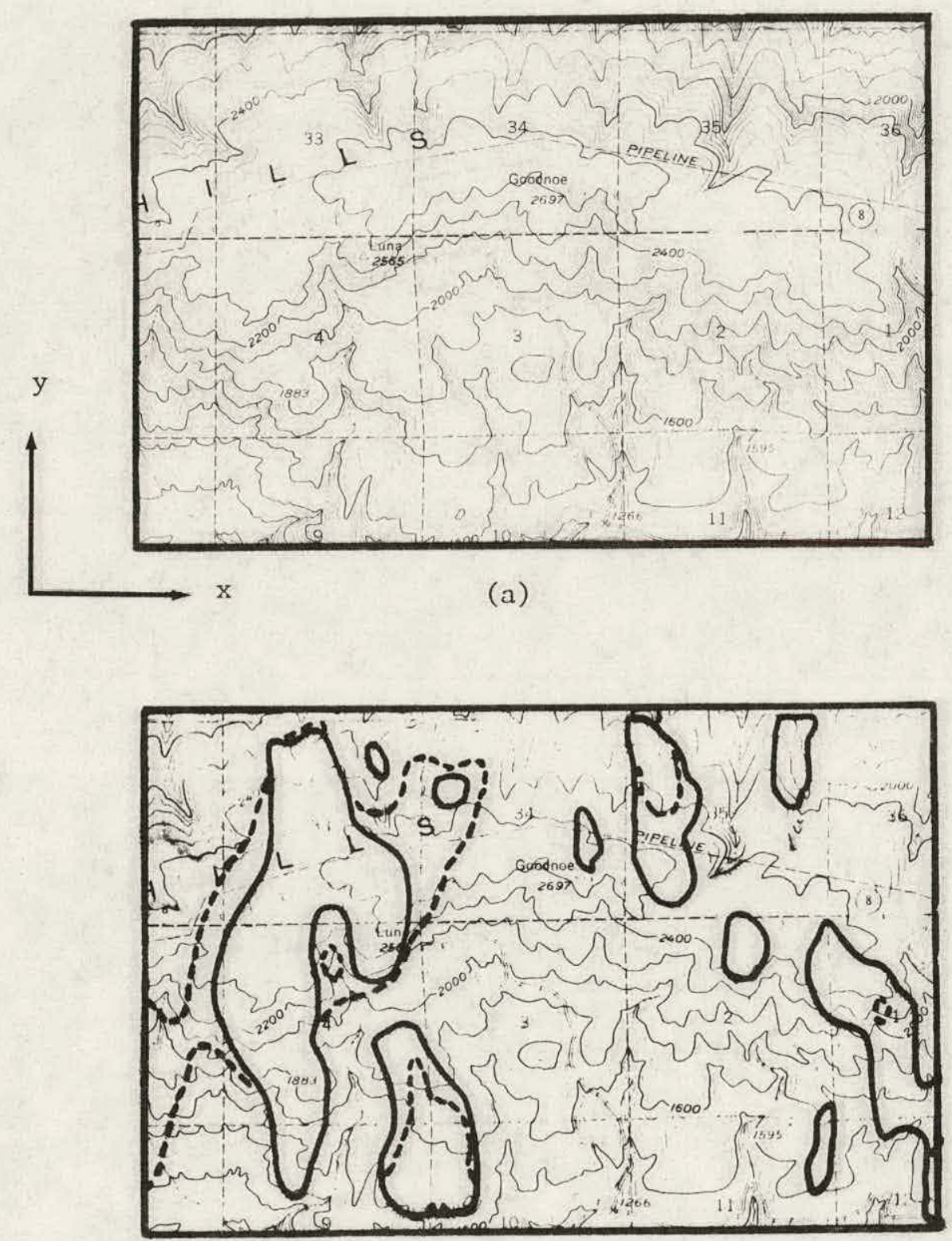

(b)

Figure 16 (a) GOODNOE Grid Area. (b) Areal Distribution of $20 \mathrm{mph}$ Isotach; $U_{0}=19.5 \mathrm{mph},-\theta_{0}=270^{\circ},--\theta_{0}=280^{\circ}$.

Scale $1: 62,500$. Grid spacing of 208 feet in $x(E-W)$ and y (N-S) directions ( .040 in. at scale shown). 


\section{Validation of Numerical Wind Estimates}

There are several validation tests that may be applied to validate the results produced by numerical models, each designed to test a specific feature of the model. Since we intend to apply the model for wind power prospecting, where an estimate of the long term mean wind speed is the first significant wind parameter encountered, we have chosen to use observed wind data from field anemometer stations to validate the wind estimates. This validation comparison imposes a severe test of the numerical approximation, however, it is the most appropriate test for the intended application.

\subsection{Quantitative Comparisons}

The results of the numerical estimates for prevailing wind direction and mean wind speed were compared with the anemometer data summarized in Table 5 to determine the accuracy of the numerical predictions. The magnitude and azimuthal direction of the numerically calculated wind vectors were taken respectively as the mean seasonal wind speed and the prevailing wind direction.

Numerical computations were conducted such that the resulting wind speed estimates were at 200 feet above ground level. The comparison between calculated and observed speeds was made at local anemometer height by adjusting the calculated wind speeds from 200 fect to ancmometer height according to a one-fifth power law for the vertical wind speed profile, i.e., $\bar{U} \sim z^{1 / 5}$. Here $\bar{U}$ is the mean wind speed and $z$ is the height above ground. The same power law was used for all anemometer locations.

At the onset of this program, we expected to achieve quantitative agreement between the numerical estimates of wind speed and the observed wind speeds with a mean error between 15 and 20 percent. The best agreement that may be expected to be achieved is limited to the overall accuracy of the observed wind data, approximately 9 percent, which may be attributed to variations in the mean wind speed from year-to-year, to anemometer calibration and to data loss (see Section 3.5). A demonstrated agreement within 15 percent between calculated and obscrved wind speeds would there- 
fore be considered a satisfactory validation of the numerical estimates, and a demonstrated agreement within 9 percent would be considered exceptiona1.

Two measures of error were calculated that describe the discrepancy between the calculated and observed mean wind speeds: the root mean square error expressed as a percentage of the input background wind speed (rms error); and the mean absolute error (mean error) calculated as the average of the absolute value of the difference between calculated and observed speeds, divided by the observed speed, and expressed as a percentage. In all cases, these two measures had the same numerical value, within one percentage point, therefore only the mean error values are presented.

The comparison between the calculated and observed prevailing wind directions is shown graphically in figure 17 for the GORGE grid. A solid curve inclined 45 degrees with respect to the horizontal axis was drawn to represent exact agreement between the calculated results and the observed values. Similar results were obtained for the other computation grids. The wind direction values, converted from compass points to azimuth degrees, appears in the table in figure 19. The calculated directions agree with the observed directions to within a mean absolute error of less than one compass point (22.5 degrees), and is stated in compass points because one compass point is the reported resolution of the observed data.

A comparison between the calculated and observed mean speeds for the summer case is shown graphically in figure 18 for the GORGE grid. The plot shown in figure 18 is a computer line printer plot produced by the computer program PREP immediately after the program WINDS was executed. The companion table shown in figure 19 was also produced by PREP at the same time. For the GORGE, the results illustrated in figures 18 and 19 were manipulated by adjusting the background wind speed and direction to obtain the best quantitative agreement between calculated and observed values. The GORGE grid was the only grid for which this manipulation was conducted. The results of the large scale GORGE grid were then used as the beginning definition of the background flow parameters for the DALLES grid computations. 


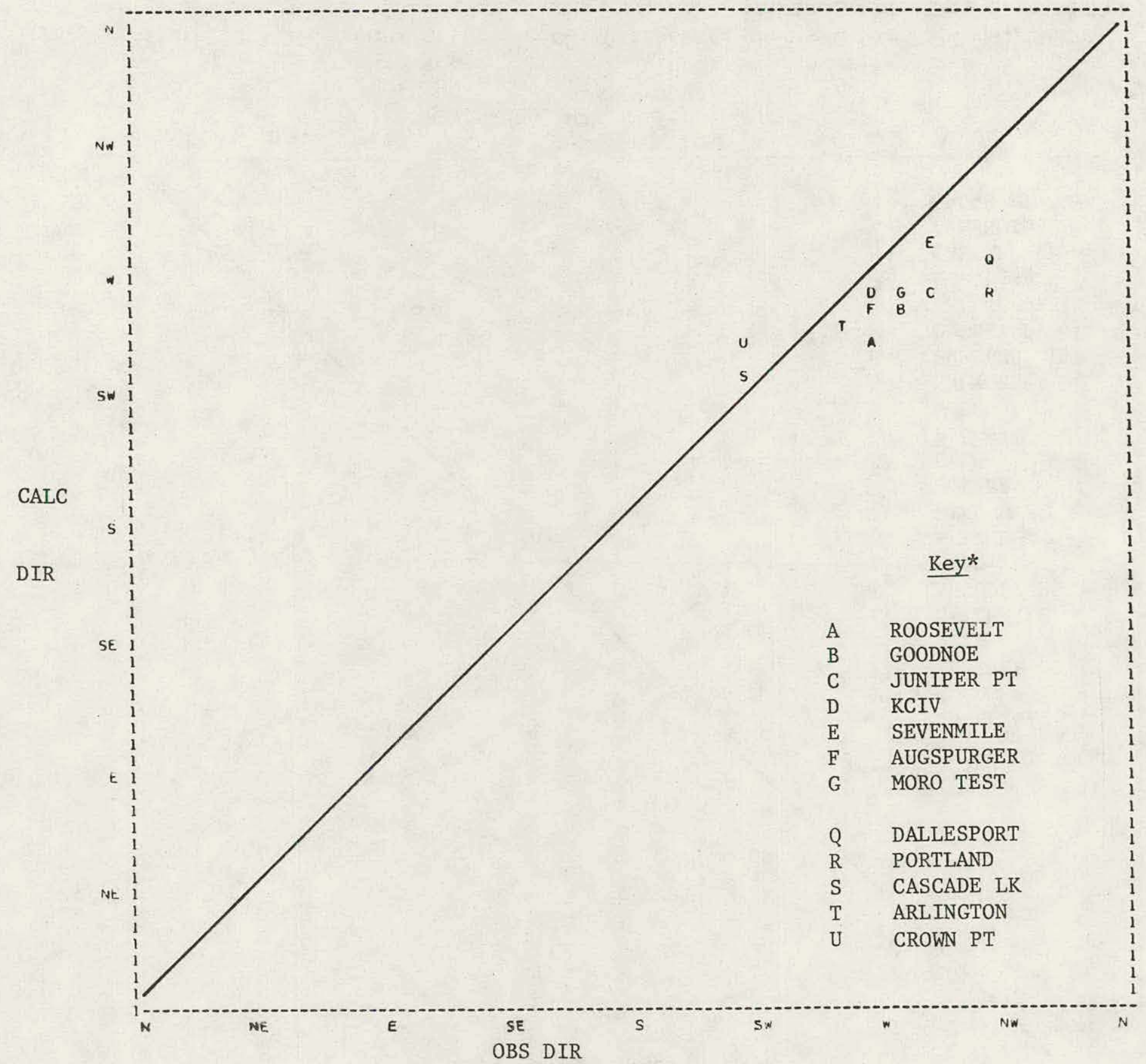

Figure 17 Comparison between Calculated and Observed Wind Directions, GORGE Grid, $\mathrm{U}_{B}=17.9 \mathrm{mph}, \theta_{0}=270^{\circ}$. *NOTE: Station key pertains to this figure only. 


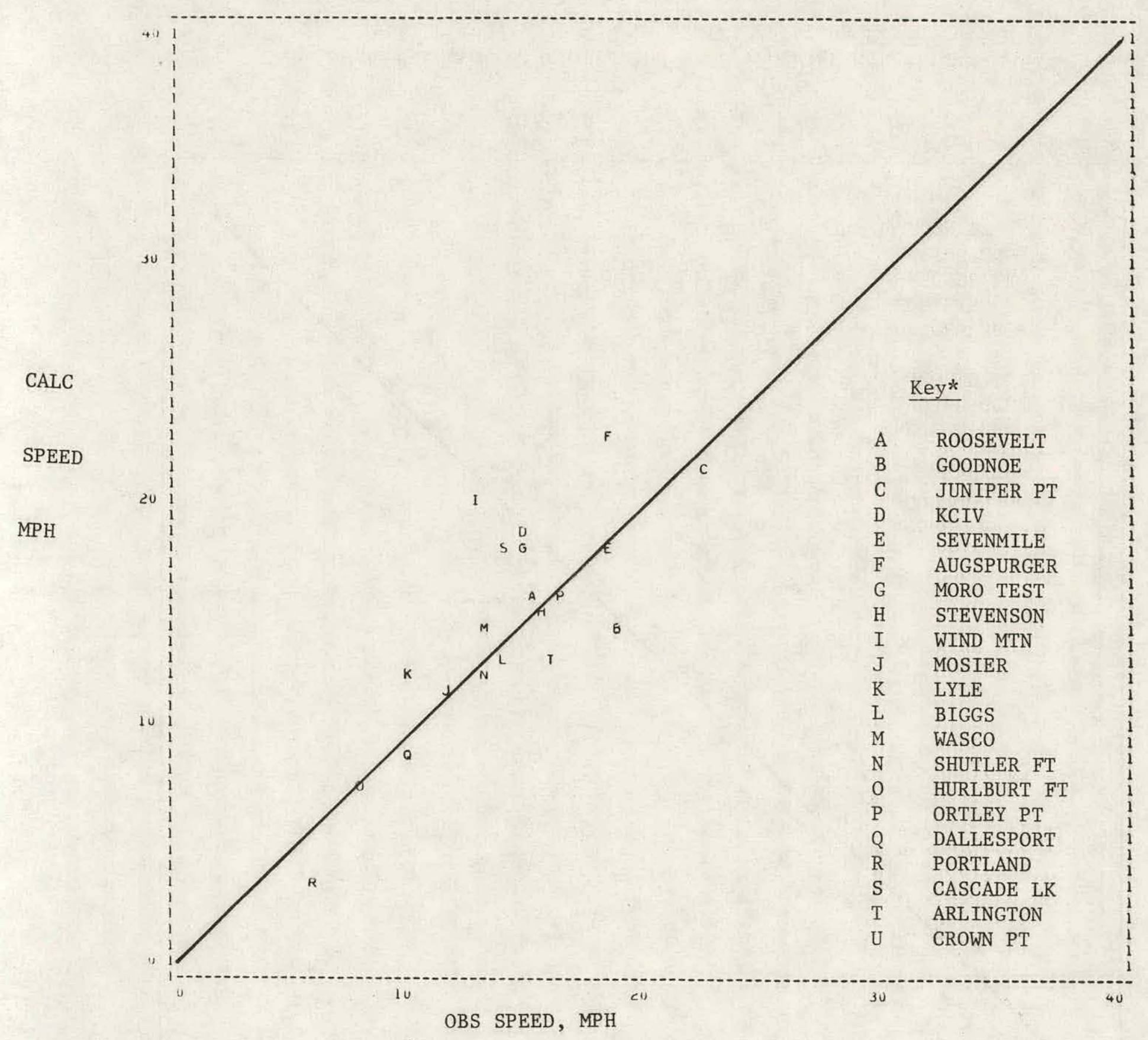

Figure 18 Comparison between Calculated and Observed Wind Speeds, GORGE Grid, $U_{B}=17.9 \mathrm{mph}, \theta_{0}=270^{\circ}$. *NOTE: Station key pertains to this figure only. 


\begin{tabular}{|c|c|c|c|c|c|c|c|c|c|c|c|}
\hline \multirow[b]{2}{*}{ STATION } & \multirow[b]{2}{*}{ ELEV } & \multirow[b]{2}{*}{$\operatorname{ELEV~}(I, J)$} & \multirow[b]{2}{*}{ I } & \multirow[b]{2}{*}{$\mathrm{J}$} & \multicolumn{3}{|c|}{ DIRECTIONS } & \multicolumn{3}{|c|}{ SPEEDS } & \multirow{2}{*}{$\begin{array}{l}\text { TOWER } \\
\text { HEIGHT }\end{array}$} \\
\hline & & & & & $\mathrm{OBS}$ & CALC & $\overline{D I F F}$ & $\overline{\mathrm{OBS}}$ & CALC & DIFF & \\
\hline Roosevelt & 1750 & 1613 & 91 & 38 & 270 & 257 & -13 & 15.3 & 15.8 & .5 & 70 \\
\hline Goodnoe & 2600 & 2610 & 79 & 39 & 280 & 264 & -16 & 18.6 & 14.8 & -3.8 & 45 \\
\hline Juniper Point & 3080 & 2800 & 73 & 37 & 292 & 276 & -16 & 22.3 & 21.4 & -.9 & 100 \\
\hline KCIV & 3120 & 3200 & 59 & 35 & 270 & 275 & 5 & 14.7 & 18.4 & 3.7 & 45 \\
\hline Sevenmile & 1840 & 1878 & 53 & 32 & 292 & 292 & 0 & 18.5 & 18.1 & -.4 & 50 \\
\hline Augspurger & 2880 & 2800 & 38 & 36 & 270 & 270 & -0 & 18.4 & 22.6 & 4.2 & 40 \\
\hline Moro Test & 2240 & 2200 & 70 & 23 & 280 & 272 & -8 & 14.9 & 17.7 & 2.8 & 155 \\
\hline Stevenson & 150 & 282 & 32 & 35 & - & 252 & 252 & 15.6 & 15.6 & -.0 & 30 \\
\hline Wind Mountain & 900 & 1058 & 35 & 35 & - & 274 & 274 & 12.8 & 19.9 & 7.1 & 40 \\
\hline Mosier & 640 & 199 & 49 & 34 & - & 277 & 277 & 11.5 & 12.0 & .5 & 30 \\
\hline Lyle & 120 & 199 & 52 & 34 & - & 284 & 284 & 10.0 & 13.0 & 3.0 & 30 \\
\hline Biggs & 760 & 600 & 68 & 32 & - & 259 & 259 & 14.1 & 13.4 & -.7 & 30 \\
\hline Wasco & 1520 & 1599 & 74 & 27 & - & 272 & 272 & 13.0 & 14.5 & 1.5 & 30 \\
\hline Shutler Ft & 1185 & 1203 & 94 & 27 & - & 263 & 263 & 13.3 & 12.7 & .6 & 40 \\
\hline Hurlburt & 603 & 597 & 98 & 38 & - & 264 & 264 & 9.9 & 9.0 & -.9 & 50 \\
\hline Ortley Point & 2040 & 1878 & 53 & 32 & - & 338 & 338 & 16.5 & 16.3 & -.2 & 30 \\
\hline Dallesport & 210 & 209 & 57 & 30 & 315 & 286 & -29 & 10.1 & 9.5 & -.6 & 16 \\
\hline Portland & 26 & 68 & 3 & 29 & 315 & 272 & -43 & 5.8 & 4.3 & -1.5 & 33 \\
\hline Cascade Locks & 140 & 316 & 31 & 33 & 225 & 242 & 17 & 14.2 & 18.0 & 3.8 & 56 \\
\hline Arlington & 850 & 899 & 93 & 36 & 258 & 259 & 1 & 15.8 & 13.3 & -2.5 & 82 \\
\hline Crown Point & 734 & 999 & 17 & 26 & 225 & 256 & 31 & 8.0 & 7.7 & -.3 & 30 \\
\hline
\end{tabular}


The results for the DALLES grid is shown graphically in figure 20 and in the tabular form at the top of figure 21. The results for the ROOSEVELT, JUNIPER, and GOODNOE grids respectively, are also shown in tabular form in figure 21. The mean error between the calculated and observed mean wind speeds were $\pm 14, \pm 13, \pm 10, \pm 7$, and \pm 17 percent for grids $1,2,3,4$, and 5. With the exception of the GOODNOE grid, grid 5, where there is only one anemometer station with which to compare, the mean error systematically decreases as the grid spacing decreases. The error observed for the GOODNOE grid is discussed further in the next section where the \pm 17 percent error is reduced to \pm 7 percent. The numerically calculated seasonal mean speeds therefore represent the true long term seasonal mean wind speeds within approximate $1 y \pm 17, \pm 16, \pm 13, \pm 11$, and \pm 11 percent $\left(\left((14 \%)^{2}+\right.\right.$ $\left.(9 \%)^{2}\right)^{\frac{1}{2}}$, etc. see section 3.5 ) for grid $1,2,3,4$, and 5 , and demonstrates the validity of the numerical approach as a tool for prospecting for land areas with high seasonal mean wind speeds in an overall siting methodology.

\subsection{Error Sources}

In the case of the GORGE grid, figure 19, the maximum difference between the calculated and observed values occurs for Wind Mountain ( $7.1 \mathrm{mph}$ ), Augspurger Mountain (4.2 mph), Goodnoe Hills $(-3.8 \mathrm{mph})$, and Cascade Locks $(3.8 \mathrm{mph})$. These stations were examined specifically to attempt to determine an explanation for the large individual discrepancies. The location of the Wind Mountain anemometer is shown with respect to the computation grid points in figure 22. The anemometer is in a saddle area northeast of Wind Mountain. The grid point corresponding to this station is the grid point nearest the station location, in this case on top of Wind Mountain where the exposure to the prevailing wind is much greater. The type of error illustrated by this example, the difficulty of matching the location of individual grid points with the specific location of an individual anemometer station, is an error that occurs when making quantitative comparisons between the numerical estimates of wind speeds and specific observed wind speeds. A significant portion of the disagreement between the calculated and observed wind speeds for Augspurger and Cascade Locks is also caused by this type of error. Although this type of error may be decreased by optimizingthe location of the grid with respect to the individual anemometer 


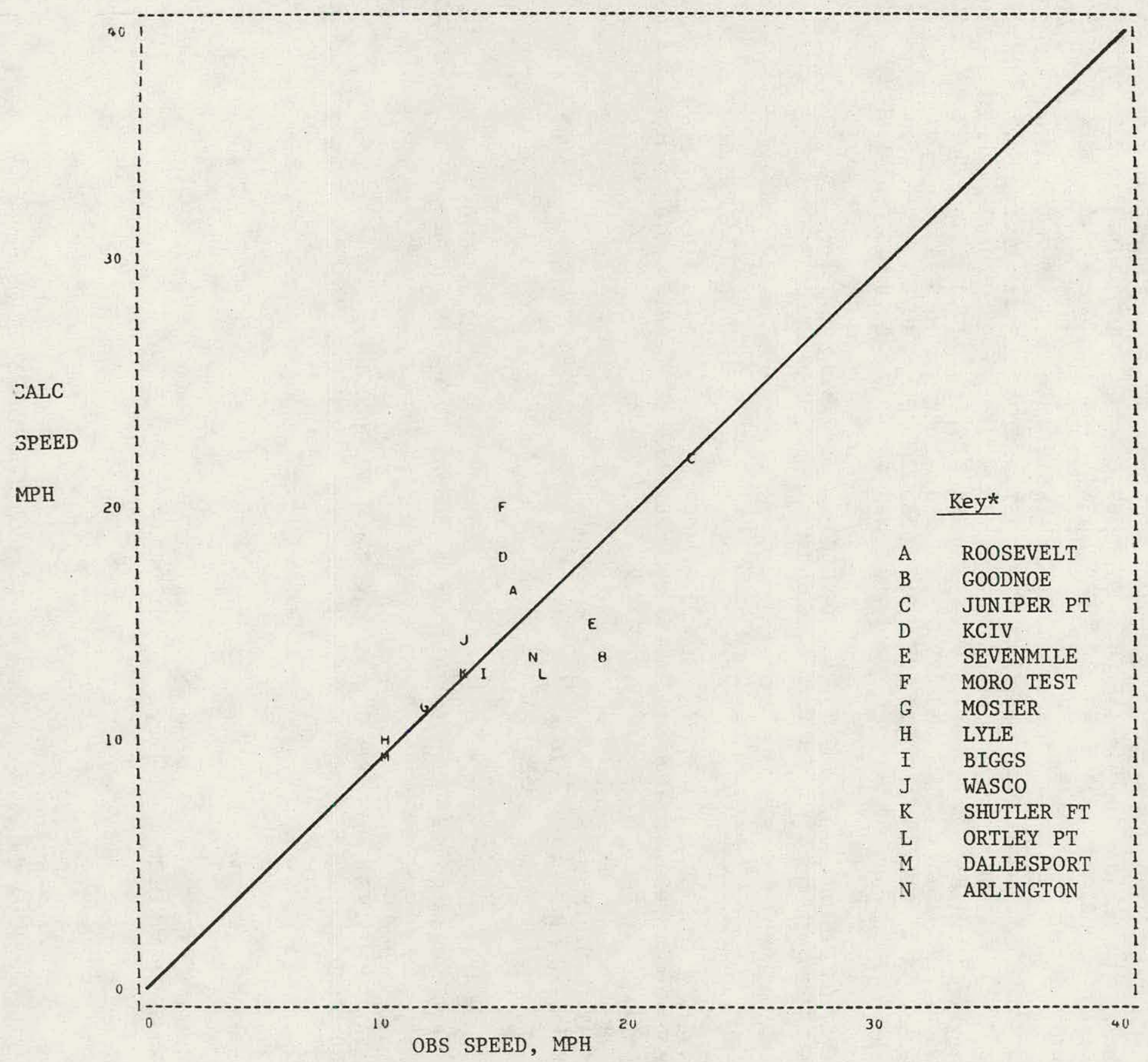

Figure 20 Comparison between Calculated and Observed Wind Speeds, DALLES Grid, $\mathrm{U}_{\mathrm{B}}=18.6 \mathrm{mph}, \theta_{\mathrm{O}}=270^{\circ}$. *NOTE: Station key pertains to this figure only. 


\begin{tabular}{|c|c|c|c|c|c|c|c|c|c|c|c|}
\hline \multirow[b]{2}{*}{ STATION } & \multirow[b]{2}{*}{ ELEV } & \multirow{2}{*}{$\begin{array}{l}\text { ELEV } \\
(I, J)\end{array}$} & \multirow[b]{2}{*}{ I } & \multirow[b]{2}{*}{$\mathrm{J}$} & \multicolumn{3}{|c|}{ DIRECTIONS } & \multicolumn{3}{|c|}{ SPEEDS } & \multirow{2}{*}{$\begin{array}{l}\text { TOWER } \\
\text { HEIGHT } \\
\end{array}$} \\
\hline & & & & & OBS & CALC & DIFF & OBS & CALC & DIFF & \\
\hline Roosevelt & 1750 & 1637 & 91 & 41 & 270 & 265 & -5 & 15.3 & 16.7 & 1.4 & 70 \\
\hline Goodnoe & 2600 & 2400 & 68 & 42 & 280 & 267 & -13 & 18.6 & 14.3 & $-4 \cdot 3$ & 45 \\
\hline Juniper Pt & 3080 & 2999 & 55 & 38 & 292 & 277 & -15 & 22.3 & 21.7 & -.6 & 100 \\
\hline $\mathrm{KCIV}$ & 3120 & 2900 & 27 & 35 & 270 & 272 & 2 & 14.7 & 18.3 & 3.6 & 45 \\
\hline Sevenmile & 1840 & 1800 & 15 & 28 & 292 & 289 & -3 & 18.5 & 15.7 & -2.8 & 50 \\
\hline Moro Test & 2240 & 2200 & 49 & 10 & 280 & 271 & -9 & 14.9 & 20.1 & 5.2 & 155 \\
\hline Mosier & 640 & 422 & 8 & 32 & - & 271 & 271 & 11.5 & 11.7 & .2 & 30 \\
\hline Lyle & 120 & 199 & 14 & 32 & - & 290 & 290 & 10.0 & 10.9 & .9 & 30 \\
\hline Biggs & 760 & 631 & 46 & 29 & - & 257 & 257 & 14.1 & 13.1 & -1.0 & 30 \\
\hline Wasco & 1520 & 1555 & 58 & 19 & - & 273 & 273 & 13.0 & 14.7 & 1.7 & 30 \\
\hline Shutler Ft & 1185 & 1200 & 97 & 18 & - & 268 & 268 & 13.3 & 13.5 & .2 & 40 \\
\hline Ortley Pt & 2040 & 1865 & 15 & 29 & - & 288 & 288 & 16.5 & 13.4 & -3.1 & 30 \\
\hline Da11esport & 210 & 222 & 23 & 25 & 315 & 280 & -35 & 10.1 & 9.7 & -.4 & 16 \\
\hline Arlington & 850 & 858 & 96 & 37 & 258 & 267 & 9 & 15.8 & 13.9 & -1.9 & 82 \\
\hline $\begin{array}{l}\text { ELEVATION } \\
\text { WIND SPEE }\end{array}$ & $\begin{array}{l}\text { NIMUM = } \\
\text { IN TMUM }\end{array}$ & & & & $\begin{array}{l}\text { MAXIM } \\
\text { MAXIM }\end{array}$ & $\begin{array}{l}1= \\
1=\end{array}$ & $\begin{array}{r}5773 . \\
30\end{array}$ & & & & \\
\hline
\end{tabular}

$\begin{array}{lrrrrrrrrrrr}\text { Roosevelt } & 1750 & 1676 & 83 & 36 & 270 & 278 & 8 & 15.3 & 16.9 & 1.6 & 70 \\ \text { Goodnoe } & 2600 & 2610 & 17 & 41 & 280 & 283 & 3 & 18.6 & 15.6 & -3.0 & 45 \\ \text { Arlington } & 850 & 784 & 97 & 27 & 258 & 279 & 21 & 15.8 & 15.1 & -.7 & 82\end{array}$

$\begin{array}{lclr}\text { ELEVATION MINIMUM }= & 199 & \text { MAXIMUM }= & 2645.0 \\ \text { WIND SPEED MINIMUM }= & 10.5 & \text { MAXIMUM }= & 25.4\end{array}$

\begin{tabular}{|c|c|c|c|c|c|c|c|c|c|c|c|}
\hline Juniper Pt & 3080 & 2999 & 32 & 30 & 292 & 277 & -15 & 22.3 & 22.0 & -.3 & 100 \\
\hline Goodnoe & 2600 & 2400 & 69 & 41 & 280 & 268 & -12 & 18.6 & 14.9 & -3.7 & 45 \\
\hline Biggs & 760 & 697 & 6 & 4 & -0 & 269 & 269 & 14.1 & 14.2 & .1 & 30 \\
\hline ELEVATION & MINIMUM = & \multicolumn{2}{|c|}{199.0} & \multicolumn{2}{|r|}{ MAXIMUM } & $I=$ & 3000.0 & & & & \\
\hline WIND SPEED & MINIMUM = & \multicolumn{2}{|c|}{10.8} & & MAXIMUM & $1=$ & 28.2 & & & & \\
\hline Goodnoe & 2600 & 2520 & 30 & 38 & 280 & 272 & -8 & 18.6 & 15.5 & -3.1 & 45 \\
\hline ELEVATION & MINIMUM = & & & & MAXIMUM & $I=$ & 2680.0 & & & & \\
\hline WIND SPEED & MINIMUM = & & & & MAXIMUM & $1=$ & 21.4 & & & & \\
\hline
\end{tabular}

Figure 21 Tabulated Comparison between Calculated and Observed Wind Speed and Direction Data, Grids 2 - 5; DALLES, $\mathrm{U}_{\mathrm{B}}=18.6 \mathrm{mph}, \theta_{0}=270^{\circ}$; ROOSEVELT, $\mathrm{U}_{\mathrm{B}}=18.3 \mathrm{mph}, \theta_{\mathrm{O}}=280^{\circ}$; JUNIPER, $\mathrm{U}_{\mathrm{B}}=19.7 \mathrm{mph}, \theta_{0}=$ $270^{\circ}$; GOODNOE, $\mathrm{U}_{B}=19.5 \mathrm{mph}, \theta_{0}=270^{\circ}$ 


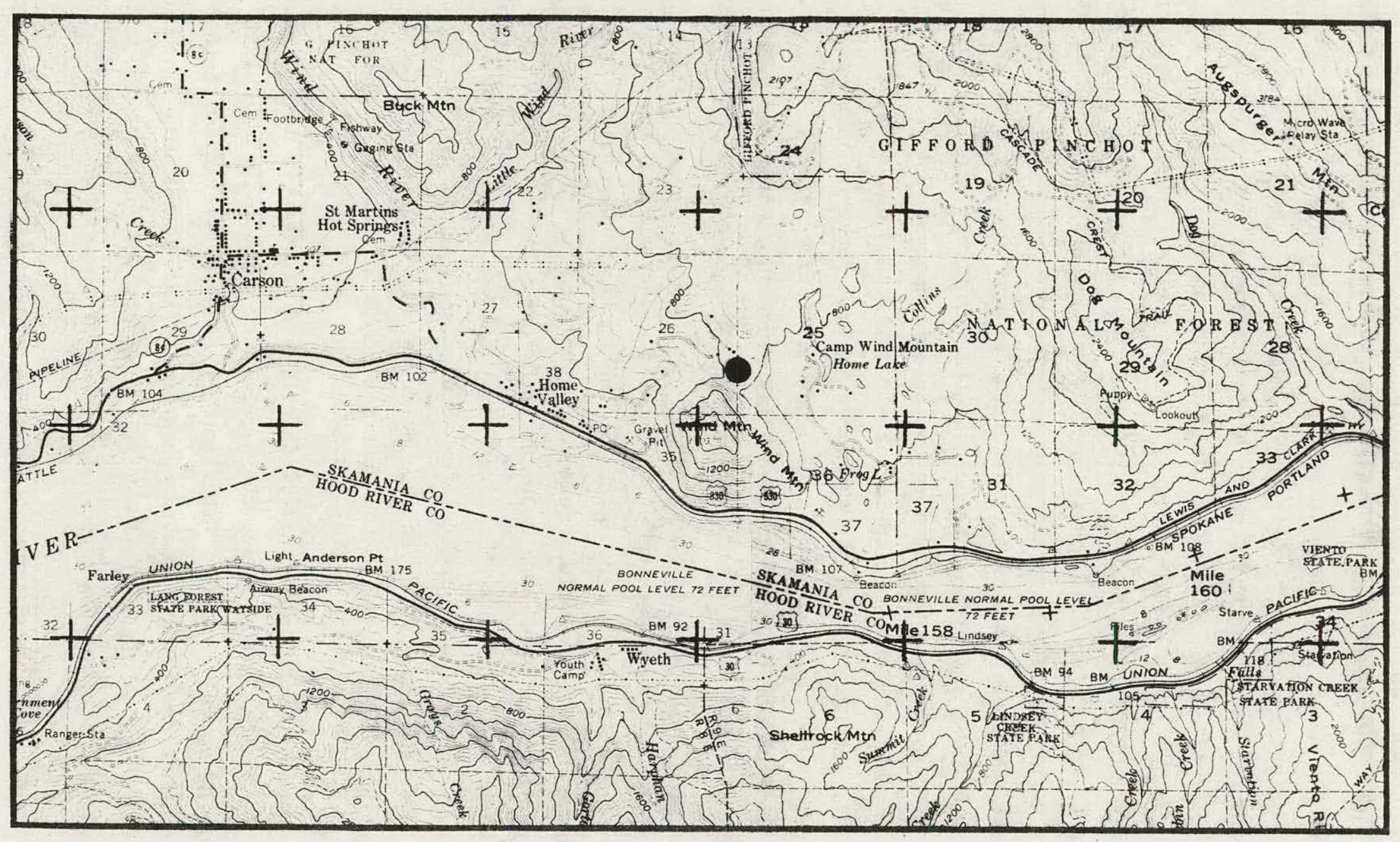


locations, no attempt was made to do so within the present program. This type of error is most significant in areas with very rugged terrain and may be partially overcome with smaller spacings between adjacent grid points.

For each of the numerical results shown in figures 20 and 21 , the numerically estimated speed for the Goodnoe Hills anemometer is consistently between 3 and 4.3 miles per hour below the observed value. The Goodnoe Hills anemometer location, shown in figure 23 with respect to the grid point locations for the GORGE grid and the DALLES grid, reflects a related difficulty to that discussed for Wind Mountain. The Goodnoe Hills anemometer is located on a narrow ridge approximately $3 / 4$ mile across and two and onehalf miles long. Two computational grid points for the GORGE grid occur on the small Goodnoe Hills ridge. Because of the relatively small extent of the Goodnoe Hills ridge area compared to the area represented by the large computational grid spacing (approximately 1:1) the Goodnoe Hills ridge is a small perturbation within the larger grid. For the DALLES grid, none of the grid points occurred on the Goodnoe Hills ridge crest. However, it should be pointed out that the Goodnoe Hills area was identified in both the GORGE and DALLES grids as a small high speed area, as shown in figures 13 and 14 .

Two additional difficulties were encountered with regard to the area near the Goodnoe Hills anemometer. Although the smaller scale grids were of sufficient resolution to include features of this narrow ridge, the ridge crest has elevations between 2600 and 2800 feet. Therefore the digital terrain tapes do not include the ridge crest because of the interpolation scheme between 200 foot contour lines as discussed in section 4 . For the results shown for grids 3, 4, and 5, the terrain in Goodnoe Hills area was hand digitized and included in the numerical computations to minimize this effect.

Even though the terrain elevation difficulties were overcome in the computations at smaller grid scales, the discrepancy between the calculated and observed wind speeds remained. The last addressed difficulty with the Goodnoe Hills locations was the smooth character of the surrounding terrain As stated previously, we assumed a one-fifth power law variation of the wind speed with height. A kite anemometer measurement of the vertical speed 


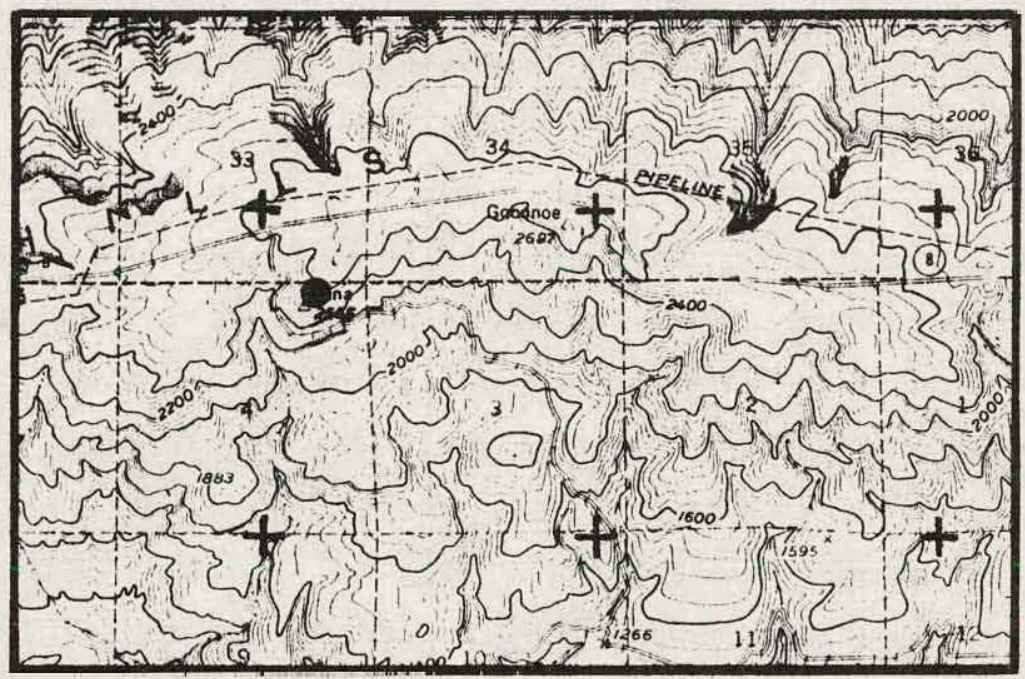

(a)

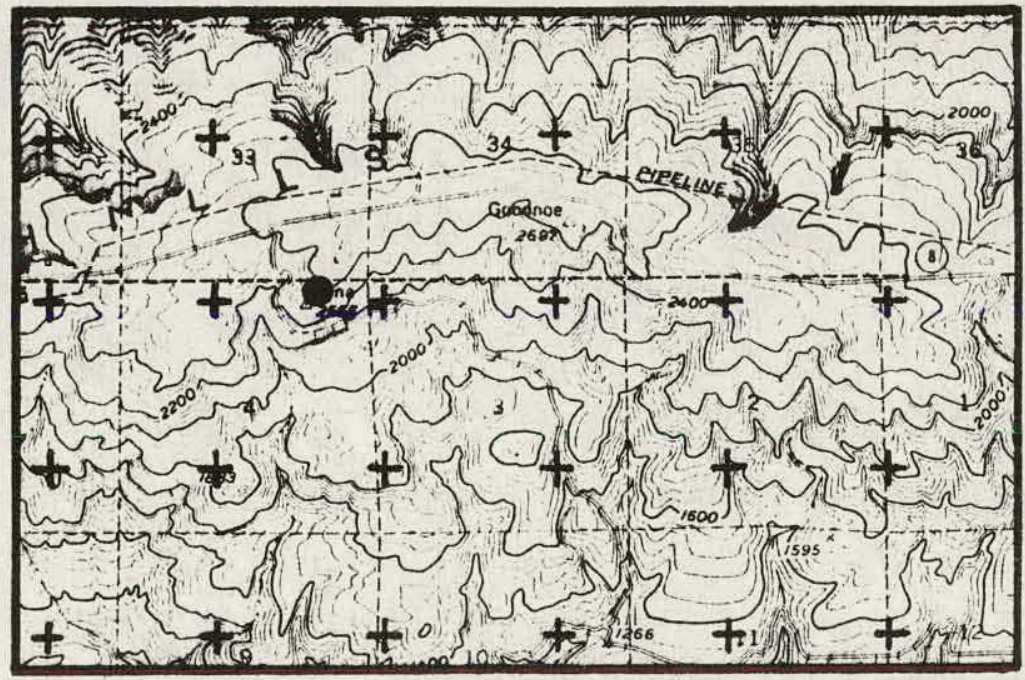

(b)

Figure 23 (a) Locations of GORGE computation grid points in the vicinity of Goodnoe Hills. (b) Location of DALLES computation grid points in the vicinity of Goodnoe Hills. Goodnoe Hills Anemometer Station. Scale 1:62,500 
profile at Goodnoe Hills by Hewson et. al. (1978) is shown in figure 24, suggesting that the wind speed varies vertically more in accordance with height to the one-eighth power (less change in speed with height) rather than with the one-fifth power. Extrapolating the predicted mean wind speed at Goodnoe Hills from 200 feet to anemometer height according to a oneeighth power law variation results in an under prediction of the observed speed by $11,15,6,10$, and 7 percent for grids 1 through 5, and approaches the range of the mean error for each scale grid stated previously.

As a result of the better agreement between calculated and observed wind speeds achieved for the Goodnoe Hills anemometer data by adopting a one-eighth power law vertical speed profile, we subjectively assigned different values of the exponent in the power law according to where the anemometer station was geographically located. Those stations located in vegetated mountainous areas were assigned an exponent of one-fourth, those located in mountainous, or vegetated areas were assigned an exponent of one-fifth, and those located in unvegetetated, even terrain areas were assigned an exponent of one-seventh. The calculated speeds were appropriately adjusted to anemometer height and the mean error recalculated, resulting in a reduction of the mean error from 14 percent to 12 percent for the GORGE grid, and from 13 to 11 percent for the DALLES grid. This small reduction in mean error for the larger scale grids was not considered significant enough to warrant an attempt to specify in detail the vertical variation of the mean wind speed for the large scale computations; however, the vertical variation does become significant for specific site locations in smaller computational grids, as in the Goodnoe Hills case.

\subsection{Seasonal Temperature and Pressure Effects}

As discussed in section 4, a temperature and pressure model that included horizontal gradients, independent of terrain variations was used to determine the temperatures and pressures at each grid point. The temperature and pressure model was used in the computations for the GORGE and the DALLES grids. Direct comparisons between the numerical results obtained with and without the temperature and pressure model indicated only 


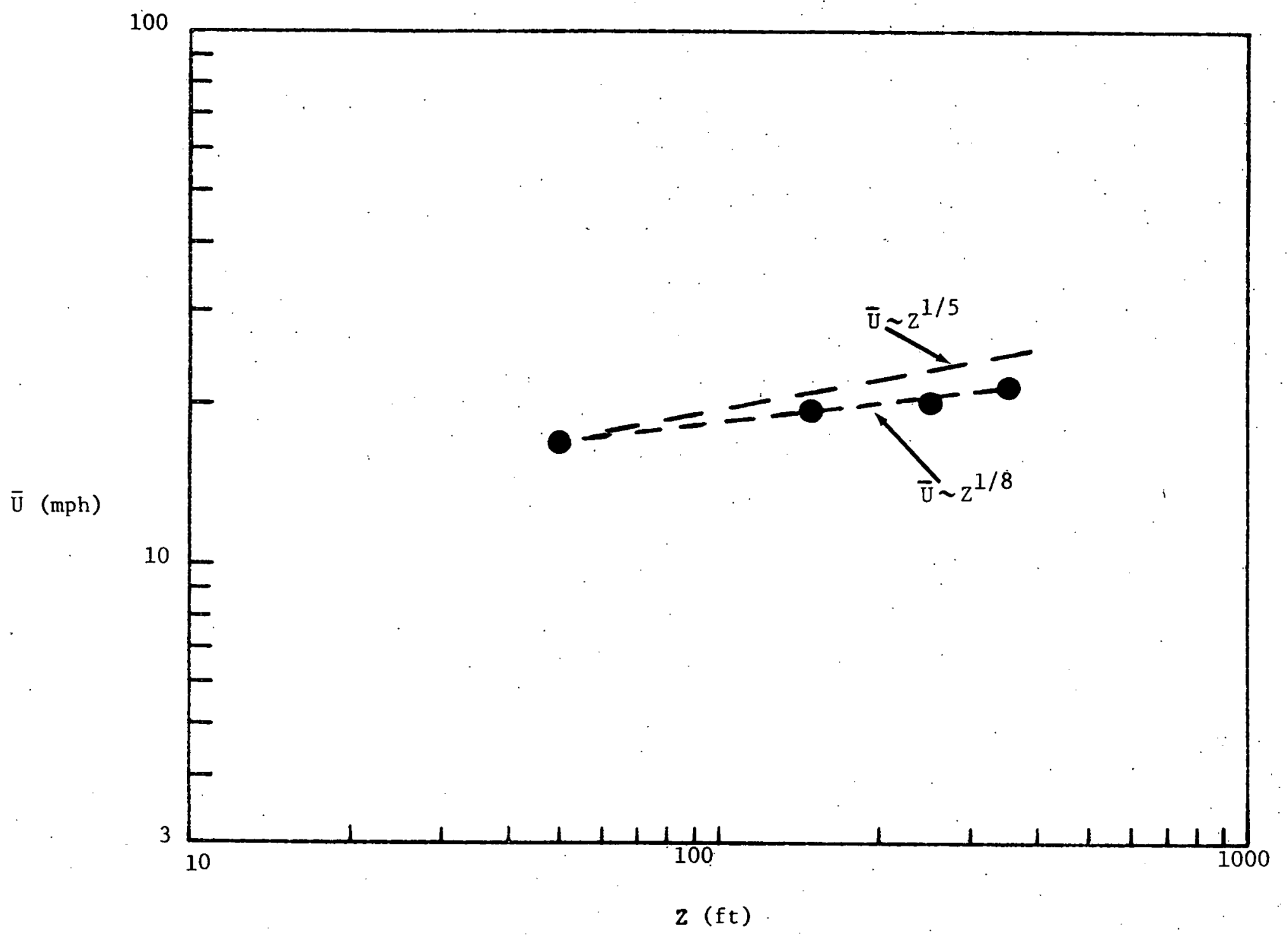

Figure $24 \quad$ Vertical profile of wind speed measured at Goodnoe Hills on 9/21/78 (0900 - 0930 PST)

(reference: Hewson et. al. (1978)) 
a 0.3 percent difference. It was therefore concluded that the weak driving forces due to temperature and pressure gradients derived from seasonal averages over an extended period are not in themselves significant to the numerical model, and that the mean seasonal driving terms are already accounted for in the background wind speed specification. The insensitivity of the "numerical results for the long term seasonal mean wind field allows for a much simpler specification of the seasonal temperature and pressure fields, and substantially reduces the effort required to specify these parameters.

\subsection{Available Wind Power Density}

For planning purposes, it is often desirable to have estimates of the : available wind power density to estimate the value of the resource. Since the mean wind speed is the most frequently available wind parameter, several methods have been put forth to relate mean wind speed measurements to available wind power density. Each of these methods relies on the assumption that the statistical distribution of wind speeds can be characterized for all stations by the same probability distribution curve. One such method is described by Justus (1978) where the Weibull distribution is used to represent the probability distribution of wind speeds. A subroutine was incorporated into the PREP computer. program to evaluate the available wind power density based upon mean wind speeds and the Weibull distribution according to Justus (1978, pp 44-50). Since the available power density not only depends upon the cube of the wind speed but the variance (the shape of the wind speed probability distribution) about the mean wind speed, three estimates of available power density were computed corresponding to a low, average, and a high variance.

To establish the applicability of the Weibull distribution for correlating mean wind speeds with available power density, we used the observed mean wind speed data to calculate available power density and compared it with the observed power density values given in Table 5. This comparison is shown graphically in figure 25 where the solid line represents a one-to-one correlation and the calculated power densities are represented by a vertical bar spanning the range from the low variance estimate to the high variance estimate. The stations that did not fall within the range of power density 


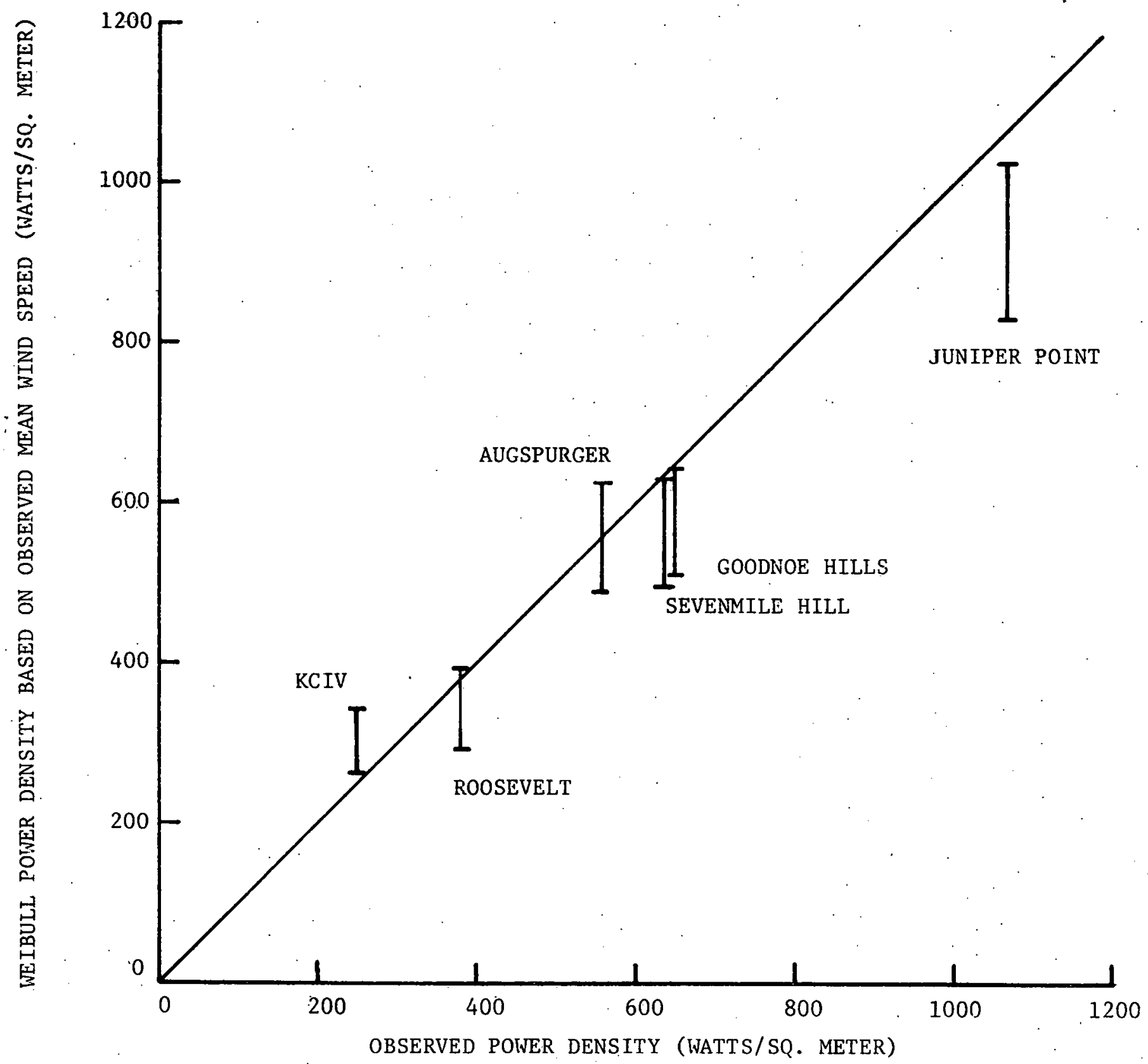

Figure 25 Comparison between Computed Power Density and Observed Power Density Based on Observed Wind Speed. 
calculated using the Weibull distributions was KCIV and Juniper Point. In general, the Weibull distributions over-estimate the power density at lower values and under-estimate the power density at higher values of mean wind speed. Taking the center value of the range of the calculated power density, the power density calculated according to the Weibull distribution using the observed mean speed is able to represent the measured power density within a mean error of \pm 11 percent and the true long term power density with a mean error of approximately \pm 22 percent $\left(\left((19 \%)^{2}+(11 \%)^{2}\right)^{\frac{1}{2}}\right.$, see section $\left.3 \% 5\right)$. The best available numerically claculated mean spè for the six stations were used to estimate the available wind power density. The comparison between the available power density calculated from the numerically estimated mean wind speeds and the observed available power density is shown in figure 26. KCIV was again the station for which the largest deviation occurred. The mean error between the numerically calculated and observed power densities was \pm 34 percent. The numerical estimates of seasonal wind power density should therefore represent the true long term mean seasonal power density within \pm 39 percent $\left.\left((19 \%)^{2}+(34 \%)^{2}\right)^{\frac{1}{2}}\right)$. 


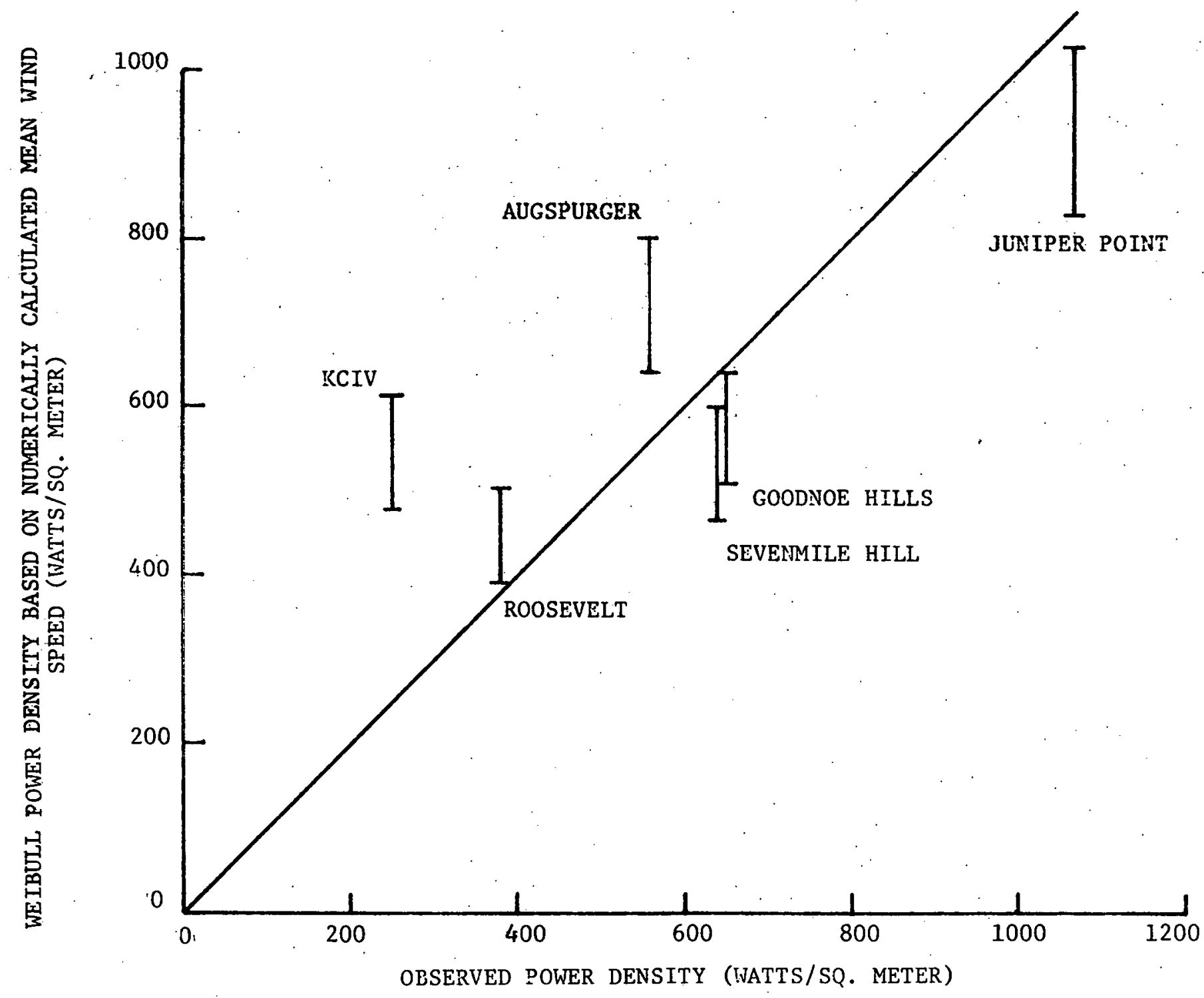

Figure 26 Comparison between Computed and Observed. Power Density Based on Numerically Calculated Wind Speed 
7. The Goodnoe Hills Wind Turbine Site

Although not analyzed in great detail, the numerical calculations were extended to provide preliminary detailed estimates of the wind field in the vicinity of the Goodnoe Hills site where three MOD-2 wind turbines are being constructed. The vertical variation of wind speed was assumed to vary with the one-elghth power of the height and the background wind direction was varied from 260 degrees to 292 degrees in accordance with the wind roses shown in figure 27 for Goodnoe Hills.

In the areal distributions of mean wind speeds shown in figures 15 (b) and $16(\mathrm{~b})$ the high speed areas were seen to change shape and size with variations in the prevailing wind directions, and it was suggested in section 5.3 that areas that remained high speed areas when the prevailing wind direction changed were preferred locations: The areal distribution of the 20 miles per hour isotach for the GOODNOE grid is. shown in figure 28(a) for $0_{0}=260$ degrees, and 292 degrees. Also shown in figure 28 are the locations of the reference anemometer and the wind turbines.

The tabulated comparison information corresponding to $\theta_{0}=260$ degrees, 280 degrees, and 292 degrees is given in figure 29. The tabulated comparison information for $\theta_{0}=270$ degrees was given in figure 21 : where the calculated speed was not corrected for vertical variation. The corrected anemometer height wind speed at the anemometer location for $\theta_{0}=270$ degrees is 17.3 miles per hour with a difference between calculated and observed mean speeds of -1.3 miles per hour.

A prevailing wind direction from nearer 292 degrees (WNW) may be more representative of an average summer prevailing 'wind, as represented by the July wind rose in figure 27, than the approximation presented in section 3 for Goodnoe Hills: For $\theta_{0}=292$ degrees the difference between calculated and observed mean wind speed is -0.1 miles per hour, or a mean error of 0.5 percent. It may be seen in figure 29 that, with a constant background speed, a systematic increase occurs in numerically calculated anemoter heilght wind speed from 17.0 miles per hour to 18.5 miles per hour as the prevail-. ing wind direction changes from 260 degrees to 292 degrees. This is interpreied as a speed-up phenomenon caused by the prevailing wind becoming more 
$-65-$

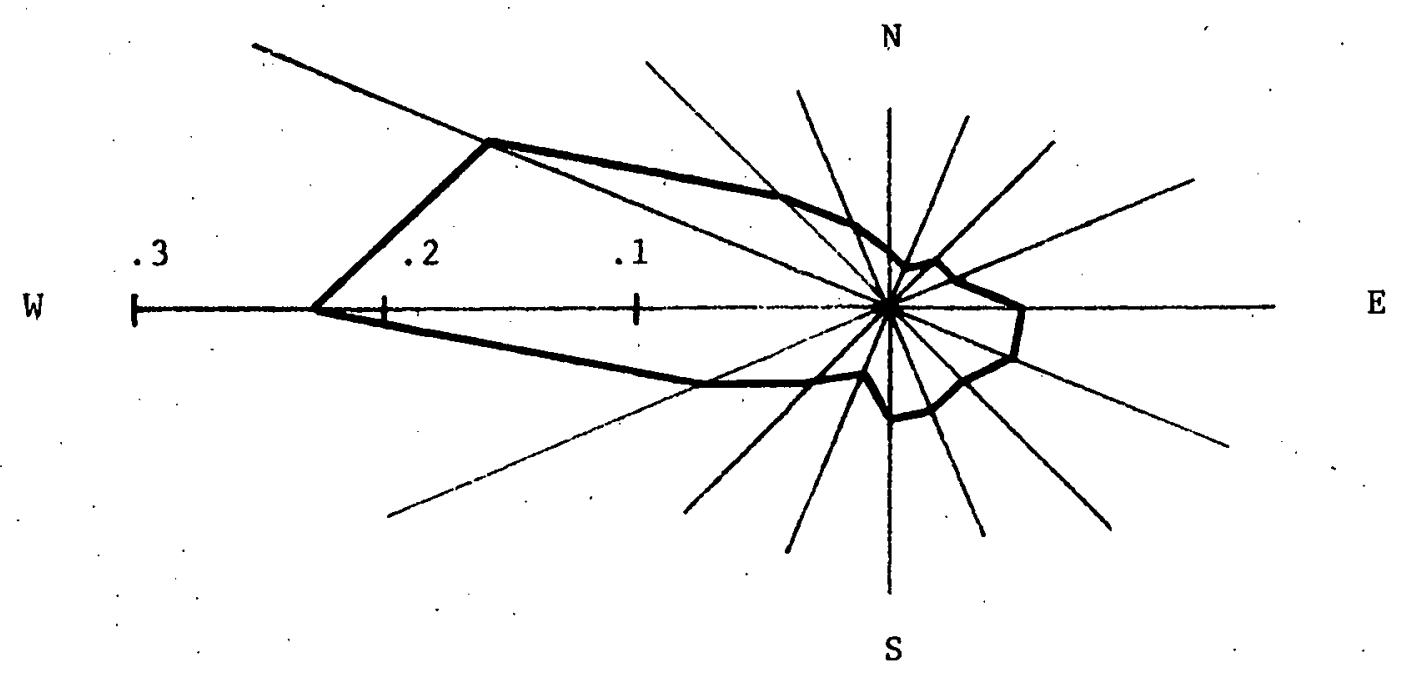

a. Annual

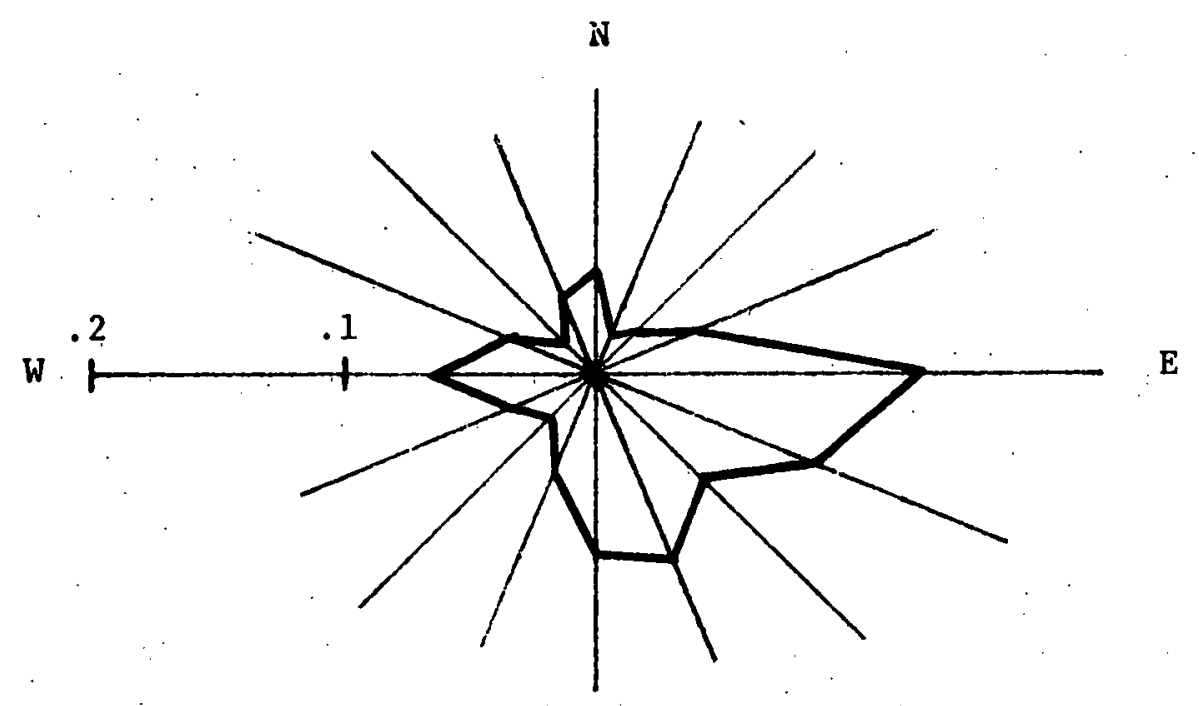

b. January

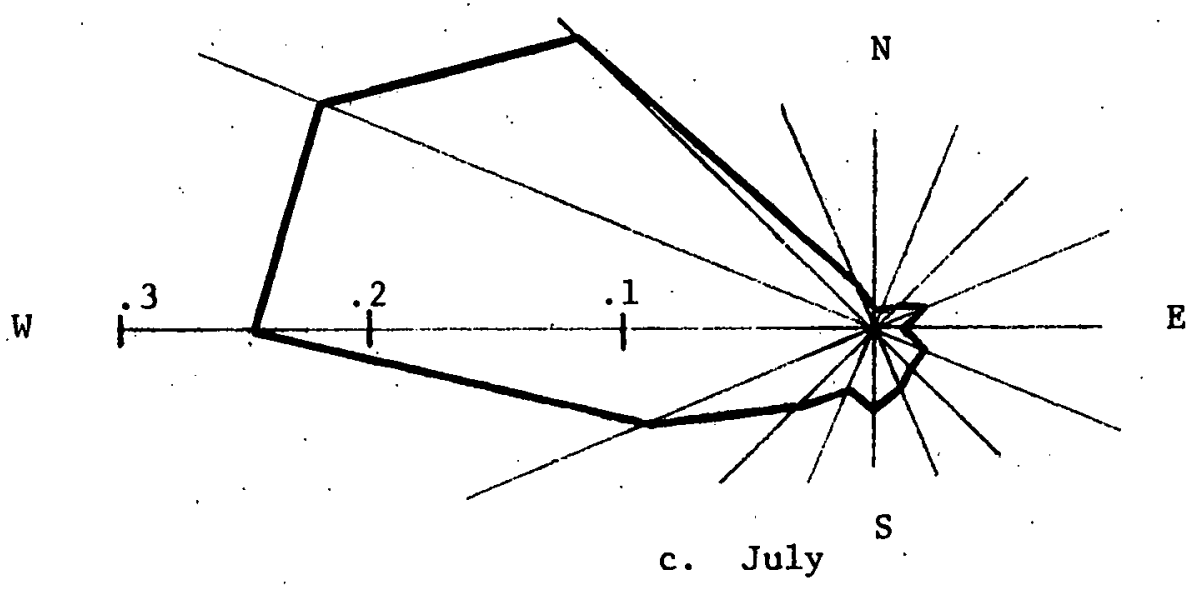

Figure 27 Wind Directions at Goodnoe Hills Anemometer Site. 
perpendicular to the ridge line as. the wind direction changes from west to west-north-west.

Since the prevailing wind directions during the summer are predominately between 270 degrees and 292 degrees, the areal distribution of the 20 miles per hour isotachs were combined into a composite 20 miles per hour isotach encompassing the area in common for $\theta_{0}=270$ degrees, 280 degrees, and 292 degrees. The areal distribution of the composite 20 miles per hour isotach is shown in figure 28(b) with respect to the reference anemometer location and the wind turbine locations. As may be seen in figure 28(b), wind turbine one is not located within the composite 20 miles per hour 1sotach. It should be emphasized, however, as mentioned in section 5.2 and shown in figure 12, the calculated mean wind speed at hub height is almost uniform over the entire GOODNOE grid, particularly along and near the ridge line. The wind speed minimum at hub height for the entire grid is shown in the tabulations in figure 21 and 27 and varies from 17.4 miles per hour to 16.2 miles per hour, both of which are above the MOD-2 cut in speed of 14.5 miles per hour. Although the application of the numerical technique to small scale regions is only preliminary in națure, this example does illustrate the utility of the numerical technique of estimating wind fields for wind power applications. 


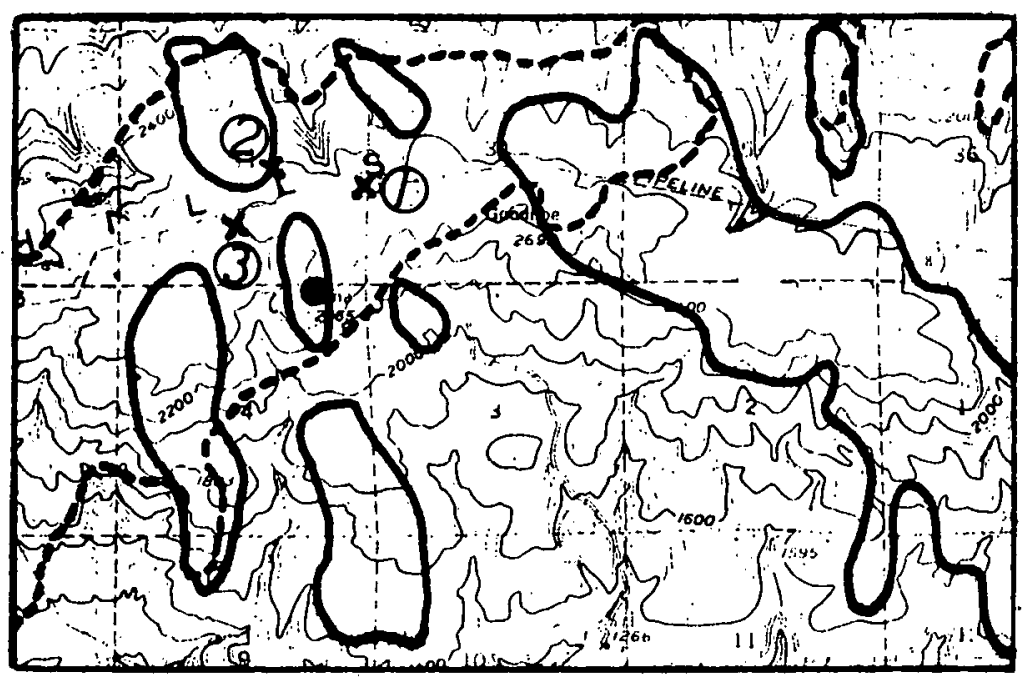

(a)

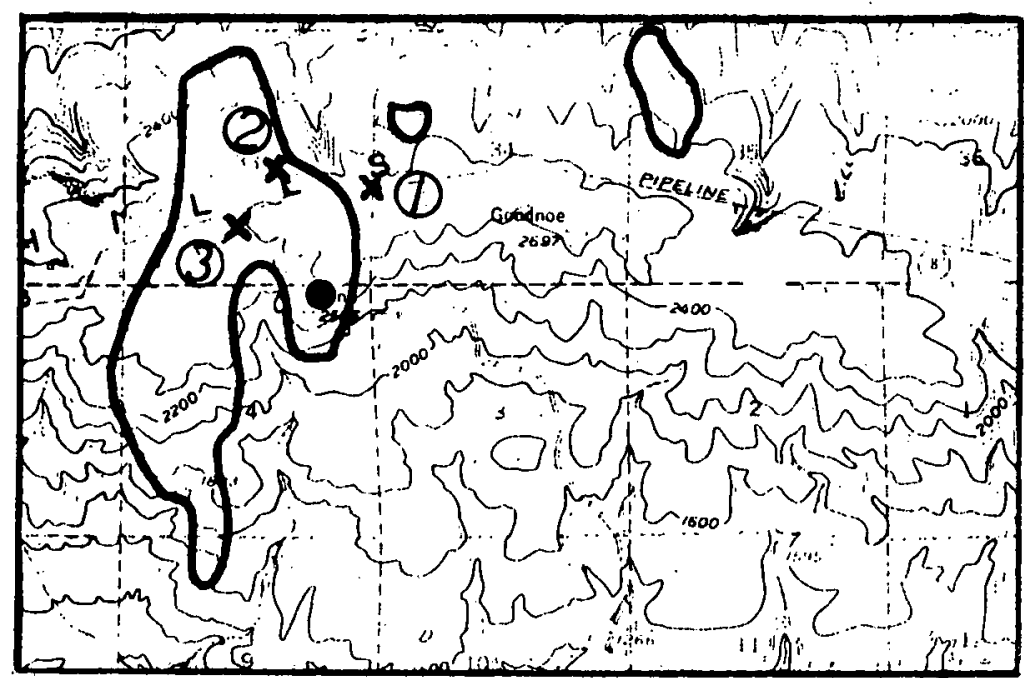

(b)

Figure 28 Areal Distribution of $20 \mathrm{mph}$ Isotach, GOODNOE Hills Wind Turbine Site: (a) $-\theta_{0}=260^{\circ}$, $--\theta_{0}=292^{\circ}$; (b) Composite of $\theta_{0} \doteq 270^{\circ}, 280^{\circ}$, and $292^{\circ}$. Goodnoe Hills Anemometer Station, $x$ MOD-2 Wind Turbine Site. Scale 1:62,500 


\begin{tabular}{|c|c|c|c|c|c|c|c|c|c|c|c|}
\hline \multirow[b]{2}{*}{ STATION } & \multirow[b]{2}{*}{ ELEV } & \multirow[b]{2}{*}{ ELEV $(I, J)$} & \multirow[b]{2}{*}{$\underline{I}$} & \multirow[b]{2}{*}{$\mathrm{J}$} & \multicolumn{3}{|c|}{ DIRECT IONS } & \multicolumn{3}{|c|}{ SPEEDS } & \multirow{2}{*}{$\begin{array}{l}\text { TOWER } \\
\text { HEIGHT } \\
\end{array}$} \\
\hline & & & & & $\overline{\mathrm{OBS}}$ & CALC & DIFF & OBS & CALC & DIFF & \\
\hline Goodnoe & 2600 & 2520 & 30 & 38 & 280 & 260 & -20 & 18.6 & 17.0 & -1.6 & 45 \\
\hline
\end{tabular}

(a) $\Theta_{0}=260^{\circ} \quad$ ELEVATION MINIMUM $=920.0 \ldots$ MAXIMUM $=2680.0$ WIND SPEED MINIMIM $=16.7, \quad$ MAXIMUM $=22.7$

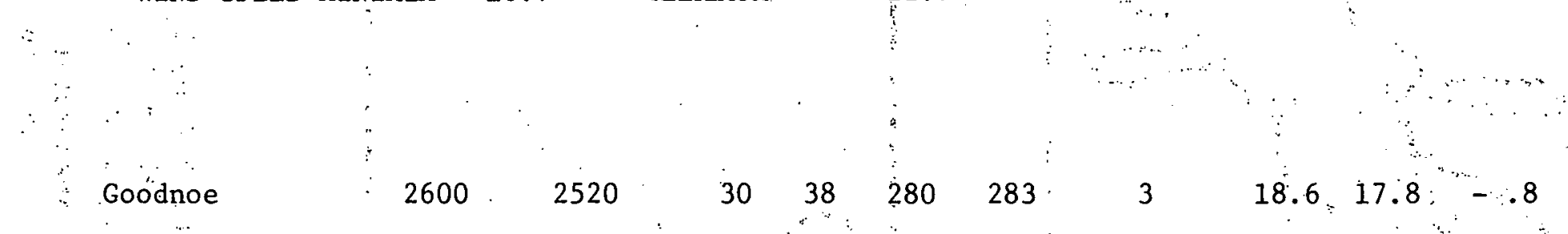

(b) $\theta_{0}=280^{\circ} \quad$ ELEVATION MINIMUM $=920.0 \quad$ MAXIMUM $=2680.0$ WIND SPEED MIN:IMUM $=17.4 \quad$ MAXIMUM $=\quad 22.0$
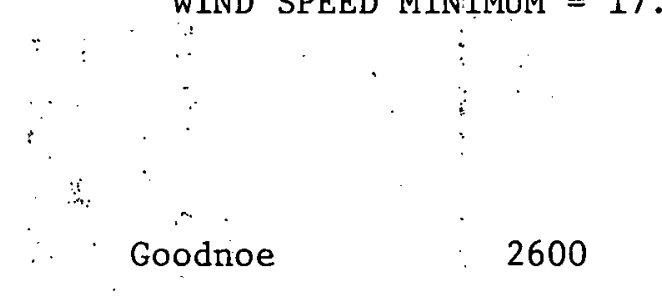

(c) $\theta_{0}=292^{\circ}$

ELEVATION MINTMUM $=920.0 ; \quad$ MAXIMUM $\neq 2680.0$

WIN̈D SPEED MINIMUM $=16.2$ MAXIMUM $=23.0$

Figure 29 Tabulated Comparison between Calculated and Observed Winds, GOODNOE Grid, $\mathrm{U}_{\mathrm{B}}=17.9 \mathrm{mph} ; \theta_{\mathrm{O}}^{\circ}=260^{\circ}, 280^{\circ}$, and $292^{\circ} \cdot \overline{\mathrm{U}} \mathrm{Z}^{1 / 8}$. 


\section{Conclusions and Recommendations}

Based upon the results and discussions summarized in previous sections of this report, the following significant conclusions and recommendations may be stated.

\subsection{Conclusions}

(i) Numerical estimation of seasonal mean wind speeds and seasonal mean power densities is a valid and useful tool for performing the initial phases of searching for wind power generating sites. The best application of the numerical technique is as a guide for locating potential high wind speed areas, and in optimizing locations for on-site anemometer stations to assess and characterize the on-site wind resource.

(ii) The demonstrated accuracy between the numerically predicted and observed seasonal mean wind speeds varies between a mean error of plus or minus 14 percent and plus or minus seven percent, depending upon the complexity of the terrain and spacing between adjacent computational grid points. The numerically calculated seasonal mean wind speeds, when an estimate of the error in the observed data of plus or minus nine percent is included, represents the true long term seasonal mean wind speeds within a corresponding mean error between plus or minus 17 percent and plus or minus 11 percent.

(iii) The demonstrated accuracy between the numerically estimated and observed available wind power density is plus or minus 34 percent. It was estimated that the observed wind power density derived from hourly averaged data is within plus or minus 19 percent of the true long term seasonal wind power density, therefore the numerical estimates of power density are within approximately plus or minus 39 percent of the true long term seasonal mean power density. Power density estimates from numerical calculations should, therefore, only be used if no other information is available and if they are properly qualified.

(iv) The technique of numerically calculating estimates of the wind field at reduced grid spacings is an effective technique that leads to improved accuracy in the predicted wind field results and a more detailed identification of high speed wind areas. 
(v) The techniques of using the predicted wind field results from the large scale computations to extend the wind field computations into smaller areas without any available wind data is an effective and useful technique.

(vi) Although only preliminary, the applicability of the numerical: method as an aid to understanding the free air flow variation at a specific. wind turbine site was illustrated. Detailed mapping of the probable wind field at very small scales, in conjunction with on-site anemometer tower measurements can be a valuable aid in understanding the mean wind field for the placement of wind instrumentation and wind turbines.

\subsection{Recommendations}

(i) During the performance of the numerical estimates of wind speeds, several high speed areas were identified, but were not investigated further. These areas were identified as being much more extensive in size" than the Goodnoe Hills site and in locations where favorable terrain for the placement of a large number of wind turbines may be found. It is recommended that the following two areas be considered in more detaii in any future siting activities; (a) the area south and west across the colum-" bia Gorge from the Goodnoe Hills site, and (b) the area east and south of Goldendale, Washington.

(ii) The applicability of the numerical method as a viable technique in a generalized wind prospecting and siting methodology was quantified and demonstrated in previous sections of this report. It is therefore recommended that the numerical technique be included as an integral part of any future" wind prospecting, or siting efforts.

(iii) The potential for using the numerical method as an aid to understanding the subtle variations in the wind field at potential wind turbine sites was demonstrated using the Goodnoe Hills wind turbine site as an example. The development of the numerical technique for this application is not complete. Because of the potential value of this application, it is recommended that the development of the numerical technique for understanding the free air flow field at specific wind turbine sites be continued in conjunction with wind turbine experiments being conducted at Goodnoe Hills. 


\section{REFERENCES}

Applications Consultants, Inc. (1979). "Surface Approximations and Contour Mapping Systems (SACM) - User's Guide", 6A30-679, ACI, Bellaire, Tex.

Corotis, R. B., Sig1, A. B., and Cohen, M. P. (1977) "Variance Analysis of Wind Characteristics for Energy Conversion", Journal of Applied Met. (Vo1. 15 (11), November.

Corotis, R. B. (1979) "Statistical Reliability of Wind Power Assessments", Department of Civil Engineering, The Technical Institute, Northwestern University.

Elliott, D. L. and Barchet, W. R. (1980) "Wind Energy Resource Atlas: Vol. 1, The Northwest Region" PNL-3195 WERA-1, UC-60, Battelle Pacific Northwest Laboratory, Richland, Wash.

Fosberg, M. A., Marlatt, W. E., and Krupnak, L. (1976) "Estimating Airflow Patterns Over Complex Terrain", USDA Forest Service Research Paper RM162, Rocky Mountain Forest and Range Experiment Station, Fort Collins, Colo., May.

Hewson, E. W. and Baker, R. W. (1978) "Windpower - Network of Wind Power Over the Pacific Northwest", Report No. BPA 77-2, Oregon State University, Corvalis, Oregon.

Hewson, E. W., Baker, R. W., Barber, D. A., and Peterson, B., (1978) "Network Wind Power Over the Pacific Northwest - Executive Summary", Report No. BPA 78-3, Oregon State University, Corvalis, Oregon.

Hewson, E. W., Wade, J. E., and Baker, R. W. (1979). "A Handbook on the Use of Trees as an Indicator of Wind Power Potential - Final Report", RLO/ 227-79-3, Oregon State University, Corvalis, Oregon.

Justus, C. G. (1978) Winds and Wind System Performance, the Franklin Institute Press, Philadelphia, $\mathrm{Pa}$.

Pacific Northwest River Basin Commission (1968), Climatological Handbook: Columbia Basin States, Vol. 3, part A, Meteorology Committee, June.

Veenhuizen, S. D. and Lin, J. T. (1979) "Wind Resource Assessment in the Olympic Peninsula and the North Cascades", Proc. Solar '79 N.W., p. 19, Seattle, Wa., Aug 10-12.

Veenhuizen, S. D., L1n, J. T., and Yamagiwa, A. T. (1980) "Wind Resource Assessment in the Upper Skagit River Valley of Washington", Proc. 15th Intersociety Energy Conversion Engineering Conference on "Energy to the 21st Century", Seattle, Wash, Aug. 18-22.

Wood, M. C., Childs, J. E., and Marlatt, W. E. (1979) "Assessing the Air Pollution Carrying Capacity of the Northern Puget Sound Region: An Application of TAPAS", Marlatt \& Associates, Fort Collins, Colo., May. 
Appendix A

"Estimating Airflow Patterns Over Complex Terrain" by Fosberg, et. at. (1976) 


\title{
Estimating Airflow Patterns Over Complex Terrain
}

\author{
Michael A. Fosberg, William E. Marlatt, \\ and Lawrence Krupnak
}

\section{Introduction}

Land managers are increasingly faced with problems requiring quantitative estimates of airflow patterns over complex terrain. Use of the wind information may range from potential air quality analysis for land use planning to predicting spread of actual wildfires. Areas in which such analysis is required are typically mountainous. Nearly always, evaluation is severely hampered by a single problem-lack of data, particularly wind data.

For these reasons, a method of determining boundary layer flow patterns is needed as an alternative to expensive data networks.

Boundary layer flow over complex terrain cannot currently be numerically modeled with complete fluid and thermodynamic equations. Accuracy and quantity of the initial data fields required for complete solution only shift the problem back to need for expensive data networks (Fosberg 1967, 1969). While these costs and efforts may be worthwhile in special locations and for specific problems, flexibility in geographic location and timeliness of solutions are sacrificed. We feel that an alternative procedure is required for wind pattern analysis which provides geographic flexibility and does not require sophisticated, expensive data networks. Such solutions cannot include all atmospheric processes, however. The governing equations must be simplified and some important effects must be represented by parameterized analogs.

A model of this type is based on tradeoffs between simplified solutions and preservation of realistic results. Several models of thermal and terrain-induced perturbation of near-ground flow have been developed recently. Anderson (1971) and Lantz ${ }^{4}$ developed single layer models of twodimensional potential flow over terrain features. Anderson (1971), Fosberg et al. (1972), and Fosberg ${ }^{5}$ examined the thermally driven flow disturbances. These studies were all based on the philosophical argument that major simplification of the equations was acceptable, and that the dis. turbed flow field could be superimposed on a mean flow field. While superficially attractive, these preliminary models did not evaluate the consequences of the simplifications, nor did they provide quantitative arguments supporting neglect of specific processes.

Each of the models describes a single layer of finite depth, depicts a quasi-horizontal slab, and treats body forces as an impulse acceleration. The models also require the flow to be statically stable. either as an incompressible fluid or through the hydrostatic assumption. Superposition of disturbed flows on the mean flow also implies limitations on the processes that can be modeled. Im. pulse accelerations tacitly imply that a model is intended as a diagnostic tool rather than a timedependent predictive model. Also, these models generally neglect or highly linearize the advection terms in the dynamic equations.

The highly idealized treatment of the advection term is probably the most serious of the assumptions. Justification is provided partially by examination of the energy integrals in Fos-

${ }^{4}$ Lantz, R. B. 1972. Application of a three dimensional numerical model to air pollution calculations. Preprint of paper presented at 65th Annu. Meet. Air Pollution Control Assoc., Miami Beach. Fla., June 18-22, $22 p$.

${ }^{5}$ Fosberg. Michael A. (in press). New technology for deter mining atmospheric influence on smoke concentrations. Proc. Int. Symp. on Air Quality and Smoke from Urban and For. Fires, 1973. $11 \mathrm{p}$. 
berg's $(1967,1969)$ analysis of flow over single ridges. Conversion of potential energy to kinetic energy dominates the kinetic energy budget. The advective redistribution of kinetic energy and the viscous dissipation are about an order of magnitude smaller. While these energy budget comparisons do not fully justify neglect of the advective processes, they do show that the assumption does not invalidate the models, but only restricts interpretation of the results.

In general, this class of airflow models excludes the small-scale physical situations in which transient or highly interactive processes such as gravity waves or unstable thermal convection dominate the flow field. Also, because of the restrictions imposed on the advection terms, downwind wake effects are not properly represented.

Use of these simplified models-rather than complex and complete solutions or as a substitute for extensive field studies-becomes attractive when extensive data are not available, or in land use planning where alternatives may be great, the time span for planning short, and the accuracy or costs of more physically precise solutions and studies unwarranted.

The model described in this paper is intended to meet these applied objectives. This model is based on simplified solutions of the complete equations. It is philosophically identical to the preliminary models, but combines more of the physical processes.

\section{Structure of the Model}

The mathematical model is based on the terrain-induced flow processes derived by Anderson (1971) and the thermally induced flows described by Fosberg et al. (1972). In addition, the frictional terms are included in the model. Anderson's model was based only on a form of the diver. gence equation, while the Fosberg et al. (1972) model was based only on the vorticity equation. The model developed here is developed from both equations.

The advection terms were neglected in both previous equations. The consequences of this: assumption are that the equations were simplified at the expense of losing a complete physical description of the dynamic processes. Thermally, frictionally and terrain-induced flows were superimposed on a background potential flow across the computational boundaries. Each of these disturbances was assumed to take place only within the computational area. Superposition of disturbances on the background flow, after ne- glecting advection terms, is physically analagous to an impulse acceleration. The diagnostic nature of the model was achieved by allowing the impulse to act over a small, finite time interval defined by phase velocities of disturbances. Flow following the ground surface was obtained by a coordinate transform. A rigid upper surface above the terrain was assumed in order to define the top of the atmospheric slab.

Procedures for solving the equations involve serial approximations which superimpose a new physical effect on the previous solution. The first step in the solution was to transfer the large-scale background wind into a terrain-induced modifica. tion of the throughflow. This step provided a local throughflow wind.

Next, thermal and frictional modification of the vorticity and divergence were introduced. These changes were superimposed on the terraininduced flow. Finally, stream functions and velocity potentials were calculated so that the windspeed and direction could be defined at all interior points.

\section{Throughflow Representation}

Total airflow through the computation field was required to satisfy conservation of mass. Since the lower surface of the layer was mountainous, provisions had to be made for local channeling and deflection. Throughflow characteristics were calculated from the steady-state mass continuity equation as outlined by Anderson (1971). Vertical integration and use of the anelastic approximation permitted local velocities to be approximated from the overall wind field and terrain features. The steady-state continuity equation is: ${ }^{6}$

$$
\nabla \cdot \rho \underset{\sim}{v}=-\frac{\partial(\rho w)}{\partial z}
$$

In this equation, $\boldsymbol{\nabla}$ is the horizontal gradient operator, $\rho$ is density, $v$ is the velocity vector, and $w$ is the vertical motion, positive upward.

Vector coordinates used in the mathematics are west to east in the $\mathrm{x}$ direction, south to north in the $y$ direction, and vertically as $z$.

The anelastic approximation, where kinematic influences on density are negligible compared to thermodynamic influences, was first applied to the equation:

$$
\bar{\rho} \nabla \cdot \underline{v}=-\frac{\partial(\rho w)}{\partial z}
$$

${ }^{6}$ See appendix for a complete description of notations used in the equations. 
Bars over a variable indicale a mean value for the slab. The equation was then integrated over the depth of the layer between the ground $(\mathrm{h})$ and the top of the slab (H).

$$
\bar{\rho} \int_{h}^{H} \nabla \cdot \underset{\sim}{v} d z=-\int_{h}^{H} \frac{\partial(\rho w)}{\partial z}
$$

Horizontal divergence was defined as $\delta=\nabla \cdot \underline{y}$ so that the integral equation was solved as:

$$
\bar{\rho} \bar{\delta}(H-h)=-\rho w(H)+\rho w(h)
$$

through the mean value theorem. A rigid lid was assumed, so $\rho \mathrm{w}(\mathrm{H})$ became zero. Vertical motion near the ground was assumed to be dominated by orographic lifting. The horizontal divergence of the mean wind field then became:

$$
\bar{\delta}=\frac{\rho}{\rho} \underset{\sim}{v} \cdot \frac{\nabla h}{(H-h)}
$$

Terrain modification of the large-scale flow could then be calculated from the channeling and deflection of this flow, and could provide a first approximation of the local wind.

\section{Thermal and Frictional Influences}

Modification of the wind field produced by thermal acceleration and retardation required invoking the assumptions associated with the advection terms of the complete equations. Frictional influences were included as spatial variations of idealized and parameterized solutions relating surface characteristics to the wind profile. The fundamental procedure was to: (1) derive the complete divergence and vorticity equations, (2) judiciously neglect the advective terms, (3) allow full influence of the thermal terms, and (4) utilize classic frictional solutions.

The procedure required for inclusion of these body forces was to define the thermal and frictional solutions in terms of the Navier-Stokes equations. The first step was to express the divergence equation utilizing these assumptions. Divergence was obtained through:

$$
\nabla \cdot \frac{\mathrm{d} v}{\mathrm{dt}}=\frac{\partial \delta}{\partial t}=\nabla \cdot\left(-c_{p} \theta \nabla p_{\star}\right)+\nabla \cdot\left(K \nabla^{2} \underset{\sim}{v}\right)
$$

where $\theta$ is the potential temperature, $p_{*}$ is the pressure variable defined as $p_{*}=T / \theta$, and $K$ is the turbulent viscosity. The friction term was simplified to:

$$
\nabla \cdot K\left(\frac{\partial^{2} v}{\partial z^{2}}\right)=K\left(\frac{\partial^{3} u}{\partial x \partial z^{2}}+\frac{\partial^{3} v}{\partial y \partial z^{2}}\right)
$$

since the horizontal dissipation terms are small compared to the vertical terms when expressed in finite-difference mesoscale models. A parameterized form of the dissipation was obtained from the logarithmic wind profile near the ground. The wind profile for an adiabatic surface layer (Sutton 1953) is:

$$
\frac{\partial u}{\partial z}=\frac{u_{\star}}{k Z} \text { and } \frac{\partial v}{\partial z}=\frac{v_{\star}}{k Z}
$$

where $u_{*}$ and $v_{*}$ are the friction velocities and $k$ is the von Karman constant. These two functions were differentiated with respect to $z$ to produce the second derivative. The terms

$$
\frac{\partial^{2} u}{\partial_{z}{ }^{2}}=-\frac{u_{\star}}{k z^{2}} \text { and } \frac{\partial^{2} v}{\partial z^{2}}=-\frac{v_{\star}}{k z^{2}}
$$

were then substituted into the divergence equation. The divergence equation then became:

$$
\begin{aligned}
\frac{\partial \delta}{\partial t}= & -c_{p} \Theta \nabla^{2} p_{\star}-c_{p} \nabla \theta \cdot \nabla p_{\star} \\
& -\frac{k}{k z^{2}}\left(\frac{\partial^{u} \star}{\partial x}+\frac{\partial^{v} \star}{\partial y}\right)
\end{aligned}
$$

Friction velocity was obtained by integrating the wind profile equation for fully rough surfaces. The friction velocities are then:

$$
\begin{aligned}
& u_{\star}=\frac{|\bar{u}| k}{\ln \left(\frac{z+z_{0}}{z_{0}}\right)} \\
& v_{*}=\frac{|\bar{v}| k}{\ln \left(\frac{z+z_{0}}{z_{0}}\right)}
\end{aligned}
$$

where $z_{0}$ is the surface roughness length and $Z$ is the height of the wind above ground.

Rotational flow characteristics were introduced through the vorticity equation. Using the same assumptions for this derivation as were 
used in the development of the divergence equation, the vorticity equation became:

$$
\begin{aligned}
\mathbf{k} \cdot \nabla \mathbf{x} \frac{\mathrm{dv}}{\mathrm{d} t}= & \frac{\partial \zeta}{\partial t}=-c_{p} \frac{\partial\left(\Theta, p_{\star}\right)}{\partial(\mathrm{x}, \mathrm{y})} \\
& -(\zeta+f) \delta-\frac{\mathrm{k}}{\mathrm{k} \mathrm{Z}^{2}}\left(\frac{\partial \mathrm{v}_{\star}}{\partial \mathrm{x}}-\frac{\partial \mathrm{u}_{\star}}{\partial \mathrm{y}}\right)
\end{aligned}
$$

The divergence and vorticity equations are time-dependent and therefore must be integrated. Divergence was integrated directly through the mean value theorem over an arbitrary time interval. Since little is known about the rate of change of divergence, a square wave impulse of interval $\Delta t_{\delta}$ was assumed. The integrating time factor then became $1 / 2 \Delta t_{\delta}$ when the magnitude of the acceleration was assumed to be $1 / 2$ the observed or maximum value. Divergence was then:

$$
\begin{aligned}
\delta=\frac{1}{2} \Delta t \delta & {\left[-c_{p} \theta \nabla^{2} p_{*}-c_{p} \nabla \Theta \cdot \nabla p_{*}\right.} \\
& \left.-\frac{k}{k z^{2}}\left(\frac{\partial u_{\star}}{\partial x}+\frac{\partial v_{\star}}{\partial y}\right)\right]+\bar{\delta}
\end{aligned}
$$

Given this solution, the vorticity equation became the ordinary differential equation of:

$$
\begin{aligned}
\frac{\partial \zeta}{\partial t}+\zeta \delta=-c_{p} \frac{\partial\left(\Theta, p_{*}\right)}{\partial(x, y)}-f \delta \\
\quad-\frac{k}{k z^{2}}\left(\frac{\partial v_{\star}}{\partial x}+\frac{\partial u_{\star}}{\partial y}\right)
\end{aligned}
$$

The solution is:

$$
\begin{array}{r}
\zeta=e^{-\int \delta d t} \int\left[-c_{p} \frac{\partial\left(\Theta, p_{\star}\right)}{\partial(x, y)}-f \delta\right. \\
\left.-\frac{k}{k z^{2}} \cdot\left(\frac{\partial v_{\star}}{\partial x}-\frac{\partial u_{\star}}{\partial y}\right)\right] \exp (\delta \delta d t) d t \\
+c e^{-\int \delta d t}
\end{array}
$$

Again, an impulse of finite time interval $\Delta t_{\zeta}$ was assumed, so that the mean value integration gave:

$$
\begin{gathered}
\zeta=\exp \left(-\frac{1}{2} \delta \Delta t_{\zeta}{ }^{\frac{1}{2} \Delta t} \zeta\right. \\
{\left[-c_{p} \frac{\partial\left(\Theta, p_{\star}\right)}{\partial(x, y)}-f \delta-\frac{k}{k z^{2}}\left(\frac{\partial v_{\star}}{\partial x}-\frac{\partial u_{\star}}{\partial y}\right)\right]} \\
\exp \left(\frac{1}{2} \delta \Delta{ }_{\zeta}\right)+c e^{-\delta \Delta t / 2} \zeta
\end{gathered}
$$

The arbitrary time intervals for the divergence and vorticity were defined in terms of phase velocities. Because a rigid lid was used as an upper boundary for the calculation and an anelastic approximation was used for compressibility, the phase velocity for divergence was taken as the speed of sound. This gave a time interval of:

$$
\Delta \mathrm{t}_{\delta}=\frac{\sec \Delta}{300 \mathrm{~m}}
$$

where $\Delta$ is the minimum distance between computational points. Phase velocities for vorticity were taken to be the large-scale windspeed, so that the time interval for vorticity was:

$$
\Delta t_{\zeta}=\frac{\Delta}{\left(u^{2}+v^{2}\right)^{\frac{1}{2}}}
$$

For typical distances of 1 to $10 \mathrm{~km}$ between computational points and windspeeds of 1 to $10 \mathrm{~m}$ per second, the time interval is of the order of 1.000 seconds. Divergence at the mesoscale is typically $10^{-5}$ to $10^{-3}$ per second. These magnitudes sug. gested the exponential term in the vorticity equation should be approximately one, except under condition of light winds and large grid spacing. The constant of integration was then taken to be the large-scale flow vorticity. The vorticity then became:

$$
\begin{aligned}
\zeta=\frac{1}{2} \Delta t \zeta & {\left[-c_{p} \frac{\partial\left(\Theta, p_{\star}\right)}{\partial(x, y)}-f \delta\right.} \\
& \left.-\frac{k}{k z^{2}}\left(\frac{\partial v_{\star}}{\partial x}-\frac{\partial u_{\star}}{\partial y}\right)\right]+\zeta_{0}
\end{aligned}
$$

Equations (1) and (6) for the frictionally, thermally and terrain-induced flow deviations on divergence, and equation (7) for the frictionally and thermally induced flow deviations on rotation, were then used to calculate the wind components. 


\section{Calculation of Local Winds}

Wind components of the flow were calculated in the area by superimposing the terrain, frictional, and thermal deviations on the large-scale wind. The wind deviations were obtained by separating the flow into an irrotational divergent component and a nondivergent rotational component. The divergent flow was described with a velocity potential and the rotational component with a stream function. The deviation velocity was then:

$$
\underline{v}=\underset{\sim}{k} \nabla \psi+\nabla \phi
$$

where $\psi$ is the stream function and $\phi$ is the velocity potential. The vorticity is:

$\zeta=\mathrm{k} \cdot \nabla \mathbf{x} \underset{\sim}{\mathrm{k}}=\nabla \underset{\sim}{\mathrm{k} x} \nabla \psi+\underset{\sim}{\mathrm{k}} \cdot \nabla \mathbf{x} \nabla \phi=\nabla^{2} \psi$

and the divergence is:

$$
\delta=\nabla \cdot \underset{\sim}{v}=\nabla \cdot \underset{\sim}{\mathrm{k}} \mathbf{x} \nabla \psi+\nabla \cdot \nabla \phi=\nabla^{2} \phi
$$

Since the vorticity and divergence were known from equations (1), (6), and (7), the stream function and velocity potential could be obtained from a numerical solution of the elliptical differential equations (8) and (9). Decomposing the velocity into the west-east component and the south-north component, and superimposing the background flow, the velocities are:

$$
u=u_{0}+\frac{\partial \phi}{\partial x}-\frac{\partial \psi}{\partial y}
$$

and

$$
v=v_{0}+\frac{\partial \phi}{\partial y}+\frac{\partial \psi}{\partial x}
$$

where $u_{0}$ and $v_{0}$ are the background velocities.

\section{Flow Near the Ground Surface}

Airflow along the terrain surface is of much more interest in fire or air-quality studies than flow at some fixed elevation. Since the equations require calculations to be made on a flat horizontal surface, transformations from the horizontal plane to the terrain surface are necessary.

Data required by the model are observed at a fixed height above the ground (generally between 1 and $3 \mathrm{~m}$ ) so the transforms chosen were to restructure the observed data to a flat surface locally, and then to consider the model as being composed of a series of adjacent horizunlal suifaces, each of slightly different elevation based on the elevation of the local terrain. The coordinate transform required expressing the derivations of the variables observed on the terrain surface as though they were along a horizontal surface. If vertical variations of the variables are known, the transform for any quantity, $S$, is then:

$$
\left.\left.\left.\frac{\partial S}{\partial x}\right)_{E}=\frac{\partial S}{\partial x}\right)_{T}-\frac{\partial S}{\partial z} \frac{\partial h}{\partial x}\right)_{T}
$$

where the unsatisfied parentheses indicate derivations taken along either constant elevation or along the terrain surface.

Second derivations were obtained similarly as:

$$
\begin{aligned}
\left.\frac{\partial^{2} s}{\partial x^{2}}\right)_{E}= & -2 \frac{\partial^{2} S}{\partial x \partial z} \frac{\partial h}{\partial x}-\frac{\partial S}{\partial z} \frac{\partial^{2} h}{\partial x^{2}} \\
* \star & +\left(\frac{\partial h}{\partial x}\right)^{2} \frac{\partial^{2} s}{\partial z^{2}}
\end{aligned}
$$

The higher order terms involving derivatives of the terrain are small compared to the linear term. Six separate derivatives of the thermal characteristics are required by the vorticity and divergence equations. These are the first derivative of potential temperature and pressure, and the second derivative of pressure in the cardinal directions.

Vertical variations of these thermodynamic variables are required. These were obtained first for potential temperature through static stability for a hydrostatically balanced atmosphere as:

$$
\begin{aligned}
& \left.\left.\left.\frac{\partial \Theta}{\partial x}\right)_{E}=\frac{\partial \Theta}{\partial x}\right)_{T}-\theta \sigma \frac{\partial h}{\partial x}\right)_{T} \\
& \left.\left.\left.\frac{\partial \Theta}{\partial y}\right)_{E}=\frac{\partial \Theta}{\partial y}\right)_{T}-\theta \sigma \frac{\partial h}{\partial y}\right)_{T}
\end{aligned}
$$

where $\sigma=\frac{1}{\theta} \frac{\partial \theta}{\partial z}$.

Vertical decrease of pressure was represented by hydrostatic equilibrium:

$$
\frac{\partial p_{\star}}{\partial z}=-\frac{g}{c_{p} \Theta}
$$

$$
\text { ** } \frac{\partial^{2} S}{\partial x^{2}}
$$


Utilizing these relationships, the pressure derivatives are:

$$
\begin{aligned}
& \left.\left.\left.\frac{\partial p_{\star}}{\partial x}\right)_{E}=\frac{\partial p_{\star}}{\partial x}\right)_{T}+\frac{g}{c_{p} \theta} \frac{\partial h}{\partial x}\right)_{T} \\
& \left.\left.\left.\frac{\partial p_{\star}}{\partial y}\right)_{E}=\frac{\partial p_{\star}}{\partial y}\right)_{T}+\frac{g}{c_{p} \theta} \cdot \frac{\partial h}{\partial y}\right)_{T} \\
& \left.\left.\left.\frac{\partial^{2} p_{\star}}{\partial x^{2}}\right)_{E}=\frac{\partial^{2} p_{\star}}{\partial x^{2}}\right)_{T}-2 \frac{g}{c_{p} \theta^{2}} \frac{\partial h}{\partial x} \frac{\partial \theta}{\partial x}\right)_{T} \\
& \left.\left.\left.\frac{\partial^{2} p_{\star}}{\partial y^{2}}\right)_{E}=\frac{\partial^{2} p_{\star}}{\partial y^{2}}\right)_{T}-2 \frac{g}{c_{p} \theta^{2}} \frac{\partial h}{\partial y} \frac{\partial \theta}{\partial y}\right)_{T}
\end{aligned}
$$

Horizontal derivatives of the friction velocities remain unchanged, since the model is designed for use in the constant flux layer where they are constant in the vertical. This shallow layer assumption then gives:

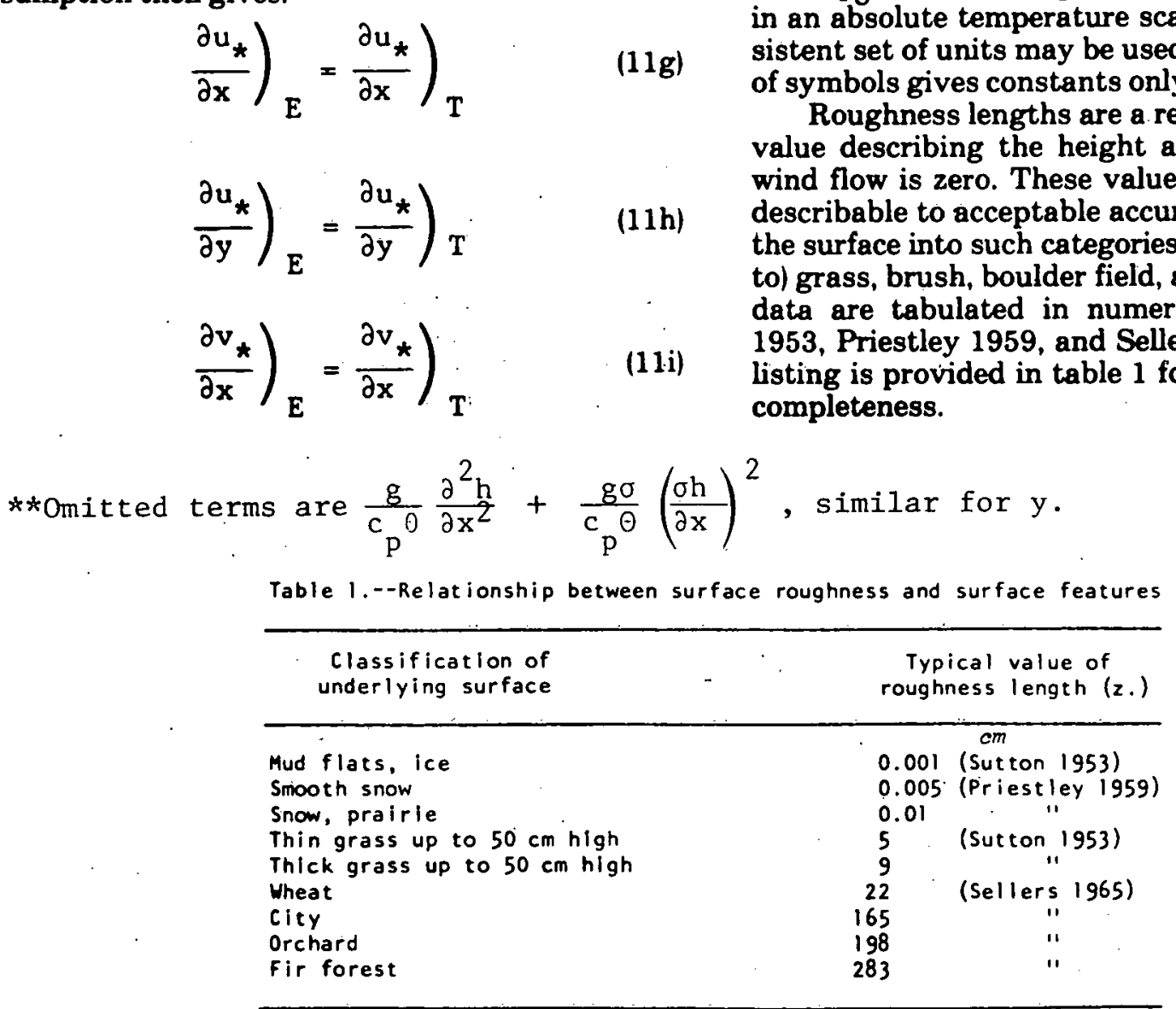

$$
\left.\left.\frac{\partial v_{\star}}{\partial y}\right)_{E}=\frac{\partial v_{\star}}{\partial y}\right)_{T}
$$

These linear coordinate transforms neglect the small changes in the grid spacing due to slope distances projected to the horizontal grid.

\section{Data Requirements and Solution Procedure}

* * Specific data required by the model are temperature, pressure, elevation, and roughness length of the underlying surface for all computational points. Temperature and pressure data are transformed thermodynamically to model variables by:

$$
\theta=\frac{T}{p_{\star}}
$$

and

$$
\mathrm{P}_{\star}=\left(\frac{\mathrm{p}}{\mathrm{p}_{\mathrm{o}}}\right)^{\frac{\mathrm{R}}{\mathrm{C}_{\mathrm{p}}}}=\left(\frac{\mathrm{p}}{\mathrm{p}_{\mathrm{o}}}\right)^{0.2857}
$$

where $p_{0}$ is a reference pressure and $T$ is expressed in an absolute temperature scale. While any consistent set of units may be used, the appendix list

Roughness lengths are a reasonably constant value describing the height at which the mean wind flow is zero. These values are conveniently the surface into such categories as (but not limited to) grass, brush, boulder field, and so forth. These data are tabulated in numerous texts (Sutton 1953, Priestley 1959, and Sellers 1965); a sample listing is provided in table 1 for convenience and completeness. 
Since the model was designed for use in moderately small areas of finite size, several singlevalued coefficients are required to complete the model. Most important of these are the static stability and the large-scale wind direction and windspeed. The large-scale winds were specified as the geostrophic wind. Less important coefficients are the eddy viscosity, the latitude (if the geographic scale of a particular solution is large so that the earth's rotation is important), and the large-scale vorticity (if strong curvature exists in the large-scale flow).

Wind patterns are calculated from a sequence of approximations, each refining the previous step by introducing a more refined physical process, and superimposing the refinement on the previous solution. The first step was to transfer the largescale background wind into a major terraininduced modification of the throughflow. This step provided a local throughflow wind.

First, the divergence was calculated through equation (1) for a smoothed terrain. This smoothed terrain was obtained by averaging the four surrounding points with each computational point; the rigid lid was placed well above the terrain in this step. Second, the terrain-induced vorticity was calculated by equation (7) with the thermal and frictional terms neglected. Once these vorticities and divergences were calculated, they were transformed to stream functions and velocity potentials through numerical solutions of equations (8) and (9), and subsequently resolved into velocities by equation (10). These first approximations to the wind field represented the influences of the large terrain feature on the throughflow.

The second level of approximation involved recalculating the terrain-induced divergence for a shallow layer. Divergence was calculated by equation (1) for the actual terrain.

The next step required using the large-scale terrain flow to calculate the friction velocities by equations (4a and $4 \mathrm{~b}$ ) and making the coordinate transforms of equation (11). These intermediate steps provided the input to the final level of approximation.

Friction terms, defined by the friction velocity, and the spatial derivations of temperature and pressure after the coordinate transform were included in the solution of equation (6) for divergence and of equation (7) for vorticity. Background divergence came from the second level of approximation, and the background vorticity came from the divergence and vorticity as in the first step through numerical solutions of equations (8) and (9). Velocity components were then calculated through equation (10), where the background velocities were defined by the first step.

\section{Evaluation of the Model}

\section{Validation}

There are several philosophies of model validation, each designed to accomplish specific objectives. Because this model is intended for use in applied meteorology, we have chosen to use actual data sets from mountain mesoscale studies to validate the wind field estimates. In adopting this approach, we have imposed a severe test since the model is limited in spatial resolution by computational filtering to approximately four times the grid distance, while the validation data have small-scale spatial resolutions defined by nearby terrain or vegetation and sensor response characteristics. Also, calculated winds represent an average wind over an area defined by the grid mesh. Such a test is desirable, however, because it defines operational uncertainty rather than model potential, and represents actual resolution attainable.

Seven data sets were used in the model validation. Six came from studies conducted by Cramer $^{7}$ in the Oregon Cascade Mountains. One data set came from central California (Fosberg and Schroeder 1966). All seven depict daytime conditions: five for midafternoon, and two for morning. One morning case occurred under overcast skies and rain. The other six occurred with strong solar heating. Background winds ranged from 2 to $5 \mathrm{~m}$ per second. The Oregon winds were calculated on a $6 \mathrm{~km}$ square grid, the California case on a $16 \mathrm{~km}$ square grid. Air temperatures were extrapolated to grid points from the field network weather stations.

Evaluation of the errors in both windspeed (fig. 1) and wind direction (fig. 2) demonstrates the utility of the model. The root mean square windspeed error was $2.0 \mathrm{~m}$ per second. Forty-five percent of the calculated windspeeds fell within $1 \mathrm{~m}$ per second of the observed wind, and 75 percent fell within $2 \mathrm{~m}$ per second. These comparisons were made over an observed range of 0.5 to 10.5 $m$ per second. Observed wind directions were reported on a 16-point compass basis. Therefore, the error analysis is presented as a compasspoint error rather than a more precise evaluation

${ }^{7}$ We thank Owen P. Cramer of the U.S. Department of Agriculture, Forest Service, Pacific Northwest Forest and Range Experiment Station, Portland, Oregon for unqualified use of original data for the model validation and for permission to reproduce unpublished results in this paper. 


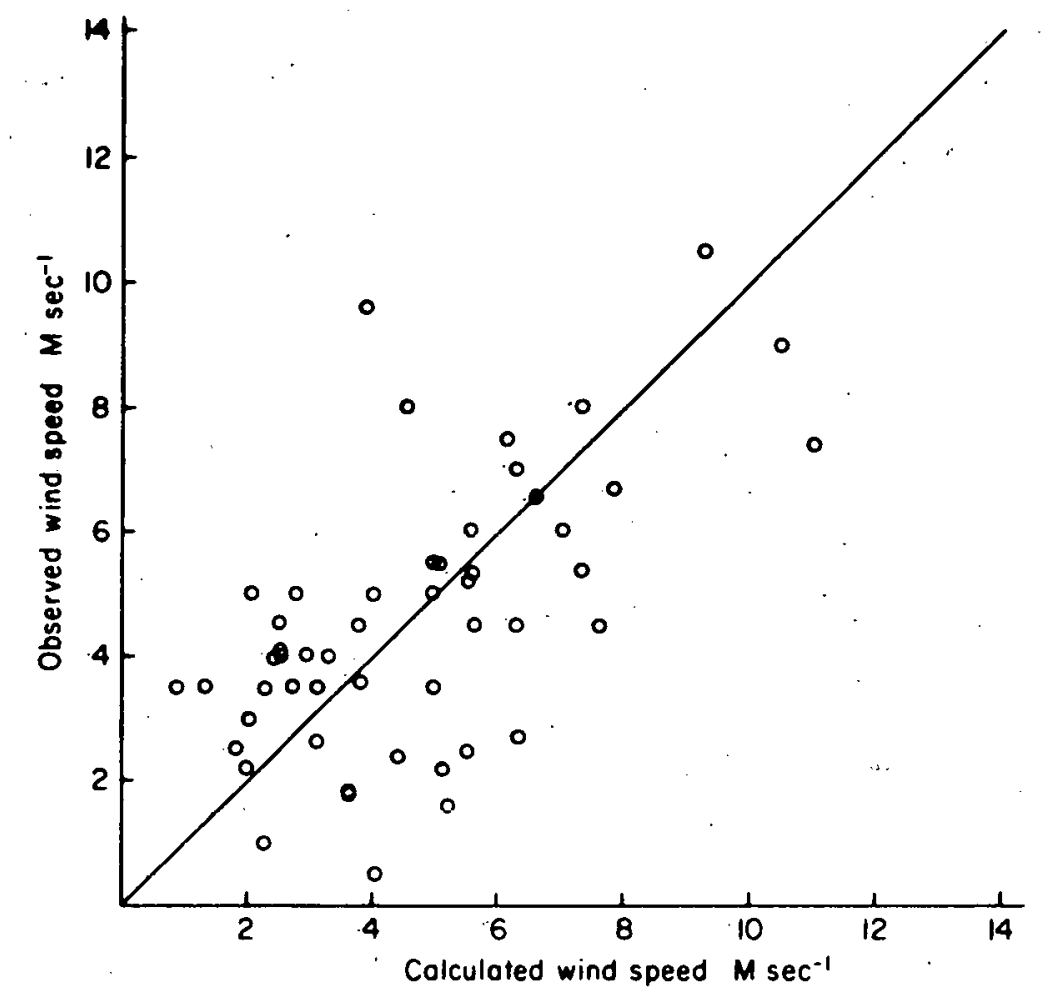

Figure 1-Comparison of calculated and observed windspeeds. Bold diagunal line defines perfect fit. Forty-tive percent of predictions tall within $1 \mathrm{~m} \mathrm{sec}^{-1}$ of the observed windspeed and 75 percent lall within $2 \mathrm{~m} \mathrm{sec}^{-1}$

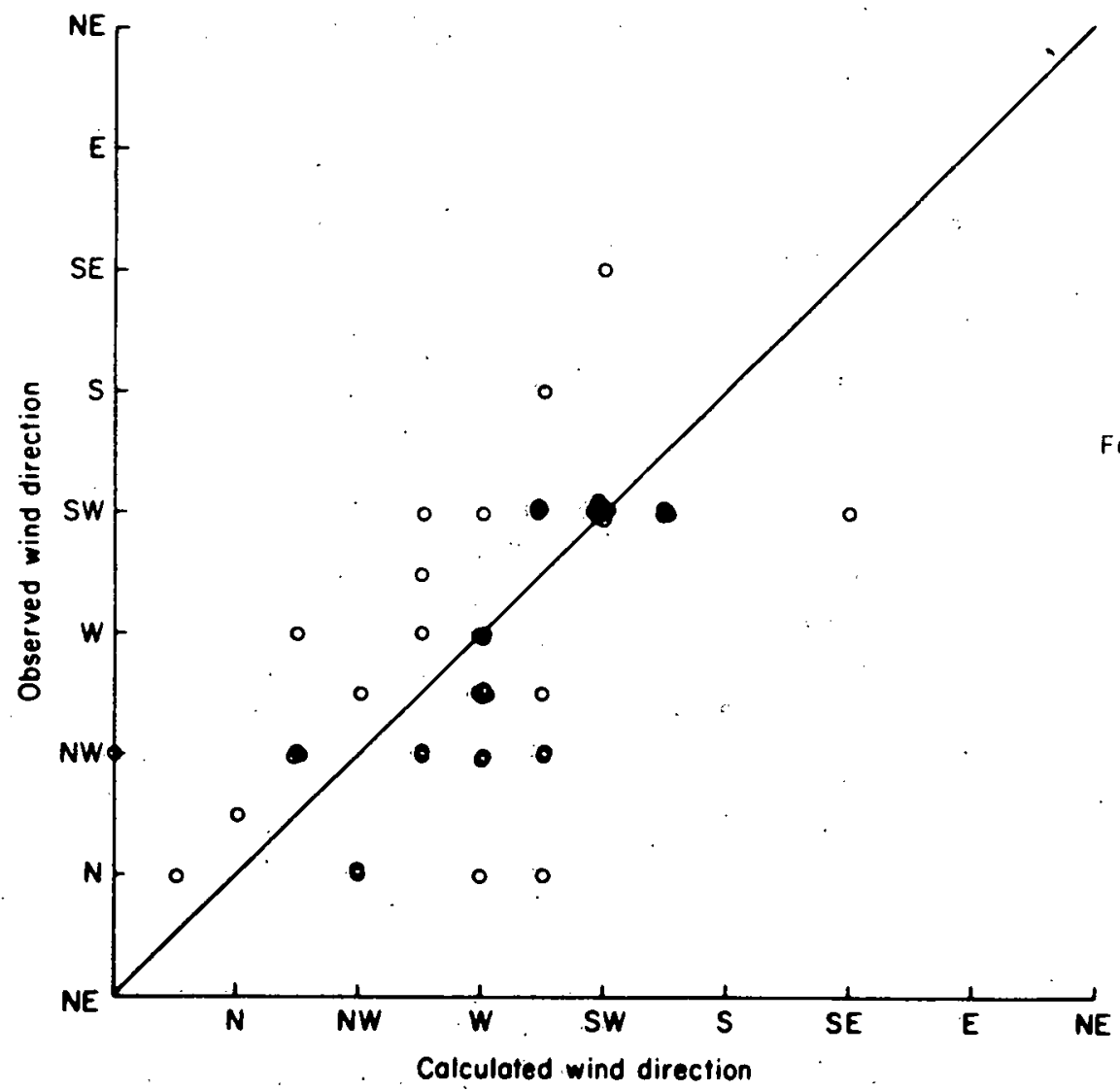

Figure 2.-Comparison of calculaled and observed wind direciion. Comparison is on a 16-poinl compass basis. Sixly pe 1 . cent of calculated direclions fall within 11 degrees and 92 percent tall within 22 degrees of observed direclions 
of angle. The root mean square direction error was 1.9 points. Sixty percent of the calculated directions fell within 1 compass point of the observed direction, and 92 percent fell within a 2-point envelope of the observed direction. Observed directions were from all compass points except for the east and northeast sections.

Models of this type implicitly require a number of specifiable coefficients which tune the model to particular geographic regions. While we have attempted to specify these coefficients through physical arguments, some are still at the discretion of the user. The integration coefficients were totally predetermined. The rigid lid coefficients for potential flow were selected through several criteria. The first was that the terrain could not penetrate the rigid lid. The second was based on a large number of solutions where the lid was systematically varied until a high level of sensitivity was reached. Lid height is based on elevation differences across the grid field. The user guidelines in the climatology section of this paper describe the techniques for determining layer thickness. They are cited here because the consequences are reflected in the error analysis.

\section{Flow Patterns}

Each of the seven cases showed similar dynamic processes (table 2). Thermally and terrainproduced divergence dominated the dynamics of the flow. Divergence-generated flow perturbations were 2.5 to 4.3 times as large as vortically generated deviations. Vortex flow accounted for 11 to 24 percent of total kinetic energy, while 32 to 69 percent was accounted for by the potential flow. Strongest local wind energetics were ob- served under conditions of light background winds and strong surface heating. As background winds increased, or the solar heating decreased, the local winds became a weaker component and less important in the total kinetic energy budget. Tests of background windspeeds for several hypothetical cases beyond the range of data used in validation show that at $0.5 \mathrm{~m}$ per second, the wind patterns are controlled completely by the thermal patterns. At $10 \mathrm{~m}$ per second, thermal control vanished and terrain influences were weak.

Mesoscale flow characteristics are best illustrated through a detailed examination of one of the case studies. The area is in the Oregon Cascades, south of Mt. Hood, north of Mt. Jefferson, and runs from the Willamette Valley across the crest of the Cascade Range to the edge of the eastern Oregon plateau. The mountains are penetrated by a major drainage on the west side, the Clackamas River. The particular case selected, August 8, 1963 at 1600 PST, was chosen as representing a typical or intermediate situation. The synoptic weather pattern was characterized by a weak upper-level, high-pressure area, and west to west-north-west geostrophic surface flow over the Cascades. Details of the observation and analysis procedures were presented in Cramer (1972) and Cramer and Lynott $(1961,1970)$. Discussion here is limited to resultant computations and estimation of the wind field from the analysis. Only salient features of Cramer's analysis are presented here for completeness.

Cramer's data analysis of temperature and $850 \mathrm{mb}$ surface heights were interpolated to $6-\mathrm{km}$ grid points. These data were converted to potential temperature and normalized station pressures for each grid point. Terrain elevation at each grid point was interpolated from a topographic map.

Table 2.--Relationship between flow energetics and weather features

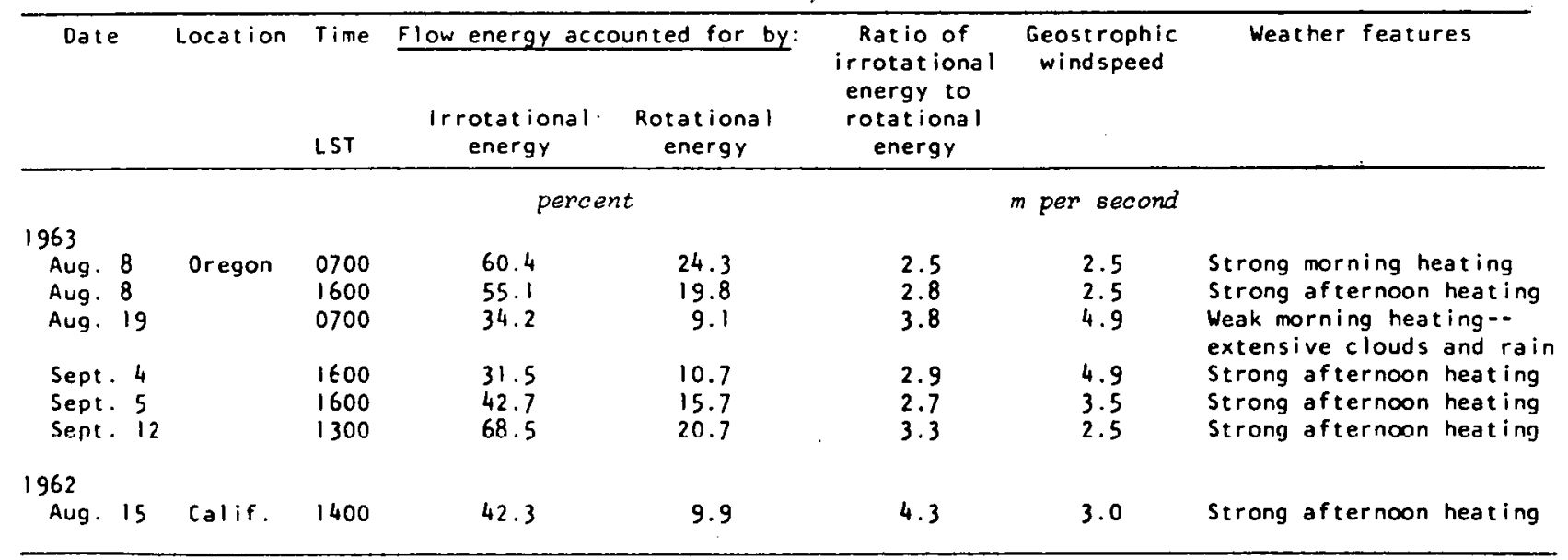


The underlying surface was almost exclusively characterized by conifer forest, so the roughness length was taken as a constant $283 \mathrm{~cm}$.

Temperature distribution (fig. 3) over this terrain generally showed a slight decrease with elevation. West-facing slopes were warmer than east-facing slopes. The major river valley was much warmer than surrounding areas, and provided strong local temperature gradients. In general, the area east of the Cascades was warmest as a result of morning heating and topographic blocking of cool marine air flowing off the Pacific Ocean.

Height of the $850 \mathrm{mb}$ pressure surface (fig. 4) generally reflected the high-pressure area over northwest Oregon. Surface heating of the mountain slopes produced the "thermal low" frequently observed along the West Coast. This "thermal low" appeared as a mesoscale low-pressure area through the higher terrain and modified the largescale pressure pattern.

These observed data were transformed to the thermodynamic variables of potential temperature and normalized nondimensional surface pressure used in the model equations. The $850 \mathrm{mb}$ surface height was reduced to the terrain surface through the hydrostatic equation using the static stability from the Salem, Oregon rawinsonde observation. Once this pressure calculation was made, the potential temperatures were calculated with these pressures and the interpolated temperatures.

Since the dynamic influences due to pressure gradients are completely reflected in the $850 \mathrm{mb}$ pressure surface height, only the potential temperature patterns will be described here (fig. 5). Potential temperature showed a highly organized pattern. Higher elevations had higher potential temperatures. Valleys where cooler marine air could penetrate from the coast were clearly marked by low potential temperature. East-slope highlands had highest potential temperatures.

These observed fields of temperature and pressure were used to calculate the fundamental kinematic characteristics of divergence and vorticity. Divergence patterns were strongly correlated with terrain. Even small topographic features such as narrow ridges and valleys stand out in the divergence patterns (fig. 6). Flow divergence was confined to lowlands and valley bottoms. Convergence zones were on ridgetops and followed the terrain contours. Gentle slopes and large continuous upland areas on the east slopes typically had weak gradients. Magnitudes of the divergence were typically $\pm 10^{-3}$ per second. The convergence areas in regions of rugged terrain were much smaller than divergence areas, and maximum values were two to three times as in- tense as the compensating divergent areas. The intense gradients generated in the rugged terrain were most noticeable between the Clackamas River valley and the surrounding ridges. Areas of moderately changing terrain had divergent and convergent patterns of roughly equal area and intensity.

Vorticity patterns (fig. 7) did not show either the response to small terrain features or the large magnitude found in the divergence fields. Vorticity was typically $\pm 10^{-5}$ per second with the strongest areas only $\pm 10^{-4}$ per second. Ridgetops tended to have anticyclonic relative vorticity of $10^{-4}$ per second while valley bottoms had cyclonic vorticities of $-10^{-4}$ per second. Areas with slowly changing elevation did not show a consistent terrain-vorticity correlation. In general, vorticity tended to have a much longer wave length than divergence. The only generalizations we can make about the patterns are that major ridges tend to favor anticyclonic vorticity, while lowlands and major valleys tend to favor cyclonic vorticity. This characteristic was probably due to the dominant influence of the divergence in flow properties.

Resultant wind fields (fig. 8) showed strong topographic and thermal control of the wind patterns. Airflow in the Clackamas River valley and the other two west-slope watersheds penetrating into the Cascades showed strong topographic channeling up the rivers and the influence of slope winds angling away from the valley axis. Westslope areas away from these major drainages generally showed upslope flow, even on the lee sides. Strongest winds were calculated on high ridgetops and at the heads of canyons as they reached the highlands. Lee effects were most noticeable along the eastern slope. Winds flowing across the ridge in the northeast portion of the area were reduced from $5 \mathrm{~m}$ per second to $1 \mathrm{~m}$ per second by the upslope influences on the lee side. Strong, thermally driven winds were calculated in the south-central and southeastern portion of the area, where prevailing winds were reduced and influences of the penetrating west-slope canyons were negligible. Those variables which had great: est impact on model reliability were determined by sensitivity analysis. Both processes and variables were systematically excluded and error. analysis conducted on all seven cases. This analy: sis indicated that frictional influences and the vorticity equation affected the resultant wind field only slightly. Terrain and thermal influences totally dominated the calculations. Neglect of either created large errors in the wind field in the test cases. Further analysis of these processes indicated that pressure variation could be excluded with introduction of a small error, but that 


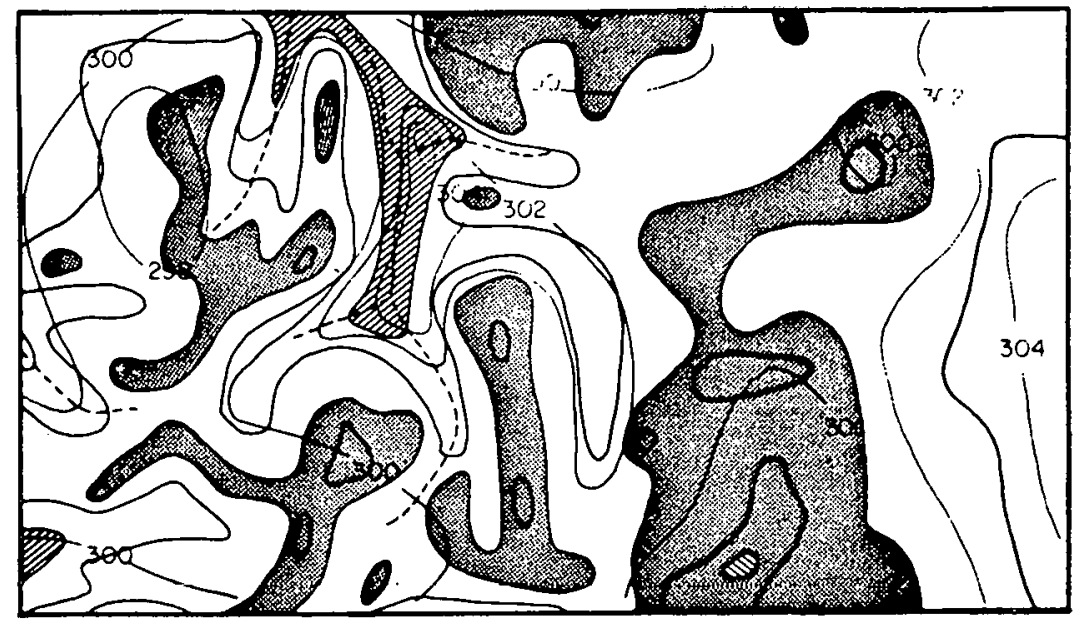

Figure 3.-Temperature field for 1600 PST, August 8, 1963. Temperatures are in degrees $\mathrm{k}$ : warmest areas are on the east slopes of the Cascade Mountains.

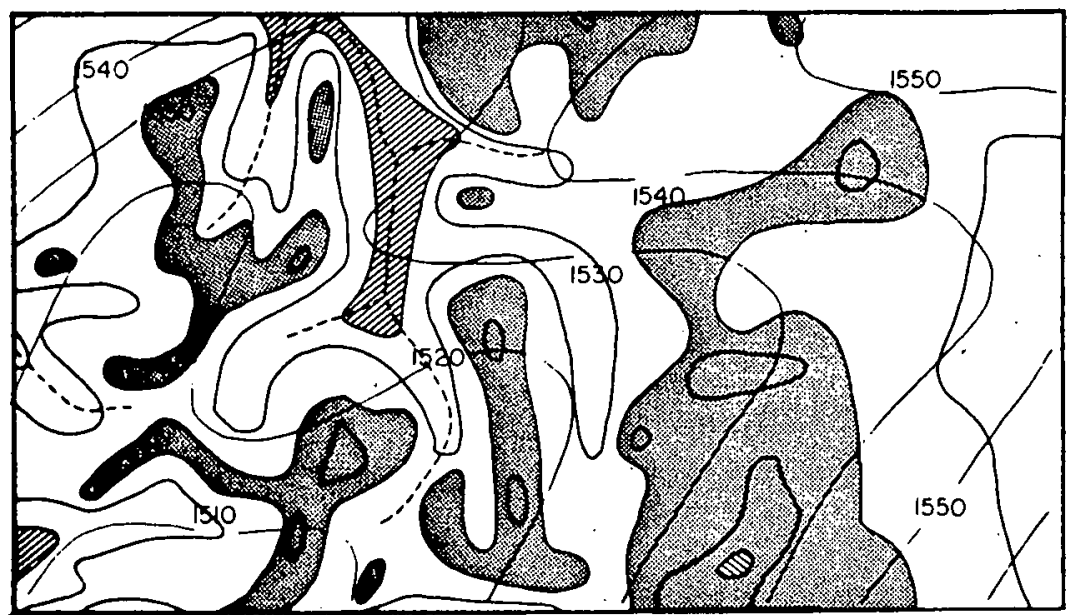

Figure 4.-Height of $850 \mathrm{mb}$ surface for 1600 PST. August 8,1963 . Height is in meters above m.s.l. Thermal trough is oriented southwest to northeast.

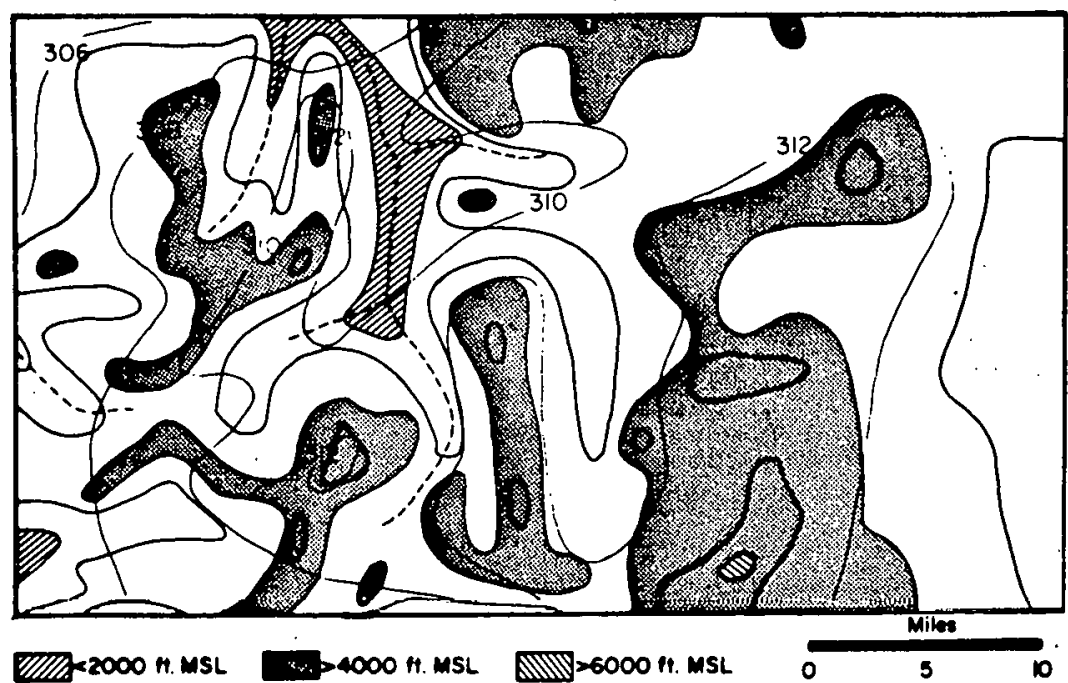

Figure 5.-Distribution of potential temperature for 1600 PST. August 8, 1963. Temperatures are in degrees k. Inversion of marine air into the mountains is confined to the Clackamas River valley. 

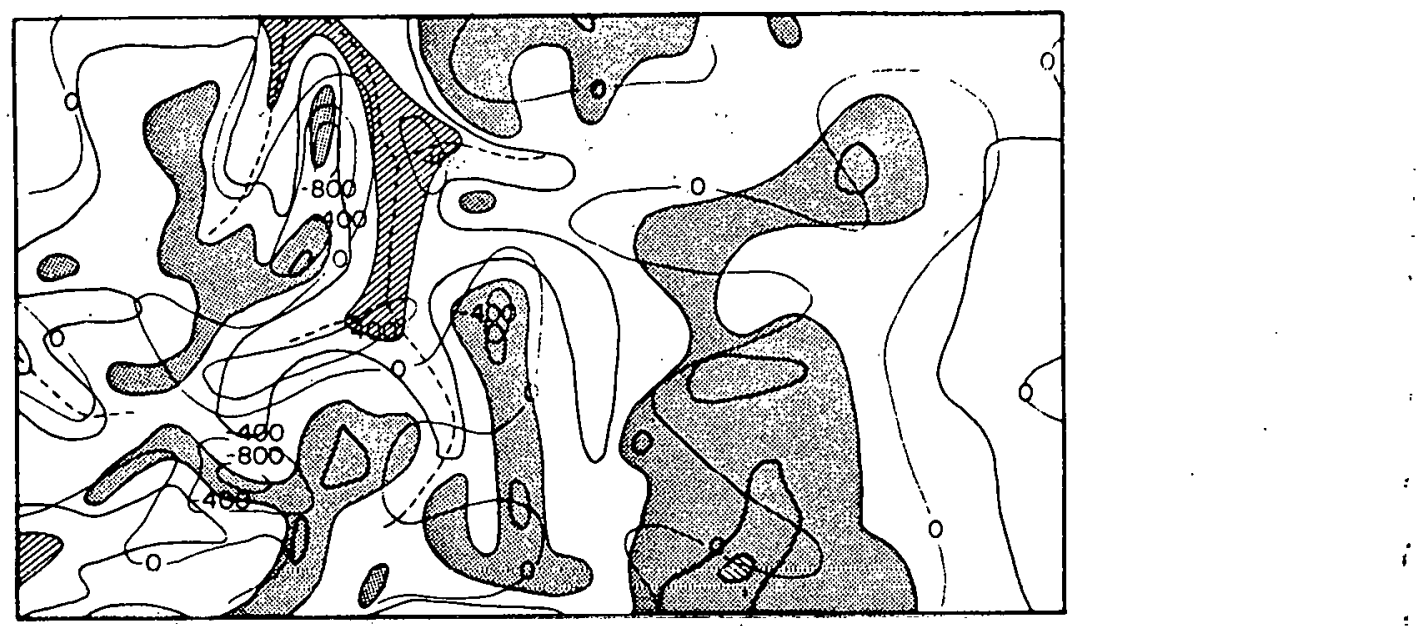

Figure 6. - Horizontal divergence field for 1600 PST, August 8, 1963. (Units are $10^{-5} \mathrm{sec}^{-1}$.) Strongest gradients of divergence are between the west side drainages and the surrounding ridges.

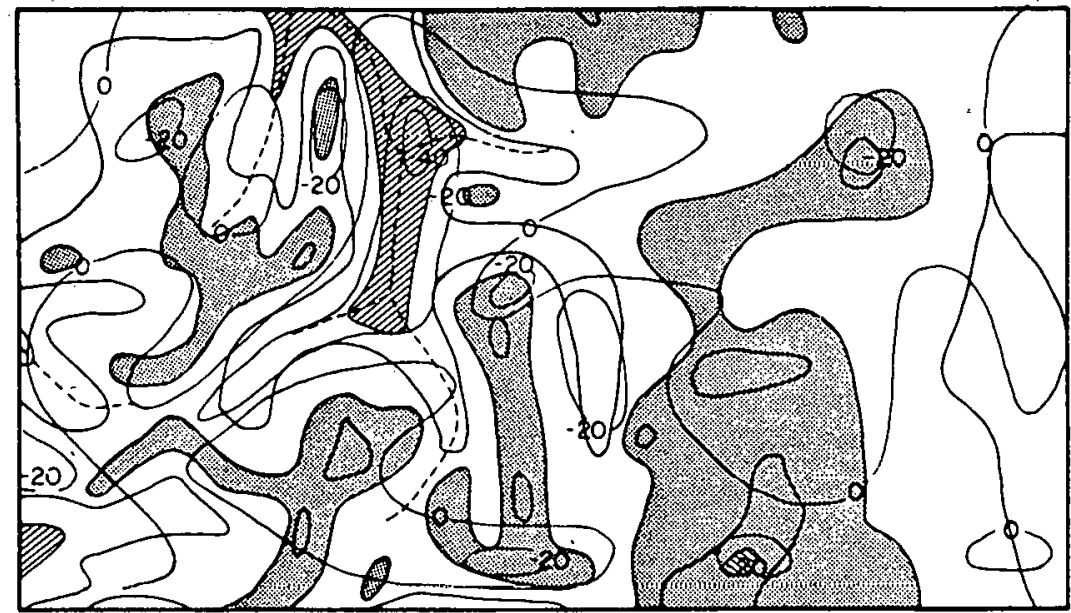

Figure 7.-Vertical component of vorticity for 1600 PST, August 8, 1963. (Units are $10^{-5} \mathrm{sec}^{-1}$.) Anticyclonic vorticity is on ridgetops and cyclonic vorticity is in valleys.

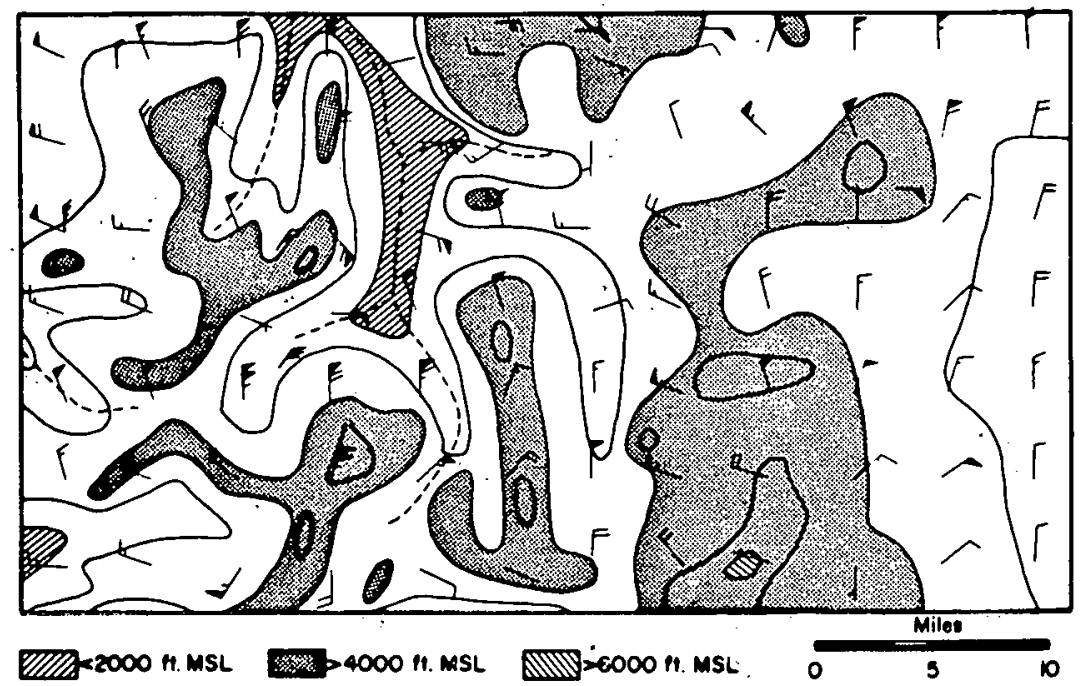

Figure 8:-Calculated and observed wind field for 1600 PST, August 8, 1963. Arrows indicate direction of wind. Speeds are given by sum of barbs and pennants on arrow tails. Pennants indicate $5 \mathrm{~m} \mathrm{sec}-1$; a full barb, $2 \mathrm{~m} \mathrm{sec}^{-1}$; a half barb. $1 \mathrm{~m} \mathrm{sec}-1$. Calculated wind field is in red; observed wind field is in black. 
the topographic and temperature field must be represented in complete detail for the model to provide realistic and verifiable results.

\section{Topography, Climatology, and Winds}

Two parameters are required if the model is to define the topographic influence on throughflow. The first of these, the depth of the rigid lid at the top of the slab, should normally be expected to be 1,500 to $2,000 \mathrm{~m}$ above the spatially smoothed terrain. The second parameter, the thickness of the shallow layer, refines the first estimate of terrain influences. It is 1.25 times the difference between the smoothed terrain and the actual terrain. These guidelines for the relationship between throughflow and terrain were determined from a large number of test cases where the coefficients were varied systematically. The final choice was a judgment of which relationships produced the most acceptable resultant wind field.

Grid point spacing is also related to topographic variations. In rugged terrain, a closely spaced grid is required to resolve the local winds, while in gently rolling terrain, a low-resolution grid will give acceptable wind fields. Guidelines for selecting appropriate grid spacing were developed from procedures similar to those used in evaluating layer thicknesses.

Numerous analyses were carried out with the same data sets so that performance could be evaluated by overall resultant wind field errors. Grid spacings between 1 and $6 \mathrm{~km}$ were evaluated for maximum terrain differences of 300 to $1,500 \mathrm{~m}$. These analyses indicated that grid spacing should be reduced by $1 \mathrm{~km}$ for every increase in terrain range of $300 \mathrm{~m}$. If the terrain within an area $10,000 \mathrm{~km}$ square varies by $300 \mathrm{~m}$ or less between the highest and lowest spatially averaged elevations, then a $6-\mathrm{km}$ grid would be appropriate. If, on the other hand, the terrain variation were $1.500 \mathrm{~m}$ a $1-\mathrm{km}$ grid would be appropriate. These spacings must be modified to the smallest grid spacing if the wind field is intended to be used for fine-scale analysis of pollution patterns or fire spread, or to larger spacing if broad geographic coverage is required. Grid spacing of $500 \mathrm{~m}$ is probably the minimum the model will treat properly. Close grid spacing does not permit a 50 - by 50-point grid to include major terrain features. These two nonmodel dependent factors (terrain complexity and computer resources) must be considered in selecting the grid interval. The spacings specified here represent maximum spacing-not optimum for any particular application.
The seven cases in this analysis all came from detailed mesometeorological research studies. Such intensive data would not normally be available. Detailed temperature patterns can be estimated from climatological relationships developed for slope temperatures. Super and Grainger (1969) and Hayes (1941) made detailed studies of slope temperatures by aspect and time of day. Baker (1944), using maximum and minimum temperatures, characterized the slope temperatures for 20 mountainous areas of the Pacific and Rocky Mountain States. These climatological relationships will approximate the temperature distribution when the available observations and topog. raphy are used to fine tune the slope functions.

\section{Using the Model for Planning - A Case Study}

Consider a case where engineers and architects are designing a new plant at a mine mouth. The mineral extraction process will create a large volume of tailings over a period of years. These tailings could be hot. In the design study the questions are asked: (1) What will be the effect of changing the terrain in the immediate area by filling the gulches and small valleys with tailings on the downwind dispersal of stack contaminants?, and (2) What will be the effect on downwind dispersal if the tailings are approximately $70^{\circ} \mathrm{C}$ warmer than the surrounding areas?

The wind model may be used to estimate probable consequences of the mining activity on pollution dispersal patterns. To illustrate this use, we assumed a light wind of $0.45 \mathrm{~m}$ per second (1 mile per hour) from the southwest; temperature distribution was given by climatology for nighttime conditions. Wind patterns before construction showed well-organized drainage flow into and down the valleys and gulches (fig. 9).

Two cases of land change were simulated to anticipate influence on the local wind patterns. In the first case, the valleys and gulches were filled with heated tailings. Changes in the flow were calculated near the modified landform. Heated areas increased the windspeeds and changed the directions to a uniform south-southwest flow down the major gulch (fig. 10). Airflow in the large river drainage to the north was turned and flowed up canyon. The second case considered was that the same gullies and canyons were filled with tailings, but the tailings were not heated. This modification also increased and organized the drainage flow (fig. 11). Winds were from the southwest over the tailings for this case. How- 


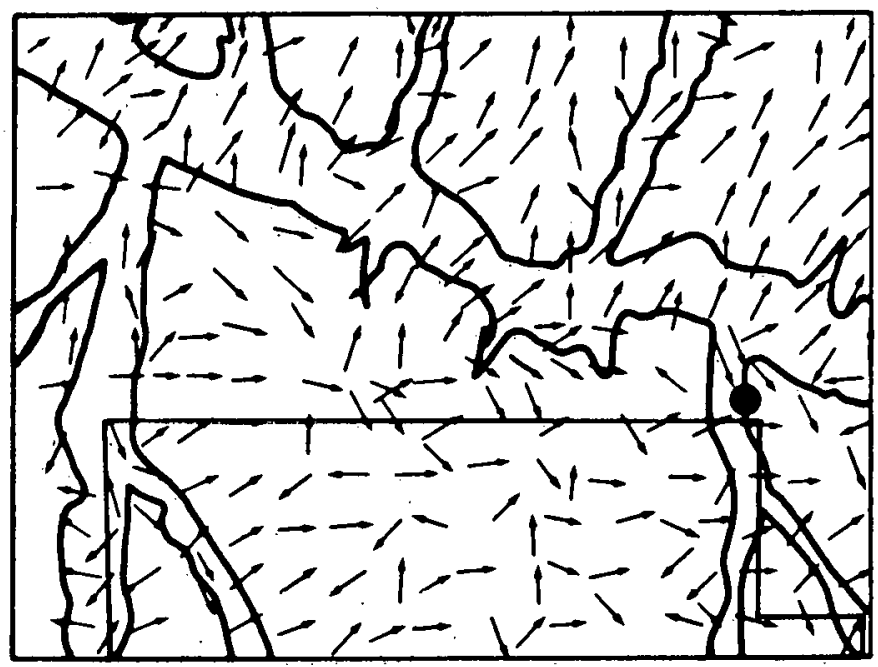

Figure 9.- Local wind pattern betore construction of a hypothelıcal plant and mıne tailings.

Figure 10.-Simulated wind field for a case with neated tallings.

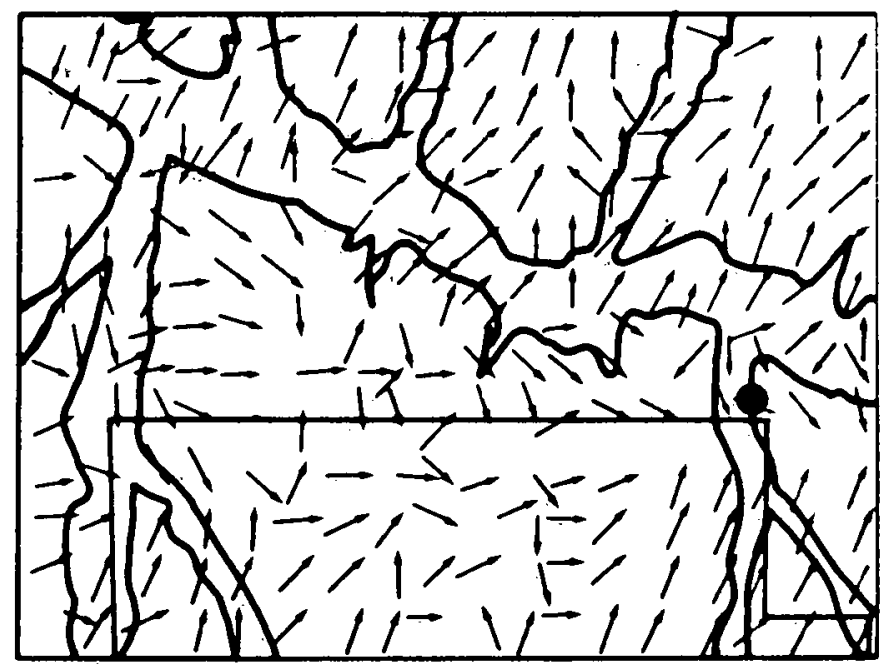

indicates plant and mine site.

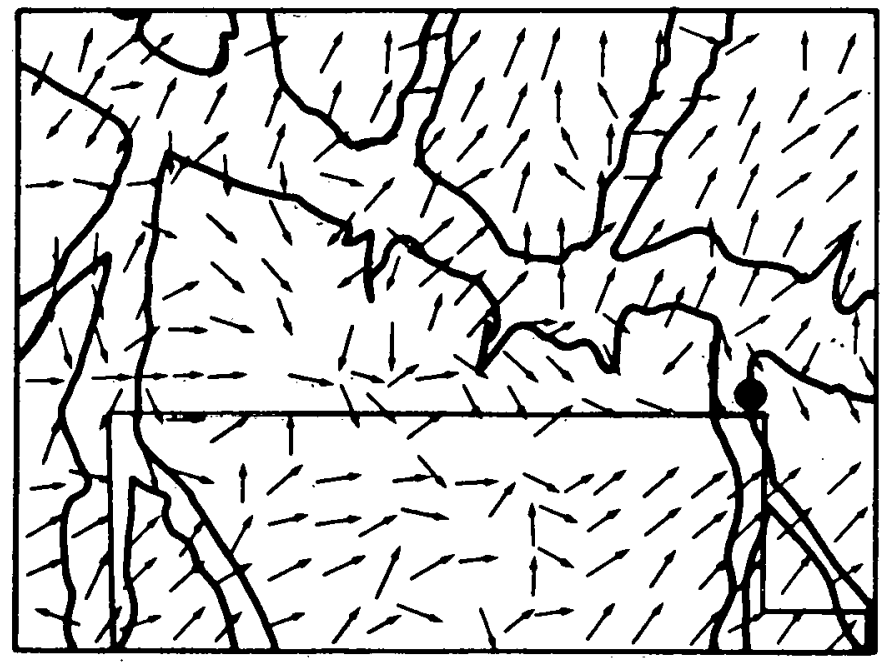

Figure 11. - Simulated wind field for a case with cold tailings. 
ever, air did not flow up the canyon from the major river drainage. The two cases predicted increases in windspeed of as much as $1 \mathrm{~m}$ per second and direction changes of 180 degrees near the planned mine activities.

\section{Summary and Conclusions}

Local thermally driven flows such as mountain and valley winds are simulated reasonably well. Interactions of these local flows, and influence of the larger scale potential flow on these local winds, are also included in the resultant flow. These thermally driven flows are determined properly primarily because the thermal forcing processes are stationary and locked to the terrain features. Also, these thermal features are in a quasi-steady state for several hours. Thus, neglect of the advective process is permissible, and the impulse integration to steady state approximates the flow field.

Thermal modification of potential flow across the terrain features dominates the driving forces. Potential flow was three times as important as rotational flow.

Error analysis of seven case studies and the application example indicated that the model could be used as an aid in fire and air-quality programs because of the low data requirements and the reduced computer effort required.

The wind model developed here was based on simplifications of the complete set of equations governing atmospheric flow over complex terrain. These simplifications imposed several limitations on the use of the model, both in types of flow that can be depicted and in spatial coverage of the solutions. Moving flow systems and flows which are characterized by intermittency or by separation are explicitly excluded, because (1) advection was eliminated, and (2) the model is intended to depict quasi-steady state processes. Coefficients describing static stability and overall wind throughflow place spatial limits on the model because (1) constant static stability prohibits larger scale baroclinicity, and (2) the single-valued wind vector prohibits large-scale flow discontinuity. Also, the neglect of advective processes excludes strong interaction of the mesoscale with larger scales, and does not allow for modification of the downwind environment.

\section{Literature Cited}

Anderson, Gerald E.

1971. Mesoscale influences on wind fields. J. Appl. Meteorol. 10:377-386.

Baker, Fredrick S.

1944. Mountain climates of the western United States. Ecol. Monogr. 14:223-258.

Cramer, Owen P.

1972. Potential temperature analysis for mountainous terrain. J. Appl. Meteorol. 11:44-50.

Cramer, Owen P., and Robert E. Lynott.

1961. Cross section analysis in the study of windflow over mountainous terrain. Bull. Am. Meteorol. Soc. 42:693-702.

Cramer, Owen P., and Robert E. Lynott.

1970. Mesoscale analysis of a heat wave in western Oregon. J. Appl. Meteorol. 9:740-759.

Fosberg, Michael A.

1967. Numerical analysis of convective motions over a mountain ridge. J. Appl. Meteorol. 6:889-904.

Fosberg, Michael A.

1969. Airflow over a heated coastal mountain. J. Appl. Meteorol. 8:436-442.

Fosberg, Michael A., and Mark J. Schroeder.

1966. Marine air penetration in central California. J. Appl. Meteorol. 5:573-589.

Fosberg, Michael A., Albert Rango, and William

E. Marlatt.

1972. Wind computations from the temperature field in an urban area. Proc. Conf. on Urban Environ. and second Conf. on Biometeorol., Oct. 31-Nov. 2, Philadelphia, Pa. p. 5-7.

Hayes, G. I.loyd.

1941. Influence of altitude and aspect on daily variations in factors of forest fire danger. U.S. Dep. Agric., Circ. 591, 37 p.

Priestley, C. H. B.

1959. Turbulent transfer in the lower atmosphere. 130 p. Univ. Chicago Press.

Sellers, William D.

1965. Physical climatology. 272 p. Univ. Chicago Press.

Super, Arlin B., and Anthony C. Grainger.

1969. Studies of the diurnal wind and temperature regimes above mountain slopes. Dep. Earth Resour., Mont. State Univ., Bozeman, Mont. Final rep. to U.S. Dep. Comm., Environ. Sci. Serv. Admin. 77 p.

Sutton, $\mathrm{O}$. G.

1953. Micrometeorology. 333 p. McGraw-Hill, N.Y. 


\section{APPENDIX}

\section{List of Symbols}

\section{Symbol}

$$
\begin{aligned}
& \mathbf{g} \\
& \mathbf{H} \\
& \mathbf{h} \\
& \mathbf{k} \\
& \mathbf{k} \\
& \tilde{\mathbf{K}} \\
& \mathbf{p} \\
& \mathbf{p}
\end{aligned}
$$$$
{ }_{\mathrm{f}} \mathrm{p}
$$$$
\mathrm{H}
$$$$
\tilde{\mathrm{K}}
$$$$
\text { po }
$$

\section{p*}

$\mathrm{R}$

$\mathrm{T}$

t

$u, \bar{u}, u_{o}$ $u_{*}$ $\tilde{v}, \bar{v}, v_{0}$ $v_{*}$ $w_{w}$ $\mathbf{x}$ $\mathbf{y}$ 2 .

$\mathrm{zo}$

d. $\bar{\delta}$

$\zeta, \bar{\zeta}$

$\theta$

$\rho$

$\phi$

$\psi$

8

$\nabla^{2}$

$\Delta$

$\Delta \mathrm{t}_{\zeta}$
Definition

Specific heat at constant pressure

Coriolis parameter

Acceleration of gravity

Thickness of rigid lid layer

Thickness of second approximation to flow von Karman constant

Unit vector in vertical direction

Turbulent viscosity

Pressure

Reference pressure

Non-dimensional pressure $\left(\frac{p}{p_{0}}\right)^{\frac{R}{c_{p}}}$

Ideal gas content

Temperature

Time

Windspeed in west to east direction

Friction velocity in west-east direction

Horizontal velocity vector

Windspeed in south-north direction

Friction velocity in south-north direction

Vertical windspeed

Horizontal coordinate in west-east direction

Horizontal coordinate in south-north direction

Vertical coordinate

Surface roughness length

Horizontal divergence

Vertical component of vorticity

Potential temperature $\theta=\frac{\mathrm{T}}{\mathrm{P}_{*}}$

Density of air

Static stability $o=\frac{1}{\theta} \frac{\partial \theta}{\partial z}$

Velocity potential

Stream function

Horizontal vector gradient operator

Horizontal laplacian operator

Horizontal grid spacing

Impulse time for vorticity

Impulse time for divergence

\section{Units}

1.003 joules $\mathrm{gm}^{-1}{ }^{\circ} \mathrm{K}^{-1}$

$\mathrm{sec}^{-1}$

$9.8 \mathrm{~m} \mathrm{sec}^{-2}$

$\mathrm{m}$

m

0.4

dimensionless

$\mathrm{m}^{2} \cdot \mathrm{sec}^{-1}$

dynes $\mathrm{cm}^{-2}$

$10^{6}$ dynes $\mathrm{cm}^{-2}$

0.287 joules $\mathrm{gm}^{-1}{ }^{\circ} \mathrm{K}^{-1}$

Deg K

Sec

$\mathrm{m} \mathrm{sec}^{-1}$

$\mathrm{m} \mathrm{sec}^{-1}$

$\mathrm{m} \mathrm{sec}^{-1}$

$\mathrm{m} \mathrm{sec}^{-1}$

$\mathrm{m} \mathrm{sec}^{-1}$

$\mathrm{m} \mathrm{sec}^{-1}$

$\mathrm{m}$

$\mathrm{m}$

$\mathrm{m}$

$\mathrm{m}$

$\sec ^{-1}$

$\sec ^{-1}$

Deg K

$\mathrm{kg} \mathrm{m}^{-3}$

$\mathrm{m}^{-1}$

$\mathrm{m}^{2} \mathrm{sec}^{-1}$

$\mathrm{m}^{2} \mathrm{sec}^{-1}$

$m-1$

$m^{-2}$

$\mathrm{m}$

sec

sec 